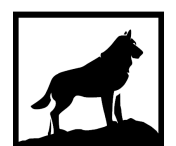

Michigan

Technological

1 8 8 5 University
Michigan Technological University

Digital Commons @ Michigan Tech

MODELING OF THERMAL DYNAMICS IN CHEVROLET VOLT GEN II HYBRID ELECTRIC VEHICLE FOR INTEGRATED POWERTRAIN AND HVAC OPTIMAL OPERATION THROUGH CONNECTIVITY

Nehal Doshi

Michigan Technological University, nehald@mtu.edu

Copyright 2019 Nehal Doshi

Recommended Citation

Doshi, Nehal, "MODELING OF THERMAL DYNAMICS IN CHEVROLET VOLT GEN II HYBRID ELECTRIC VEHICLE FOR INTEGRATED POWERTRAIN AND HVAC OPTIMAL OPERATION THROUGH CONNECTIVITY", Open Access Master's Thesis, Michigan Technological University, 2019.

https://doi.org/10.37099/mtu.dc.etdr/871

Follow this and additional works at: https://digitalcommons.mtu.edu/etdr

Part of the Automotive Engineering Commons, and the Energy Systems Commons 


\title{
MODELING OF THERMAL DYNAMICS IN CHEVROLET VOLT GEN II HYBRID ELECTRIC VEHICLE FOR INTEGRATED POWERTRAIN AND HVAC OPTIMAL OPERATION THROUGH CONNECTIVITY
}

By

Nehal Doshi

\begin{abstract}
A THESIS
Submitted in partial fulfillment of the requirements for the degree of MASTER OF SCIENCE

In Mechanical Engineering

MICHIGAN TECHNOLOGICAL UNIVERSITY
\end{abstract}

2019

(C) 2019 Nehal Doshi 

This thesis has been approved in partial fulfillment of the requirements for the Degree of MASTER OF SCIENCE in Mechanical Engineering.

Department of Mechanical Engineering-Engineering Mechanics

Thesis Co-advisor: $\quad$ Dr. Mahdi Shahbakhti

Thesis Co-advisor: $\quad$ Dr. Darrell Robinette

Committee Member: Dr. Jeffrey Naber

Department Chair: Dr. William W. Predebon 



\section{Dedication}

To my mother, father and sister

who have never wavered in their support and without whose resolute belief in me, neither I nor this work would be what it is today. 



\section{Contents}

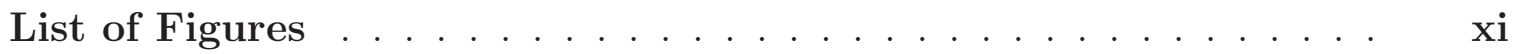

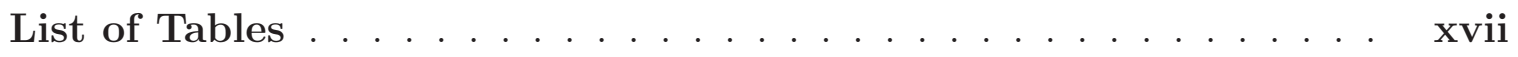

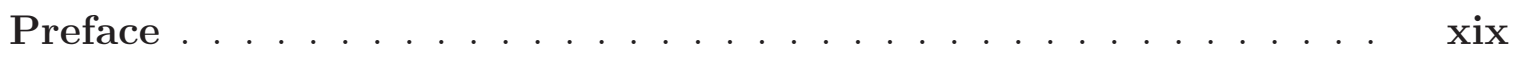

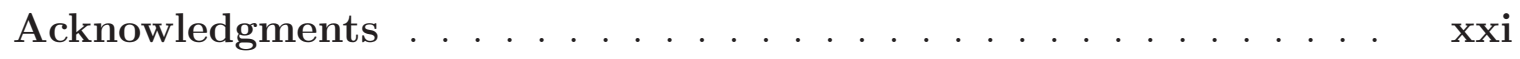

List of Abbreviations ................. xxiii

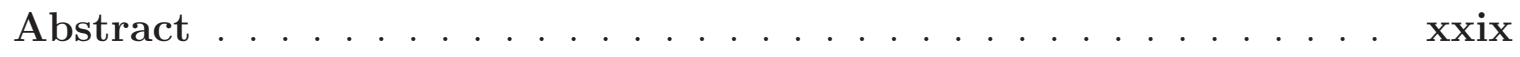

1 Background and Introduction . . . . . . . . . . . . . . . 1

1.1 Trends in Modern Automotive Industry . . . . . . . . . . . . . 1

1.2 NEXTCAR Program . . . . . . . . . . . . . . . . . 4

1.3 Literature Review . . . . . . . . . . . . . . . . . . . . . . . . . 7

1.4 Motivation . . . . . . . . . . . . . . . . . . . 10

1.5 Organization of Thesis $\ldots \ldots \ldots \ldots \ldots \ldots$

2 Experimental Setup . . . . . . . . . . . . . . . . . 15 
2.1 Vehicle Specifications . . . . . . . . . . . . . . . . 15

2.2 Cabin Temperature Measurement . . . . . . . . . . . . . 16

2.3 Solar Irradiation Measurement . . . . . . . . . . . . . . . . . . . . 17

2.4 Cabin Blower Flow Rate Measurement . . . . . . . . . . . . . 18

2.5 Cabin Thermal Masses Characterization . . . . . . . . . . . 20

2.6 CAN Data Acquisition . . . . . . . . . . . . . . . 21

2.7 Argonne National Laboratory (ANL) Test Data . . . . . . . . . . . 23

3 Modeling . . . . . . . . . . . . . . . . . . 25

3.1 Background ........................... 25

3.1.1 HVAC Heating Loop . . . . . . . . . . . . . . . . 28

3.1.2 HVAC Cooling Loop . . . . . . . . . . . . . . 28

3.2 Cabin Thermal Model . . . . . . . . . . . . . . . . 31

3.2.1 HVAC supply heat flow rate . . . . . . . . . . . . . . . 32

3.2.2 Heat transfer interactions . . . . . . . . . . . . . . 33

3.2.3 Radiative heat transfer . . . . . . . . . . . . . . . . . . 34

3.2.4 Heat from occupants . . . . . . . . . . . . . . 35

3.2.5 Auxiliary heat . . . . . . . . . . . . . . . 35

3.2.6 Solar heat flow rate . . . . . . . . . . . . . . . . 35

3.2.7 Solar irradiation load . . . . . . . . . . . . . . . . . 36

3.3 Engine Coolant Temperature Model . . . . . . . . . . . . . . . . 38

3.4 Cabin Electric Heater Model . . . . . . . . . . . . . . . . . . . . . . 39 
3.5 Battery Electric Heater Model . . . . . . . . . . . . . . . . . . 41

3.6 Cabin Heater Core Model . . . . . . . . . . . . . . . . . . . . . . . 41

3.7 Catalyst Temperature Model . . . . . . . . . . . . . . 44

3.8 Compressor Model . . . . . . . . . . . . . . . 46

4 Model Validation . . . . . . . . . . . . . . . . . . 51

4.1 Characterization of Cabin Thermal Dynamics . . . . . . . . 51

4.2 Cabin Blower Characterization . . . . . . . . . . . . . 53

4.3 Cabin Temperature .................. 54

4.4 Coolant Temperature . . . . . . . . . . . . . . 57

4.5 Catalyst Temperature . . . . . . . . . . . . . 60

4.6 Cabin Electric Heater Energy _. . . . . . . . . . . . . . . 62

4.7 A/C Compressor Energy . . . . . . . . . . . . . 63

5 Vehicle Energy Consumption Reduction Strategies . . . . . . . 65

5.1 Integrated HVAC - Powertrain Operation . . . . . . . . . . 65

5.1 .1 Case Study . . . . . . . . . . . . . . . . . . . . . 68

5.2 Coordinated Thermal Management . . . . . . . . . . 74

5.2.1 Case Study . . . . . . . . . . . . . 76

5.3 Monte Carlo Simulations . . . . . . . . . . . . . . . . 81

5.3.1 Integrated HVAC - Powertrain Operation . . . . . . . . 83

5.3.2 Coordinated Thermal Management . . . . . . . . . . 85 
6 Conclusion and Future Work . . . . . . . . . . . . . . . 87

6.1 Conclusion . . . . . . . . . . . . . . . . . 88

6.2 Future Work . . . . . . . . . . . . . . . . . . . . . 89

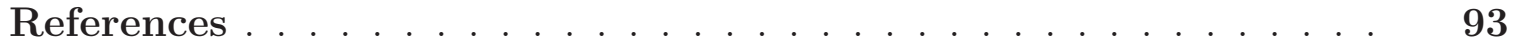

A Publication from thesis . . . . . . . . . . . . . . 103

B Summary of Model and Data Files . . . . . . . . . . . . 105

B.1 Chapter $1 \ldots \ldots \ldots \ldots$. . . . . . . . . . . . . . . . 105

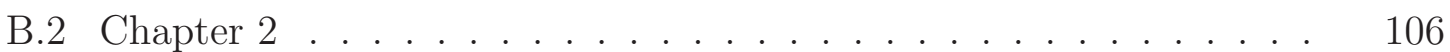

B.3 Chapter $3 \ldots \ldots \ldots$. . . . . . . . . . . . . . . 107

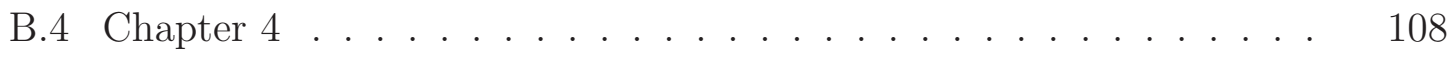

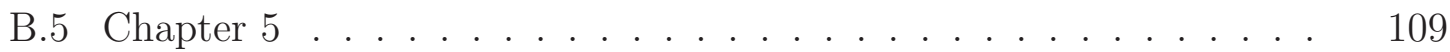

C Summary of Figure Files . . . . . . . . . . . . . . . . 113 


\section{List of Figures}

1.1 Projected trends in global light-duty vehicle fleet [1] . . . . . . .

1.2 Projected market share (in USD Billion) of connected vehicles in North America $[2] \ldots \ldots \ldots \ldots \ldots$

1.3 Connected and autonomous vehicles global market share [3] . . . .

1.4 Existing and NEXTCAR's proposed system interactions . . . . . .

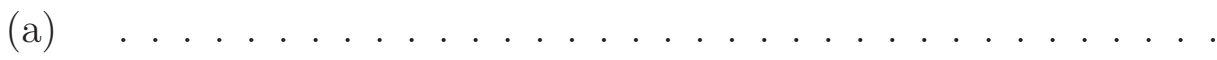

(b)

1.5 Overview of Michigan Tech's NEXTCAR project proposal . . . . .

1.6 Custom drive cycle devised by the MTU NEXTCAR team . . . . .

(a) Drive cycle on map . . . . . . . . . . . . . . . .

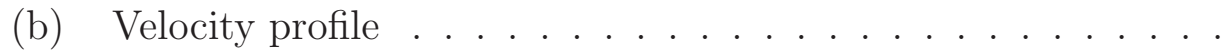

1.7 Comparison of total vehicle energy distribution to understand HVAC contribution (Experimental data) . . . . . . . . . . . .

1.8 Experimental test data in cold ambient conditions for MTUDC . . .

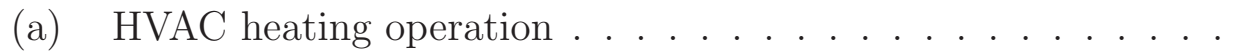

(b) Energy distribution summary . . . . . . . . . . . 
2.1 Test vehicle setup for solar load measurement at Keweenaw Research

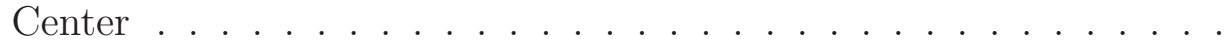

2.2 Flow bench setup for test vehicle cabin blower characterization at Advanced Power Systems Research Center Laboratory . . . . . . . . .

2.3 Cabin thermal mass characterization test setup at Advanced Power Systems Research Center Laboratory . . . . . . . . . . . . .

2.4 CAN data acquisition setup in test vehicle . . . . . . . . . . . .

(a) Vector CANoe setup .................. 22

(b) dSpace MicroAutoBox setup . . . . . . . . . . . 22

3.1 Overview of integrated HVAC - VD\&PT model . . . . . . . . 27

3.2 Test vehicle's cabin heating loop . . . . . . . . . . . . . . . 29

3.3 Test vehicle's integrated cooling loops . . . . . . . . . . . . . . . 30

3.4 Cabin model control volume with heat loads . . . . . . . . . . . . 31

3.5 Schematic of lumped engine coolant temperature model . . . . . . . 39

3.6 Schematic of cabin heater core model . . . . . . . . . . . . . . . 42

3.7 Schematic of three-way catalyst temperature model . . . . . . . . 45

3.8 Schematic of A/C compressor neural network model . . . . . . . . . 47

3.9 Performance R-values for trained compressor neural network . . . . 48

3.10 Cross-validation test results for trained neural network . . . . . . . 49

4.1 Results of cabin thermal mass characterization test . . . . . . . 52

4.2 Results of cabin blower characterization test . . . . . . . . . . 54 
4.3 Temperature distribution inside test vehicle cabin . . . . . . . . .

4.4 Validation of cabin temperature during heating and cooling . . . . .

(a) Cabin heating validation . . . . . . . . . . . 56

(b) Cabin cooling validation ............... 56

4.5 Validation of solar irradiation model during a 24hr. test . . . . . . . 57

4.6 Effect of vehicle speed on coolant temperature at 20mph cruising

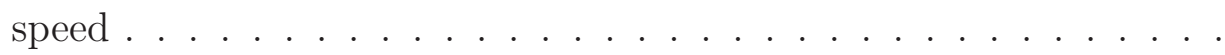

4.7 Effect of vehicle speed on coolant temperature at $55 \mathrm{mph}$ cruising

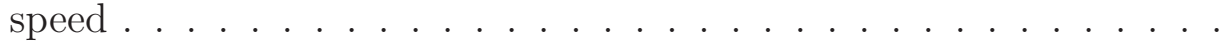

4.8 Validation of coolant temperature model at $T_{\text {ambient }}=-4^{\circ} \mathrm{C} \ldots$.

4.9 Validation of catalyst temperature during cool-down in 2 different operating conditions . . . . . . . . . . . . . . .

(a) Validation at $T_{\text {ambient }}=-7^{\circ} \mathrm{C} \ldots \ldots . \ldots$

(b) Validation at $T_{\text {ambient }}=22^{\circ} \mathrm{C} \ldots \ldots \ldots$

4.10 Validation of catalyst temperature during heat-up in 2 different operating conditions ....................... 61

(a) Validation at $T_{\text {ambient }}=-7^{\circ} \mathrm{C} \ldots \ldots$............. 61

(b) Validation at $T_{\text {ambient }}=22^{\circ} \mathrm{C} \ldots \ldots \ldots 61$

4.11 Validation of cabin electric heater energy consumption . . . . . . 62

(a) Validation at $T_{\text {ambient }}=-4^{\circ} \mathrm{C} \ldots \ldots$. . . . . . . 62

(b) Validation at $T_{\text {ambient }}=-10^{\circ} \mathrm{C} \ldots \ldots 62$ 
4.12 Validation of electric compressor energy consumption . . . . . . .

5.1 Sample simulation example to illustrate integrated HVAC - Powertrain operation for cabin heating . . . . . . . . . . . . . .

5.2 Sample test data collection at APSRC Labs to illustrate baseline cabin heating operation in cold ambient conditions . . . . . . . . . .

5.3 Model-based optimization for integrated HVAC - Powertrain opera-

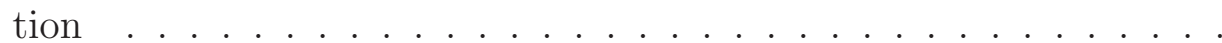

5.4 Comparison of cabin air temperature between baseline and integrated HVAC - Powertrain operation . . . . . . . . . . . . . .

5.5 Comparison of cabin heating operation between baseline and optimal

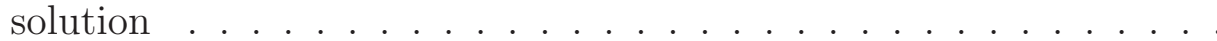

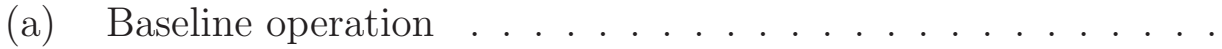

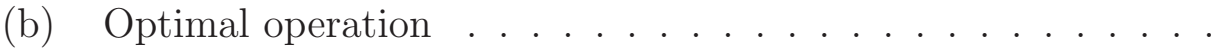

5.6 Sample simulation example of coordinated thermal management at $T_{\text {ambient }}=22^{\circ} \mathrm{C} \ldots \ldots \ldots \ldots$. . . . . . . . . . . . 76

(a) Coolant temperature-Baseline . . . . . . . . . . 76

(b) Catalyst temperature-Baseline . . . . . . . . . . 76

(c) Coolant temperature-Improved . . . . . . . . . . 76

(d) Catalyst temperature-Improved . . . . . . . . . . 76

5.7 Case A: Baseline operation without coordinated thermal management $\quad 77$

(a) Engine and battery state . . . . . . . . . . . . 77 
(b) Coolant temperature and electric heater . . . . . . . . 77

(c) Catalyst temperature . . . . . . . . . . . . . . 77

(d) Cabin Temperature . . . . . . . . . . . . . 77

5.8 Case B: Optimal operation with coordinated thermal management . $\quad 78$

(a) Engine and battery state . . . . . . . . . . . . 78

(b) Coolant temperature and electric heater . . . . . . . . 78

(c) Catalyst temperature ................. 78

(d) Cabin Temperature .................... 78

5.9 Distribution of ambient temperature [4] . . . . . . . . . 82

5.10 Normally distributed sample of ambient temperature data . . . . 83

5.11 Total vehicle energy savings distribution for Integrated HVAC - Powertrain Operation . . . . . . . . . . . . . . . 84

5.12 Total vehicle energy savings distribution for Coordinated Thermal Management strategy . . . . . . . . . . . . . . . 



\section{List of Tables}

2.1 Cabin Dimensions of Test Vehicle . . . . . . . . . . . . . 16

2.2 EasyLog Temperature Sensor Specifications . . . . . . . . . . . 17

2.3 Specifications of Vector CAN tool (VN5610A) used for data acquisi-

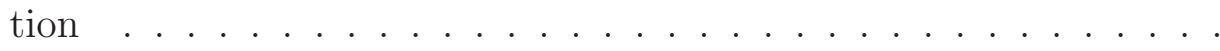

2.4 ANL vehicle data summary . . . . . . . . . . . . . . . .

4.1 Cabin Thermal Masses . . . . . . . . . . . . . . . . . 52

5.1 Engine Coolant Temperature Parameters for Cabin Heating . . . . 68

5.2 Energy Consumption Summary . . . . . . . . . . . . 73

5.3 Energy Consumption Summary . . . . . . . . . . . . 75

5.4 Energy Consumption Summary . . . . . . . . . . . . . . 80

B.1 MTUDC Energy Distribution Data . . . . . . . . . 105

B.2 CAD Files . . . . . . . . . . . . . . . . . 106

B.3 Vector CAN Files . . . . . . . . . . . . . . 106

B.4 ANL Data Files . . . . . . . . . . . . . . . . . 106

B.5 Cabin Thermal Mass Characterization Data and Model . . . . . . 108 
B.6 Cabin Blower Characterization Data and Model . . . . . . . . . . 109

B.7 Cabin Temperature Distribution Data Files . . . . . . . . . . 109

B.8 Cabin Temperature Validation Data and Model . . . . . . . . . 109

B.9 Solar Irradiation Validation Data and Model . . . . . . . . . . . . 110

B.10 Coolant Temperature Model . . . . . . . . . . . . . . . . . 110

B.11 Catalyst Temperature Model . . . . . . . . . . . . . . . . . . . 110

B.12 Cabin Electric Heater Model . . . . . . . . . . . . . . . . . . 111

B.13 A/C Compressor Model . . . . . . . . . . . . . . . 111

B.14 Integrated HVAC - Powertrain Operation Model . . . . . . . . . . . 111

B.15 Coordinated Thermal Management Model . . . . . . . . . . . . . . 112

C.1 Chapter $1 \ldots \ldots \ldots 113$

C.2 Chapter $2 \ldots \ldots \ldots \ldots$. . . . . . . . . . . . . . . . 114

C.3 Chapter $3 \ldots \ldots \ldots$. . . . . . . . . . . . . . . . . . . . . . . . 114

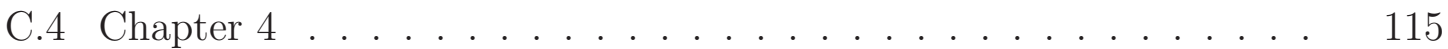

C.5 Chapter $5 \ldots \ldots \ldots \ldots$. . . . . . . . . . . . . 116 


\section{Preface}

The work presented in this thesis is built upon the work done by Rajeshwar Yadav

[5]. The vehicle dynamics and powertrain model was developed in [5], which was further developed in this work to build the thermal coupling between the powertrain and HVAC systems. The engine coolant model developed in Section 3.3 is taken from [5] and further modifications to the model to incorporate effects of varying operating conditions are developed in this work. The model development and testing work related to Section 3.2 was carried out in collaboration with Drew Hanover. The model validation tasks related to Section 4.4 and 4.6 were carried out in collaboration with Sadra Hemmati. Dr. Mahdi Shahbakhti provided technical guidance on all aspects of the project including modeling, experimental data collection and analysis and development of HVAC optimization strategies. Chris Morgan contributed to the brainstorming sessions and technical discussions related to the strategy presented in Section 5.1. 



\section{Acknowledgments}

I would like to extend my utmost thanks to my advisors Dr. Mahdi Shahbakhti and Dr. Darrell Robinette for their constant support and guidance throughout my research. Their doors were always open for me whenever I found myself stuck or bereft of ideas. They helped me steer this research in the right direction.

I would also like to thank Dr. Jeffrey Naber for his constructive criticism and inputs to my work and for his participation in my defense committee.

I would like to acknowledge Chris Morgan for his sharp insights on my work and my colleague, Drew Hanover, who helped me build the foundations of my research early on and collaborated with me on some testing, modeling and validation tasks.

I would also like to acknowledge the NEXTCAR program and my colleagues therein; particularly Sadra Hemmati and Saurabh Bhasme, who helped me further my research with their stimulating discussions and assistance with some testing and validation.

Finally, I would like to thank Michigan Technological University, the Mechanical Engineering-Engineering Mechanics department, the Advanced Power Systems Research Center Labs and all my friends and colleagues without whose constant support and motivation I could not have accomplished this work. 



\section{List of Abbreviations}

\section{Acronyms}

\begin{tabular}{|c|c|}
\hline $\mathrm{A} / \mathrm{C}$ & Air-conditioning \\
\hline ANL & Argonne National Laboratory \\
\hline $\mathrm{APRF}$ & Advanced Powertrain Research Facility \\
\hline APSRC & Advanced Power Systems Research Center \\
\hline ARPA-E & Advanced Research Projects Agency-Energy \\
\hline ASHRAE & American Society of Heating, Refrigerating \\
\hline & and Air-Conditioning Engineers \\
\hline ASME & American Society of Mechanical Engineers \\
\hline $\mathrm{BEV}$ & Battery electric vehicle \\
\hline CAD & Computer-aided design \\
\hline CAFE & Corporate Average Fuel Economy \\
\hline CAN & Controller Area Network \\
\hline CAV & Connected and Automated vehicles \\
\hline $\mathrm{CD}$ & Charge depleting \\
\hline CS & Charge sustaining \\
\hline CSV & Comma-separated values \\
\hline $\mathrm{DBC}$ & Data Base Container \\
\hline
\end{tabular}




\begin{tabular}{ll} 
DOE & Department of Energy \\
ECU & Electronic control unit \\
EPA & Environmental Protection Agency \\
EV & Electric vehicle \\
FCV & Fuel cell vehicle \\
GM & General Motors \\
GPS & Global Positioning System \\
HEV & Hybrid electric vehicle \\
HV & High Voltage \\
HVAC & Heating, ventilation and air conditioning \\
HWFET & Highway Fuel Economy Test \\
ICE & Internal Combustion engine \\
IEEE & Institute of Electrical and Electronics Engineers \\
KRC & Keweenaw Research Center \\
LHV & Lower heating value \\
LVD & Longitudinal vehicle dynamics \\
MPC & Model predictive control \\
MSE & Mean square error \\
MTU & Michigan Technological University \\
NEXTCAR & NEXT- Generation Energy Technologies for Connected and \\
& \\
& Model year \\
\hline
\end{tabular}


Automated On-Road Vehicles

\begin{tabular}{|c|c|}
\hline NHTSA & National Highway Traffic Safety Administration \\
\hline NTU & Number of thermal units \\
\hline $\mathrm{OBD}$ & On-board diagnostics \\
\hline OEM & Original Equipment Manufacturer \\
\hline PHEV & Plug-in hybrid electric vehicle \\
\hline PT & Powertrain \\
\hline PVC & Poly-vinyl chloride \\
\hline RMSE & Root mean square error \\
\hline $\mathrm{RPM}$ & Revolutions per minute \\
\hline $\mathrm{SOC}$ & State of charge \\
\hline Std. & Standard \\
\hline Temp. & Temperature \\
\hline TWC & Three-way catalyst \\
\hline UDDS & Urban Dynamometer Driving Schedule \\
\hline US & United States \\
\hline $\mathrm{V} 2 \mathrm{C}$ & Vehicle-to-cloud \\
\hline V2I & Vehicle-to-infrastructure \\
\hline $\mathrm{V} 2 \mathrm{~V}$ & Vehicle-to-vehicle \\
\hline V2X & Vehicle-to-everything \\
\hline VD\&PT & Vehicle dynamics and powertrain \\
\hline
\end{tabular}




\section{Symbols}

T

$P \quad$ Pressure $(\mathrm{Pa})$

$\dot{Q} \quad$ Heat flow rate $(\mathrm{W})$

C Heat capacity $(\mathrm{W} / \mathrm{K})$

$\dot{m} \quad$ Mass flow rate $(\mathrm{kg} / \mathrm{s})$

$c_{p} \quad$ Specific heat capacity at constant pressure $(\mathrm{J} /(\mathrm{kg}-\mathrm{K}))$

t

A Surface area $\left(m^{2}\right)$

$U \quad$ Overall heat transfer coefficient $\left(\mathrm{W} /\left(\mathrm{m}^{2}-\mathrm{K}\right)\right)$

$\sigma \quad$ Stefan-Boltzmann constant $=5.67 \mathrm{e}-8 \mathrm{~W} /\left(m^{2}-K^{4}\right)$

$\alpha$

$\tau$

$G^{\prime} \quad$ Global solar irradiance $\left(\mathrm{W} /\left(m^{2}\right)\right)$

$h \quad$ Convective heat transfer coefficient $\left(\mathrm{W} /\left(m^{2}-\mathrm{K}\right)\right)$

$\varepsilon \quad$ Effectiveness $(-)$

$\omega_{e} \quad$ Engine speed $(\mathrm{RPM})$ 
$Q_{L H V} \quad$ Lower heating value of gasoline $=43,420 \mathrm{~kJ} / \mathrm{kg}$

\section{Subscripts}

$\begin{array}{ll}\text { ambient/amb/e } & \text { Ambient air } \\ \text { aux } & \text { Auxiliary } \\ \mathrm{f} & \text { Engine fuel flow } \\ \mathrm{i} & \text { Cabin window glass } \\ \mathrm{m} & \text { Cabin interior air } \\ \text { occ } & \text { Cabin interior mass } \\ \text { setpoint } & \text { Passenger occupant } \\ \text { sky } & \text { Cabin temperature setpoint on climate control panel } \\ \text { sol } & \text { Atmospheric environment } \\ \text { sup } & \text { Solar } \\ \text { tot } & \text { Supply air from cabin vents } \\ \text { w } & \text { Total } \\ & \text { Cabin walls }\end{array}$





\section{Abstract}

Integrated thermal energy management across system level components in electric vehicles $(\mathrm{EVs})$ and hybrid electric vehicles $(\mathrm{HEVs})$ is currently an under explored space. The proliferation of connected vehicles and accompanying infrastructure in recent years provides additional motivation to explore opportunities in optimizing thermal energy management in EVs and HEVs with the help of this newly available connected vehicle data. This thesis aims to examine and analyze the potential to mitigate vehicle energy consumption and extend usable driving range through optimal control strategies which exploit physical system dynamics via controls integration of vehicle subsystems.

In this study, data-driven and physics-based models for heating, ventilation and airconditioning (HVAC) are developed and utilized along with the vehicle dynamics and powertrain (VD\&PT) models for a GM Chevrolet Volt hybrid electric vehicle to enable co-optimization of HVAC and VD\&PT systems of HEVs. The information available in connected vehicles like driver schedules, trip duration and ambient conditions is leveraged along with the vehicle system dynamics to predict operating conditions of the vehicle under study. All this information is utilized to optimize the operation of an integrated HVAC and VD\&PT system in a hybrid electric vehicle to achieve the goal of reduced energy consumption.

xxix 
For achieving the goals outlined for this thesis, an integrated HVAC and VD\&PT model is developed and the various components, sub-systems and systems are validated against real world test data. Then, integrated relationships relevant to the thermal dynamics of an HEV are established. These relationships comprise the combined operational characteristics of the internal combustion (IC) engine coolant and the cabin electric heater for cabin heating, coordinated controls of IC engine using engine coolant and catalyst temperatures for cabin thermal conditioning in cold ambient conditions and the combined operational characteristics of the air-conditioning compressor for conditioning both cabin and high-voltage battery in an HEV. Next, these sub-system and system relationships are used to evaluate potential energy savings in cabin heating and cooling when vehicle's operating schedule is known.

Finally, an optimization study is conducted to establish an energy efficient control strategy which maximizes the HVAC energy efficiency whilst maintaining occupant comfort levels according to ASHRAE standards, all while improving the usable range of the vehicle relative to its baseline calibration. The mean energy savings in overall vehicle energy consumption using an integrated HVAC - Powertrain control strategy and a coordinated thermal management strategy proposed in this work are $3 \%$ and $14 \%$ respectively. 


\section{Chapter 1}

\section{Background and Introduction}

\subsection{Trends in Modern Automotive Industry}

Future fuel economy and emission regulations under the Corporate Average Fuel Economy (CAFE) standards [6] administered by NHTSA and Clean Air Act under the Environmental Protection Agency (EPA) dictate fuel efficiency improvements required by automotive manufacturers in the US. Globally, the energy demand for transportation is expected to rise by about $30 \%$ between 2014-2040 [1]. This is a consequence of the steady proliferation of the global light-duty vehicle fleet as shown in Figure 1.1.

We observe an exponential increase in the non-conventional fuel powered vehicles, 


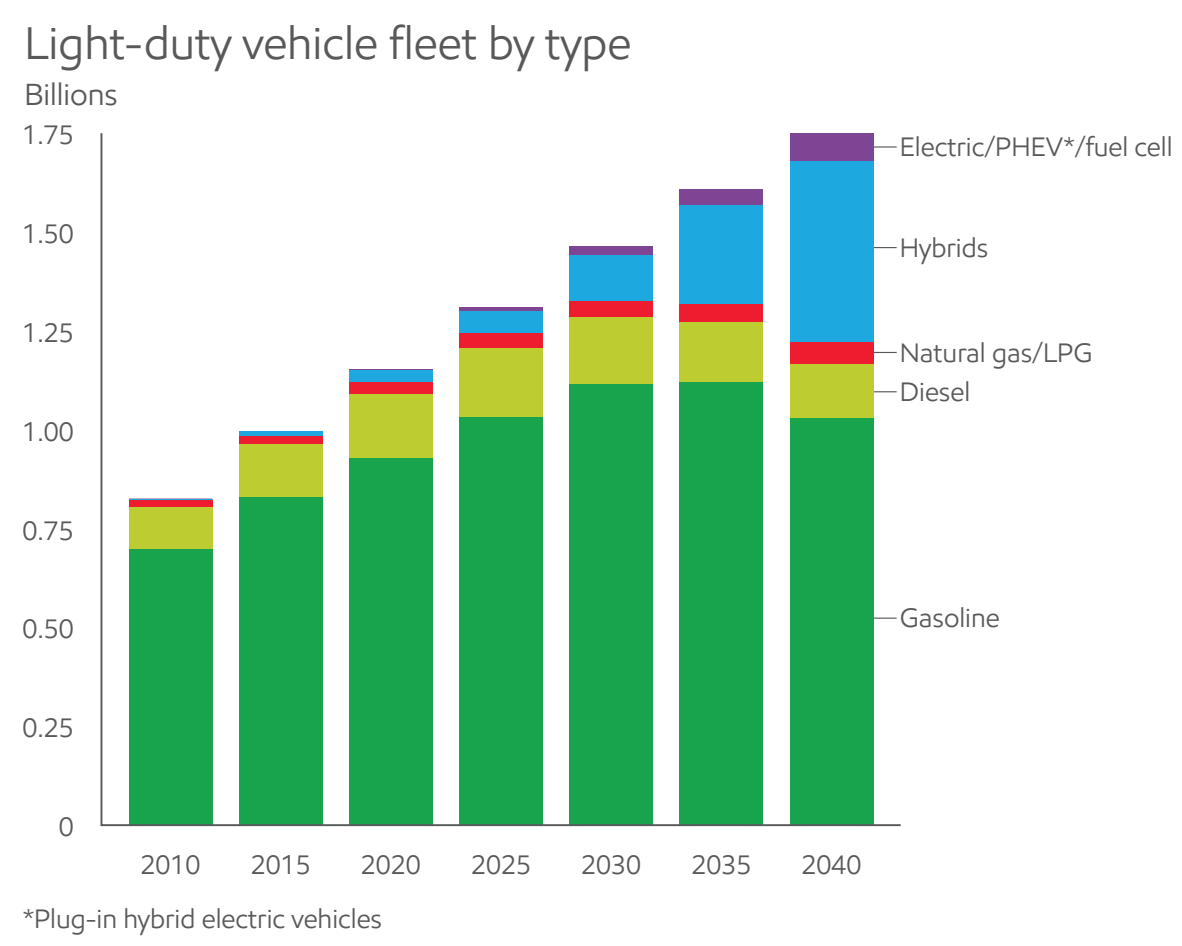

Figure 1.1: Projected trends in global light-duty vehicle fleet [1]

highlighted by the projected increase in hybrid vehicles. Engineering solutions to negate the effects of increasing energy demands and pollution by the transportation sector involve a mix of improvements in the well-established components of a vehicle along with hybridization and integration of electrified powertrains.

In recent years it has been the understanding that this energy burden can be alleviated by the advent of a connectivity infrastructure. According to IEEE, a connected vehicle refers to applications, services, and technologies that connect a vehicle to its surroundings [7]. The connected vehicle infrastructure includes all communication devices which allow for information transfer between vehicles and their surroundings 
as well as between several vehicles and within vehicles. According to [2], the market share of connected vehicles in North America is expected to grow as shown in Figure 1.2 .

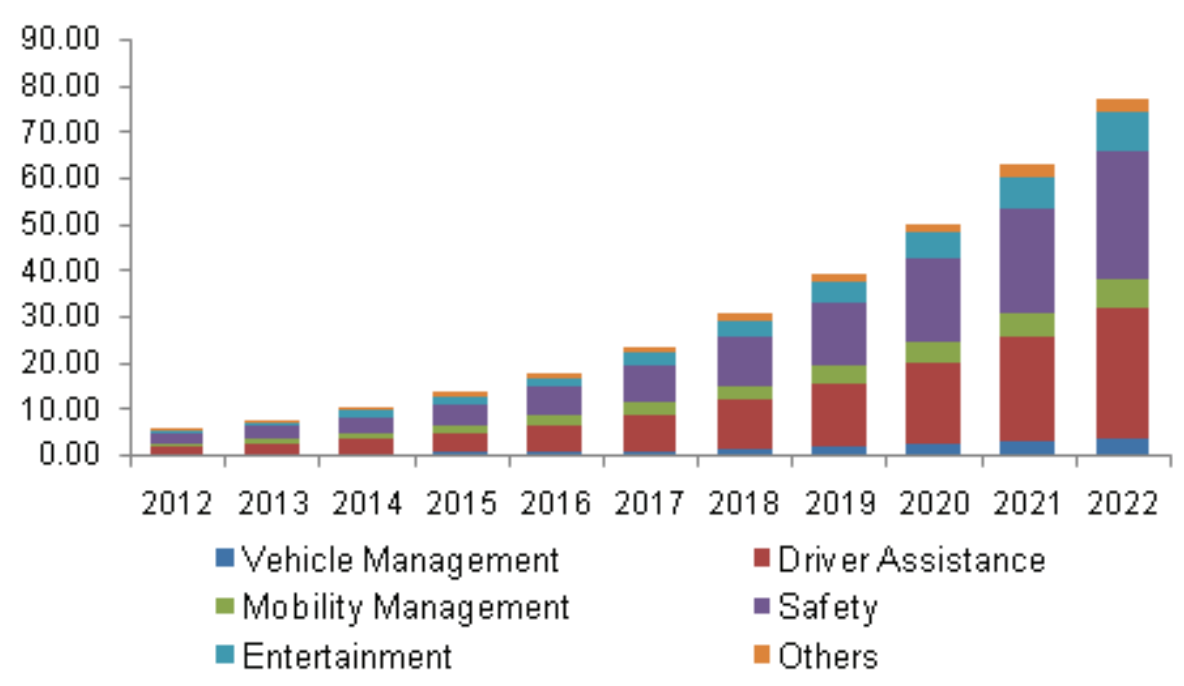

Figure 1.2: Projected market share (in USD Billion) of connected vehicles in North America [2]

We observe that while safety, which is the major driving force in increasing penetration of connected and autonomous vehicles, remains a major application area, the share of vehicle management grows steadily. This application area refers to the implementation of energy management strategies utilizing the connectivity infrastructure. The market penetration of connected and autonomous vehicles, illustrated in Figure 1.3, presents great potential in improving vehicle energy efficiency as we strive to meet future fuel economy and emission standards while managing the global energy demand of transportation. 


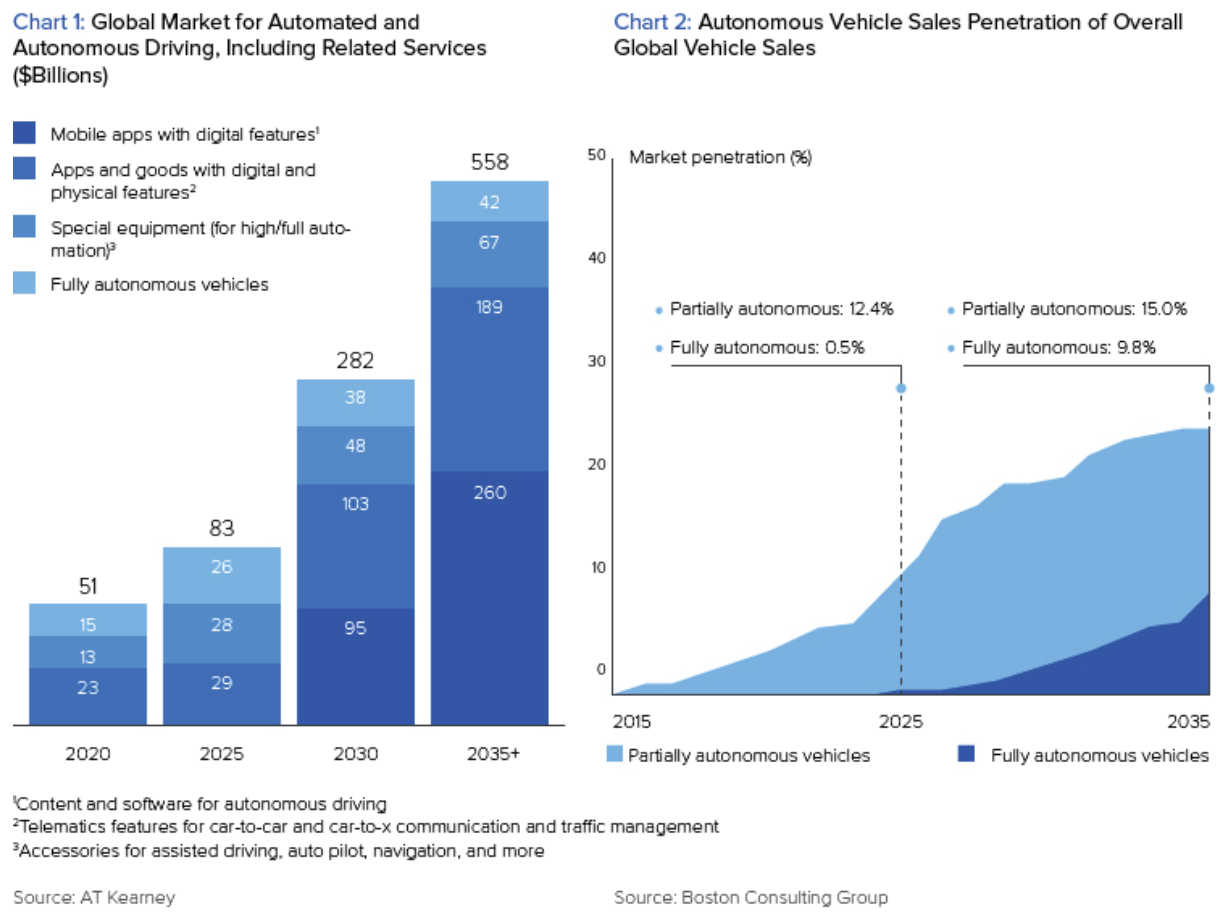

Figure 1.3: Connected and autonomous vehicles global market share [3]

\subsection{NEXTCAR Program}

This thesis comprises work done under the Advanced Research Projects Agency Energy (ARPA-E) NEXT-Generation Energy Technologies for Connected and Automated on-Road Vehicles (NEXTCAR) Program (heretofore referred as only "program') [8] which was commissioned primarily to tap the significant potential of vehicle connectivity and automated operation in improving the efficiency of energy usage and reducing energy-related emissions. There exist some vehicle energy efficiency studies in the area of connected and automated vehicles (CAVs), which present energy consumption reduction solutions $[9,10,11,12]$. However, ARPA-E notes that there is 
a dearth of real-world/on-road test validation data for these proposed technologies. Additionally, to date, two independent approaches for improving vehicle energy efficiency, namely; a purely connectivity-driven and a purely regulatory-driven approach, have shown significant depth of research. This program aims to bridge the technical gap in this area through co-operative efforts of these independent research communities. The schematics in Fig. 1.4 show the status-quo and the vision of the NEXTCAR program in Fig. 1.4(a)and 1.4(b) respectively. It aims to enable co-optimization of vehicle dynamics and powertrain (VD\&PT) level control and optimization techniques for the purpose of reducing overall energy consumption.

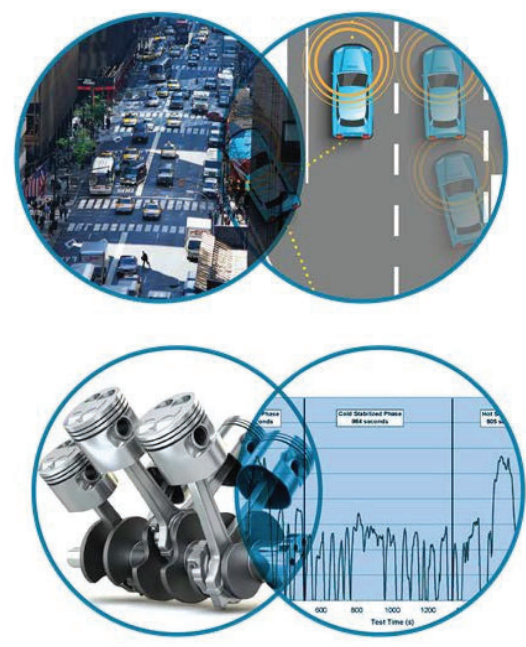

(a)

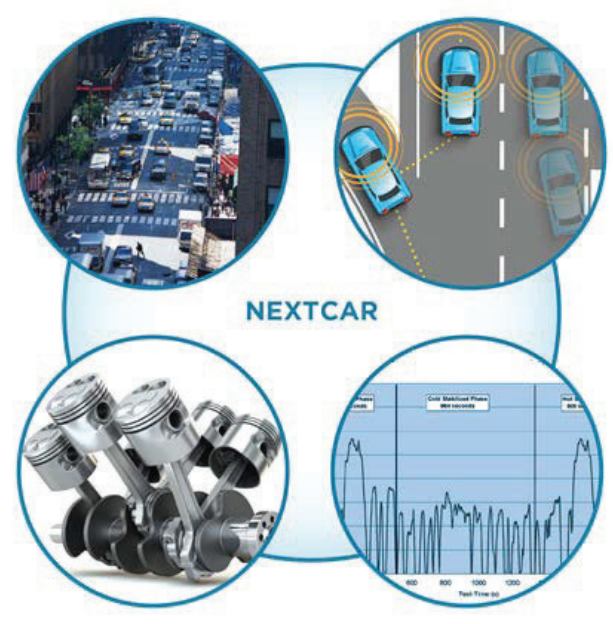

(b)

Figure 1.4: Existing and NEXTCAR's proposed system interactions

Under this program, the Michigan Technological University (MTU) team, in collaboration with General Motors (GM), is implementing a vehicle platooning approach to leverage vehicle-to-vehicle (V2V), vehicle-to-infrastructure (V2I) and vehicle-to-cloud 
(V2C) communication and thereby enable VD\&PT control and optimization. A fleet of 8 hybrid electric Chevrolet Volt MY2017 vehicles (heretofore referred as 'test vehicle') is used in conjunction with a custom 18-wheeler Mobile Lab, for real-world validation tests implementing the model-predictive control on vehicle dynamics, powertrain and heating, ventilation and air-conditioning (HVAC) operation. Figure 1.5 shows an overview of the connected vehicle system and the flow of information as proposed by the MTU NEXTCAR team. The goal of this project is to develop technologies which can demonstrate a $20 \%$ reduction in energy consumption and improve electric range by $6 \%$ in future CAVs.

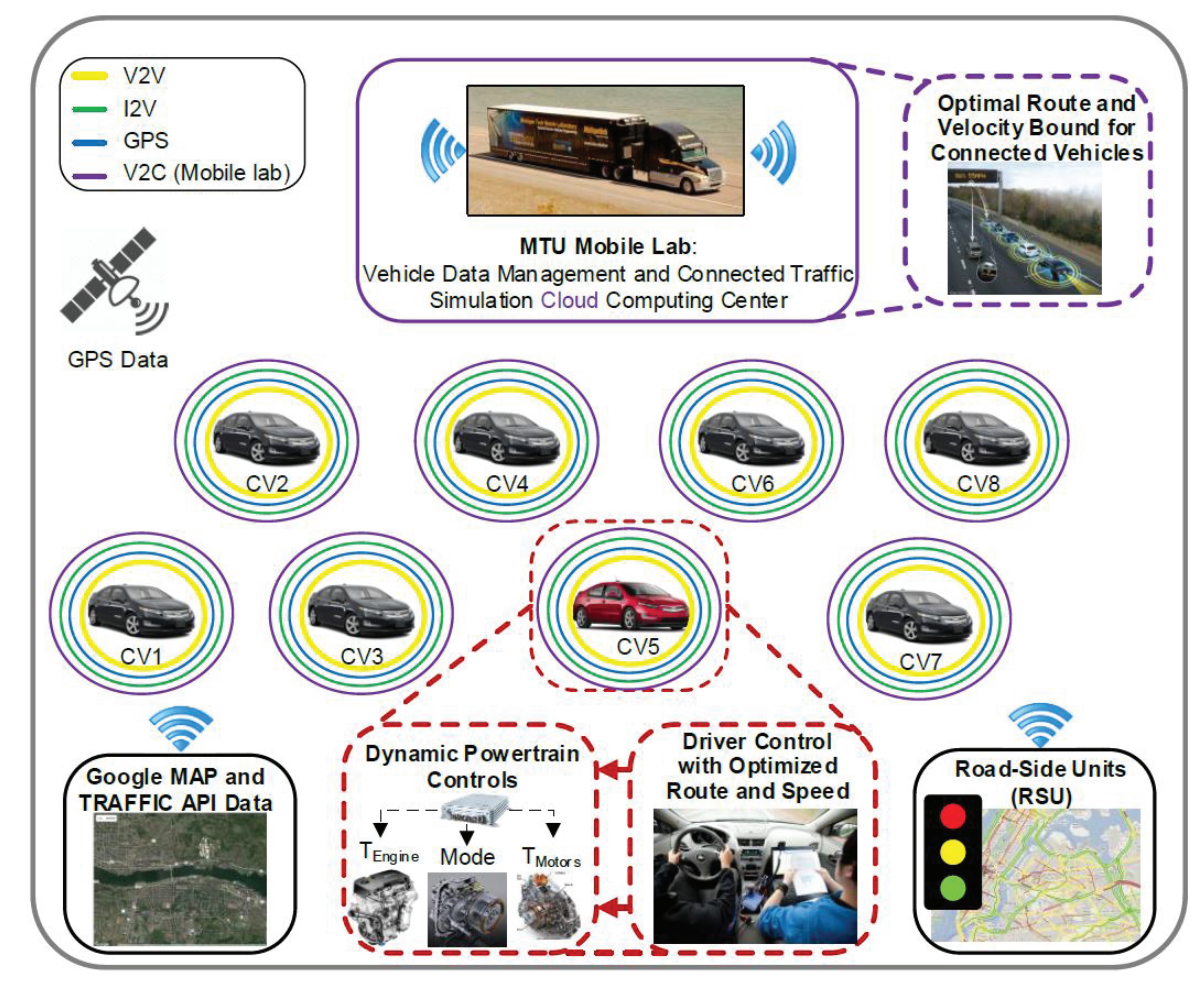

Figure 1.5: Overview of Michigan Tech's NEXTCAR project proposal 


\subsection{Literature Review}

Due to federal regulations and customer demands, vehicle HVAC systems are required to provide passengers with safe and comfortable driving conditions. Heating and cooling the vehicle cabin, to meet these requirements, has been shown to consume large amounts of energy available in conventional vehicles as well as HEVs and EVs. According to a study of several EVs, PHEVs and HEVs conducted by Argonne National Laboratory (ANL), cabin conditioning can reduce the electric range by $20 \%-59 \%$ in $20^{\circ} \mathrm{F}$ ambient conditions [13]. For a pure battery electric vehicle (BEV), the Ford Focus, it has been reported that air-conditioning results in a $53.7 \%$ reduction in electric range, whereas cabin heating results in a $59.3 \%$ reduction in electric range over the Urban Dynamometer Driving Schedule (UDDS) drive cycle [14]. Another study conducted at ANL by Lohse-Buch et al. evaluated the effects of varying ambient conditions on fuel and energy consumption due to cabin climate control in several EVs, HEVs, PHEVs and conventional vehicles [15].

A recent study by Wang et al. proposed a model predictive controller (MPC) for efficient cabin air-conditioning $(\mathrm{A} / \mathrm{C})$ compressor operation by leveraging vehicle speed profile information available in a connected vehicle framework [16]. Similarly, Eckstein et al., in another study [17], proposed an MPC to improve EV range. Zhang et al. presented an energy-optimal control scheme for complex non-linear vehicle A/C 
models to manage trade-offs between fuel savings and cabin comfort [18]. However, optimal HVAC control first requires modeling and validation of the vehicle's HVAC system components. The modeling of cabin thermal dynamics is a well-explored area. A simple transient thermal model for vehicle cabin is developed by Marcos et al. [19], while a two-zone transient thermal model is developed and validated by Torregrosa-Jaime et al. [20]. Fayazbakhsh et al. proposed a heat balance method for estimating cabin heating and cooling loads to develop cabin thermal models [21]. The component and sub-system comprising the vehicle HVAC system are also important to model accurately to aid implementation of thermal management strategies. The sub-system configuration and control schemes in the test vehicle are comprehensively analyzed by ANL researchers in [22]. Further individual test vehicle systems are explained in detail in $[23,24,25]$. The work done earlier to model the VD\&PT system of the test vehicle in [5] as part of this NEXTCAR project is built upon in this thesis. The VD\&PT model comprises of physical-empirical models of test vehicles IC engine, lithium-ion battery, 2 electric motor-generators among others. Although several recent studies have focused on powertrain and energy management control strategies utilizing connected vehicle information, there has not been substantial research in co-optimization of vehicle HVAC operation and integrated thermal management of electrified powertrain and HVAC in a connected vehicle infrastructure. The work done in this thesis covers development of control-oriented models of vehicle HVAC and integrating powertrain thermal management with vehicle HVAC to ensure cabin 
comfort while reducing energy consumption.

It must be understood that these integrated control strategies will be largely dependent on the degree of hybridization of the vehicle powertrain and configuration of the vehicle HVAC system. In several EVs, HEVs and PHEVs, heat pumps which use either waste heat from electronic components or ambient air heat for cabin conditioning as studied in $[26,27]$. Several optimization studies for improving energy efficiency of the heat pumps have been performed in $[28,29]$. A dual source heat pump with multiple operation modes using independently or some combination of air and waste heat as heat sources is proposed in [30]. They showed improvements in the heating performance of dual source heat pumps compared to single source ones. However, heat pumps pose some problems in their usage in EVs and HEVs. The issues of adverse effects on their energy efficiency in cold ambient conditions are explored in [31, 32]. In several practical implementations, heat pumps are supplemented by electric heaters which use battery power for cabin heating purposes. An energy consumption analysis of the HVAC system and overall vehicle energy under different operating conditions is carried out by simulating cabin HVAC model for an electric vehicle [33]. However, in several current production EVs, HEVs and PHEVs, including our test vehicle, heat pumps are entirely eliminated from the HVAC system due to complexity, cost and packaging issues. 


\subsection{Motivation}

The vehicle HVAC system is the largest contributor to ancillary load in conventional vehicles with as much as $5.5 \%$ of total vehicle fuel demand coming from the cabin cooling demand, corresponding to $18 \%$ of fuel economy drop as reported in [34]. Particularly, for hybrid electric vehicles, this issue is compounded due to the absence of continuous waste heat from the internal combustion engine. Limited availability of this waste energy for cabin conditioning makes the energy requirement for heating and cooling the cabin much more significant. As explained in Section 1.3, overall vehicle energy efficiency and electric range is considerably affected by the vehicle HVAC loads.

To fulfill the program's real-world validation test requirement, a custom drive cycle (heretofore referred as 'MTUDC') shown in Figure 1.6 was devised. It comprises of city driving with several start-stop events, highway driving at cruising speeds and some rapid acceleration and deceleration events to replicate real-world driving as close as possible.

The energy consumption of test vehicle was analysed on MTUDC under varying operating and ambient conditions to quantify the impact of vehicle HVAC loads on overall vehicle energy and electric range. Two instances are shown in Figure 1.7. 


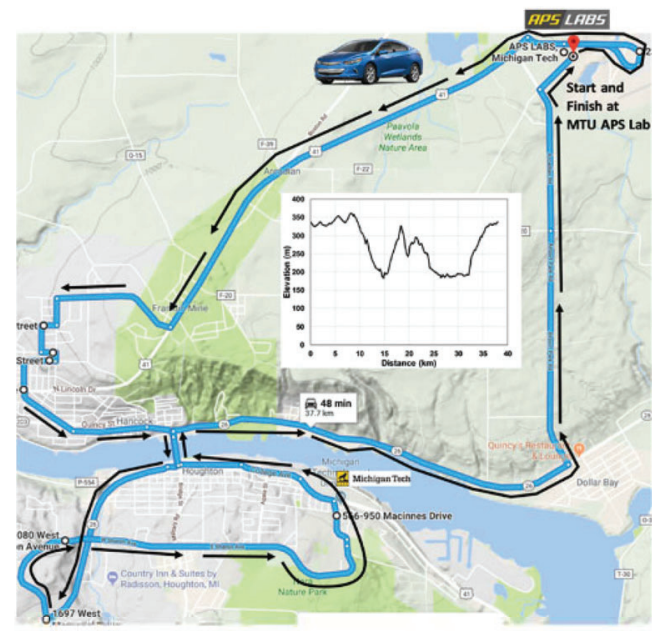

(a) Drive cycle on map

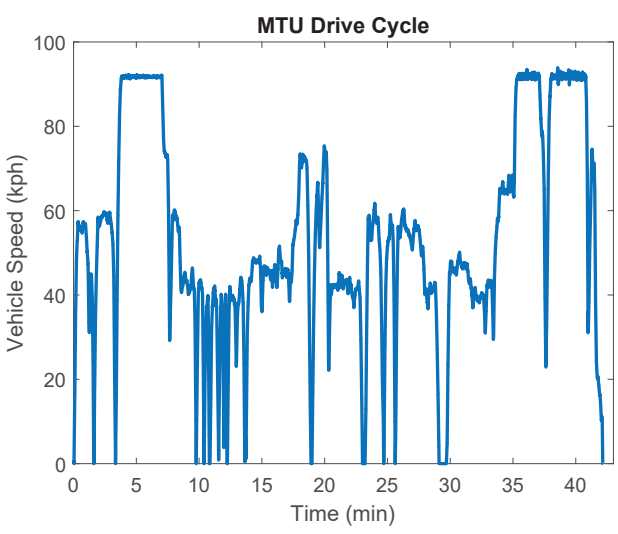

(b) Velocity profile

Figure 1.6: Custom drive cycle devised by the MTU NEXTCAR team

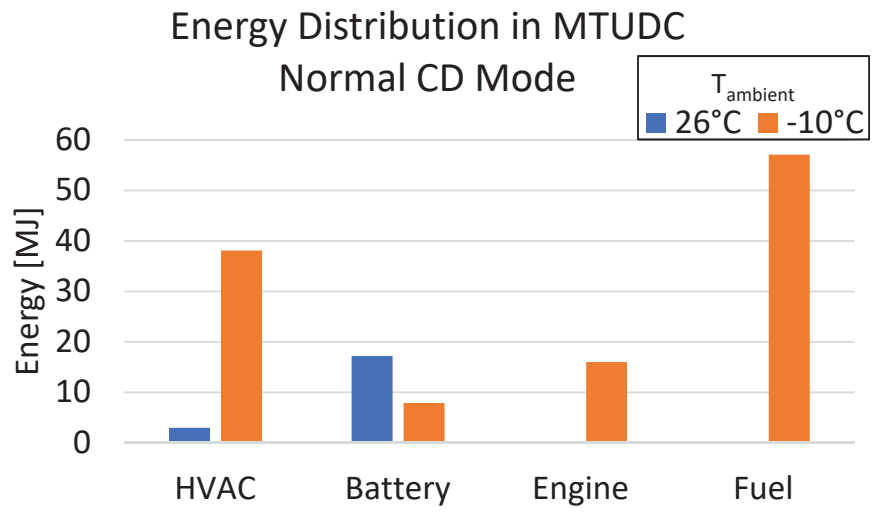

Figure 1.7: Comparison of total vehicle energy distribution to understand HVAC contribution (Experimental data)

It was observed that for cold ambient conditions, the test vehicle utilized a large amount of energy for cabin conditioning when operating in charge depleting (CD) mode. The engine speed profile for a sample MTUDC test, shown in Figure 1.8(a), illustrates the energy intensive operation of the test vehicle due to the multiple engine on events to provide engine assist via engine waste heat. In contrast, the energy 
efficient electric heater contributes a much lower proportion of energy for cabin conditioning, which is illustrated as 'HVAC-Heater' in Figure 1.8(b). Additionally, the engine on events near the end of the drive cycle will potentially contribute very little in maintaining cabin comfort level while consuming relatively large amounts of energy. The emissions related issues with engine on events in cold ambient conditions compound the high energy consumption issues. All these issues can be positively tackled by optimizing integrated operation for thermal management and utilizing connected vehicle information and thus provides motivation to the work done in this thesis.

In Figure 1.8(b), the energy consumed by the battery and the engine together constitute the traction energy. The 'HVAC-Heater' is the cabin electric heater energy and 'HVAC-Fuel (Engine assist)' represents the engine fuel energy utilised for cabin thermal conditioning purposes. Note that the thermal energy losses involved are not considered in analyzing the energy distribution shown here. 


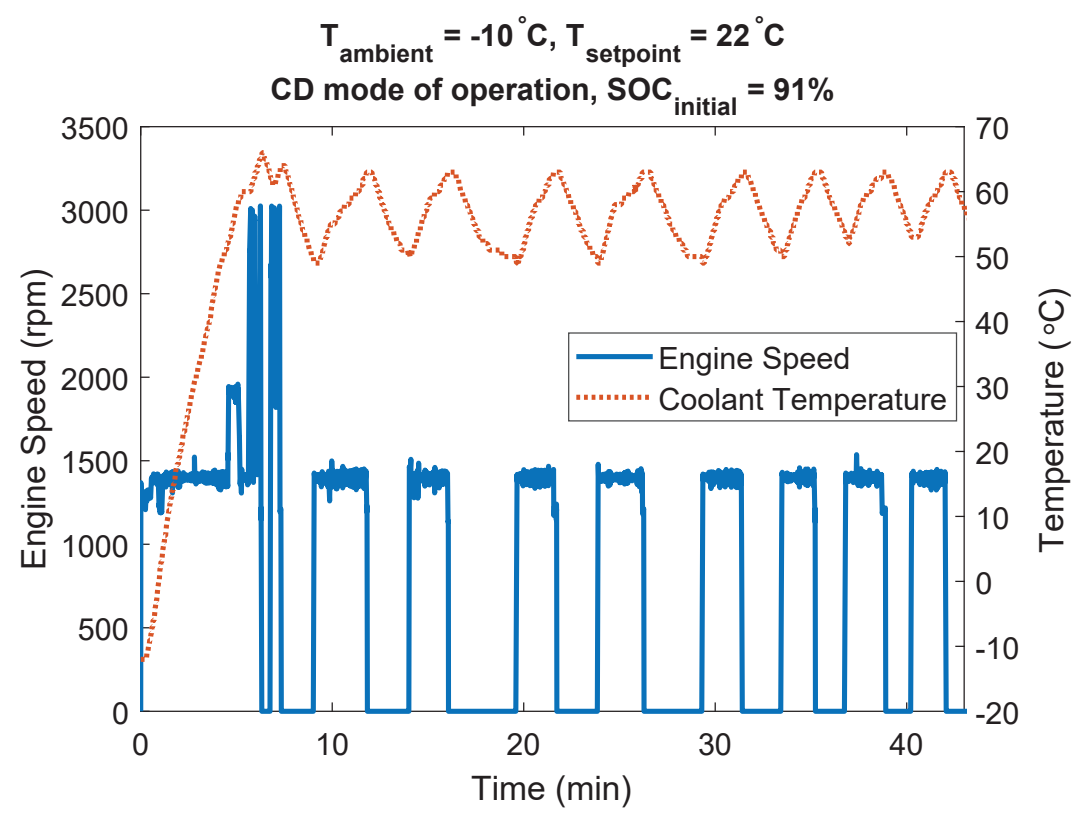

(a) HVAC heating operation

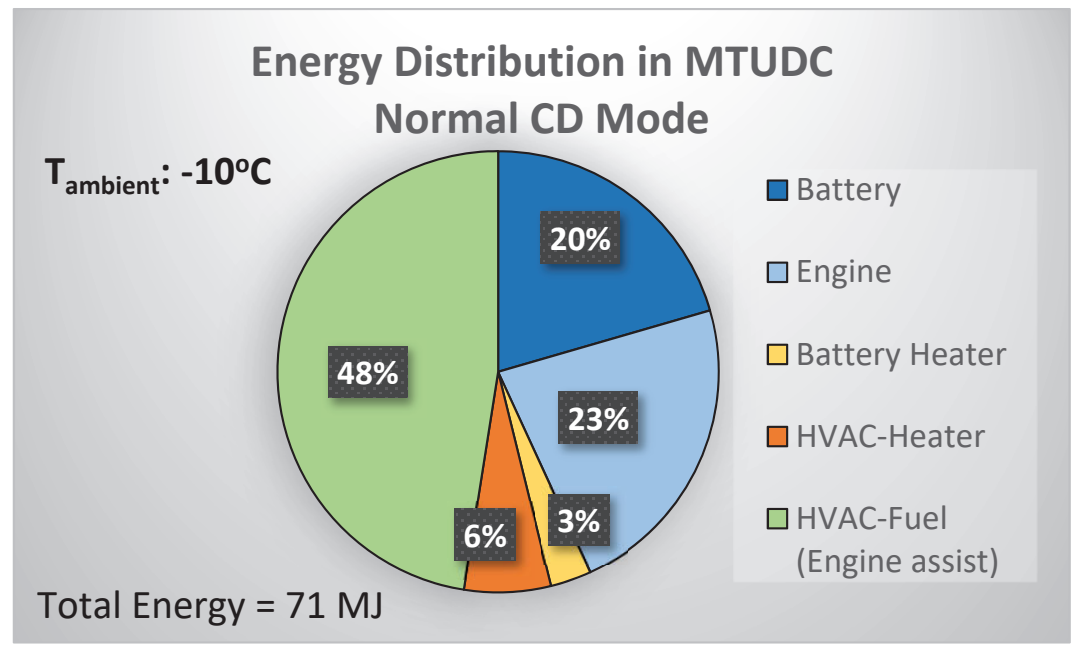

(b) Energy distribution summary

Figure 1.8: Experimental test data in cold ambient conditions for MTUDC 


\subsection{Organization of Thesis}

The work presented in this thesis is organized as follows: Chapter 2 covers the experimental setup required for the various tests conducted during the course of this thesis. Chapter 3 covers the modeling tasks undertaken to develop MATLAB/Simulink based models of the various components, sub-systems and systems comprising the test vehicle HVAC system to help analyze and develop energy saving strategies in this work. Chapter 4 presents the validation results of all the models developed in this work against experimental data collected from the corresponding tests. Chapter 5 proposes modifications in the test vehicle control strategies for reduction in the total vehicle energy consumption. It presents 2 case studies to illustrate the energy savings due to the synergistic combination of control strategies in connected vehicle scenarios. Additionally, Monte Carlo simulations are conducted to evaluate effect of random variables on the energy saving potential of the proposed strategies. Finally Chapter 6 presents the findings of this work and proposes some direction for future work that can build upon the work accomplished in this thesis. 


\section{Chapter 2}

\section{Experimental Setup}

\section{$2.1 \quad$ Vehicle Specifications}

The GM Chevrolet Volt MY2017 PHEV test vehicle is used as the baseline vehicle for all work done in this thesis under the NEXTCAR program. To build the cabin thermal model, a first-order computer-aided design (CAD) model is developed on SolidWorks to extract vehicle specific dimensions. The CAD model is built using measurements made on the test vehicle at MTU Advanced Power Systems Research Center (APSRC) Laboratory. The Table 2.1 shows the extracted dimensions used in the cabin thermal model. 
Table 2.1

Cabin Dimensions of Test Vehicle

\begin{tabular}{ll}
\hline \multicolumn{1}{c}{ Parameters } & Values \\
\hline Cabin Shell (Wall) & $6.82 \mathrm{~m}^{2}$ \\
Cabin Interior Mass & $8.31 \mathrm{~m}^{2}$ \\
Horizontal Walls & $2.04 \mathrm{~m}^{2}$ \\
Front Walls & $1 \mathrm{~m}^{2}$ \\
Front Windshield & $1.26 \mathrm{~m}^{2}$ \\
Right \& left-side Walls & $1.88 \mathrm{~m}^{2}$ \\
Right \& left-side Windows & $0.71 \mathrm{~m}^{2}$ \\
Rear Walls & $1.19 \mathrm{~m}^{2}$ \\
Rear Windshield & $1 \mathrm{~m}^{2}$ \\
Angles of tilt: & \\
$\quad$ Front Windshield & $26.94^{\circ}$ \\
$\quad$ Rear Windshield & $16.37^{\circ}$ \\
\hline
\end{tabular}

\subsection{Cabin Temperature Measurement}

Cabin temperature measurement during in-vehicle on-road tests required WiFienabled temperature sensors. A set of five thermocouple sensors with attached probe and data logging capabilities from Lascar Electronics were used. The sensor specifications are described in Table 2.2. The collected temperature data is uploaded to the EasyLog Cloud software on host PC when WiFi network is available after completion of a test. The data can be exported in several usable formats including comma-separated values (CSV) files. The cabin thermal model developed in Chapter 3 Section 3.2 was validated in part using the test data collected from the thermocouple sensor setup described here and in part using available test data described in 
Section 2.7.

Table 2.2

EasyLog Temperature Sensor Specifications

\begin{tabular}{|c|c|}
\hline Measurement Range & $-20^{\circ} \mathrm{C}$ to $+60^{\circ} \mathrm{C} /-4^{\circ} \mathrm{F}$ to $+140^{\circ} \mathrm{F}$ \\
\hline Accuracy & $\pm 0.2^{\circ} \mathrm{C} / \pm 0.4^{\circ} \mathrm{F}$ \\
\hline Logging Rate & Selectable between 10 sec and 12 hours \\
\hline
\end{tabular}

\subsection{Solar Irradiation Measurement}

For the solar load characterization tests, the pyranometer setup at Keweenaw Research Center (KRC) weather station was used. The weather station is equipped with two pyranometers which record both shortwave and longwave radiation along with surface albedo. The solar azimuth and elevation angles for a given latitude and longitude position and time of day were acquired from an online calculator provided by Keisan Casio [35], but are also easily available from vehicle controller area network (CAN) data. A sample test setup is shown in Figure 2.1. 


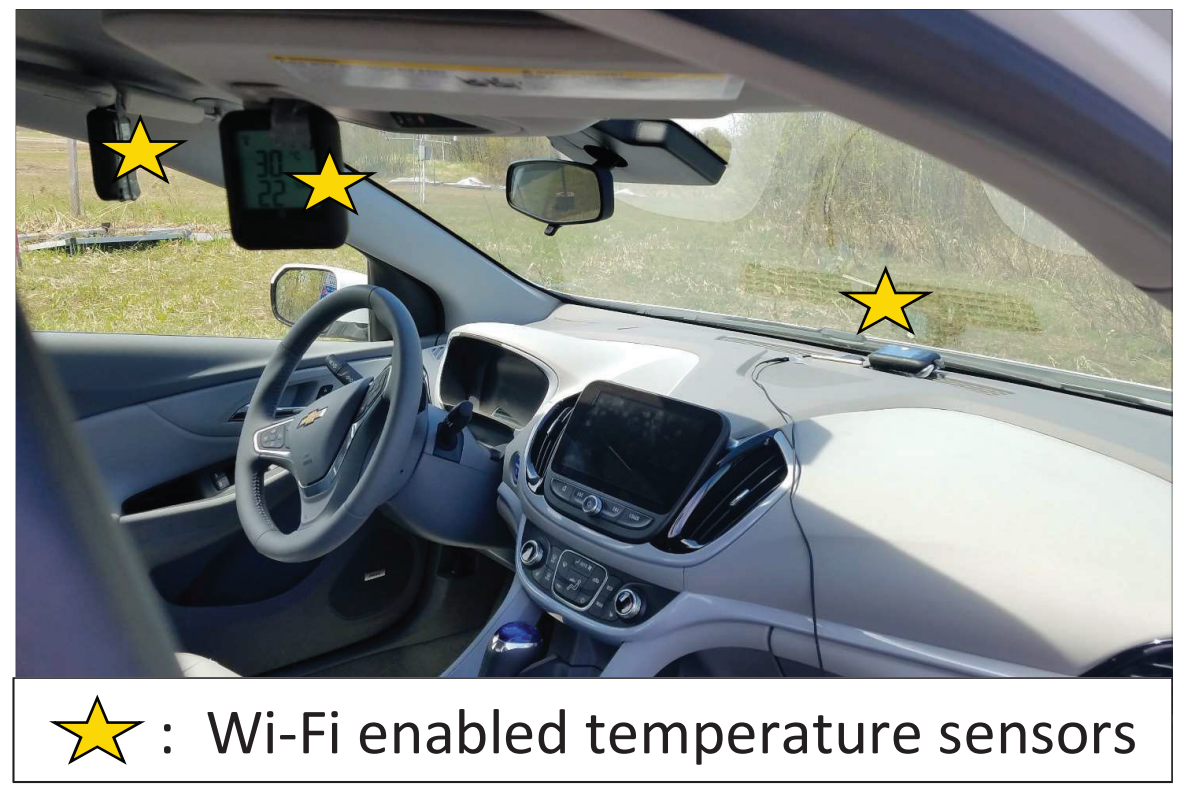

Figure 2.1: Test vehicle setup for solar load measurement at Keweenaw Research Center

\subsection{Cabin Blower Flow Rate Measurement}

The cabin blower characteristics were not provided by the vehicle manufacturer and it was not feasible to disassemble the blower fan and motor to determine the specifications. However, it was imperative to determine the air volume flow rate entering the test vehicle cabin for varying user-defined fan speed settings. The rate of heat removal or addition in the vehicle cabin is dependent on the air volume flow rate through the

cabin blower. The test setup, adopted from [36] and [37], for characterizing the cabin blower consists of a specialized sheet metal flow box interfacing with the air inlet on 
the test vehicle. Figure 2.2 shows the test setup constructed at MTU APSRC Labs according to the ASME standard [38]. One end of the flow box connects with the air inlet accessed by removing the cowl covering it on the top right side of the hood and the other end is interfaced with a 5 feet long, 4 inch outer diameter polyvinyl chloride (PVC) pipe. The other end of the PVC pipe is fitted with a $65 \mathrm{~mm}$ orifice plate using an adapter and pressure taps for connecting an oil manometer.

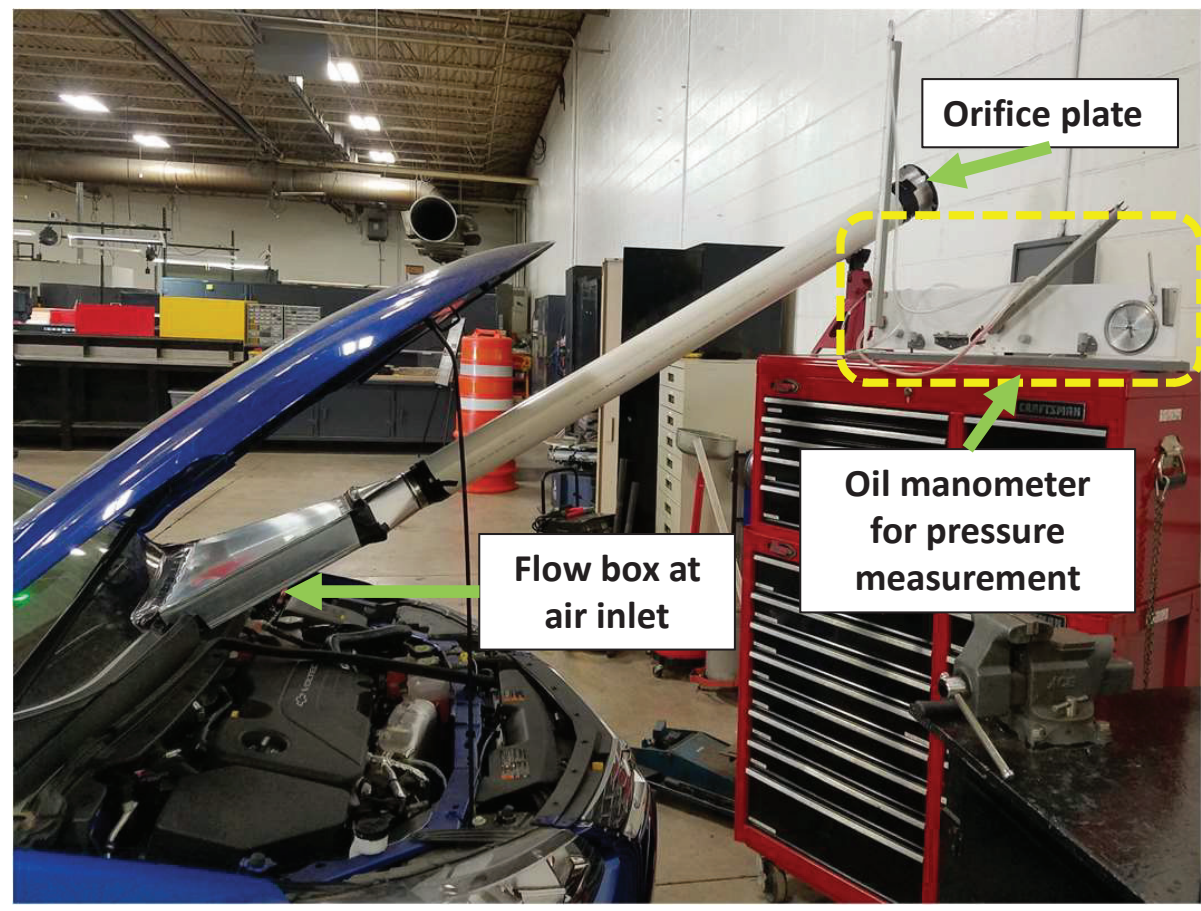

Figure 2.2: Flow bench setup for test vehicle cabin blower characterization at Advanced Power Systems Research Center Laboratory 


\subsection{Cabin Thermal Masses Characterization}

The first-order estimation of the physical dimensions of test vehicle cabin carried out in Section 2.1 give us the surface areas and volumes of the components inside the vehicle cabin. However, along with these physical dimensions, the thermal masses of the nodes, defined in the cabin thermal model, are important parameters to estimate the thermal energy gained and lost by the respective nodes. The test setup for this characterization test involves introducing a known heat source inside a vehicle cabin instrumented with thermocouples as illustrated in Figure 2.3. The test vehicle was positioned stationary, indoors, and turned off for this test. An electric resistive heater of known heat capacity was placed inside the test vehicle and the cabin doors and windows were shut with no passengers inside to minimize additional heat loads and leakages to the environment. 


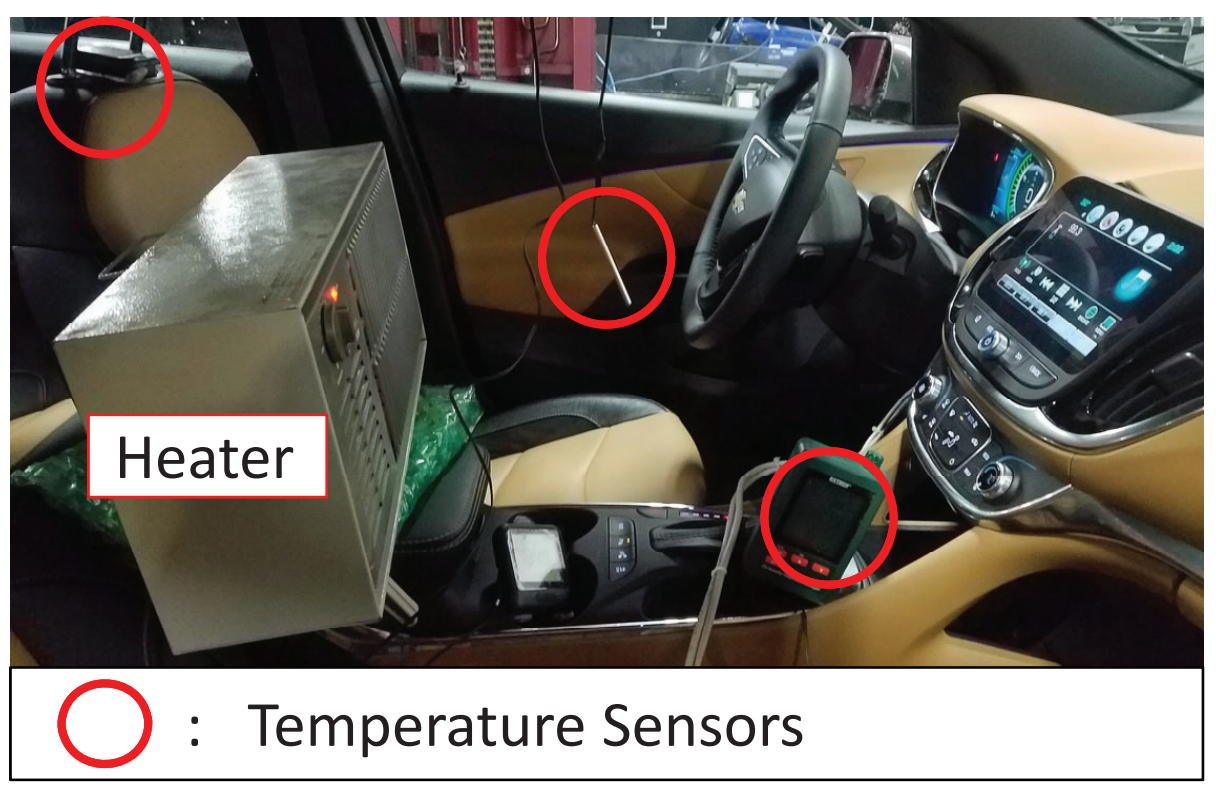

Figure 2.3: Cabin thermal mass characterization test setup at Advanced Power Systems Research Center Laboratory

\subsection{CAN Data Acquisition}

The vehicle CAN data acquisition through the on-board diagnostic (OBD) port of the test vehicle was carried out using both Vector Informatik GmbH VN5610A network interface tool and dSpace MicroAutoBox. Both the data acquisition setups are shown in Figure 2.4. The technical specifications of the Vector CAN tool used in our tests are detailed in Table 2.3.

A Data Base Container (DBC) file was provided by GM along with their 


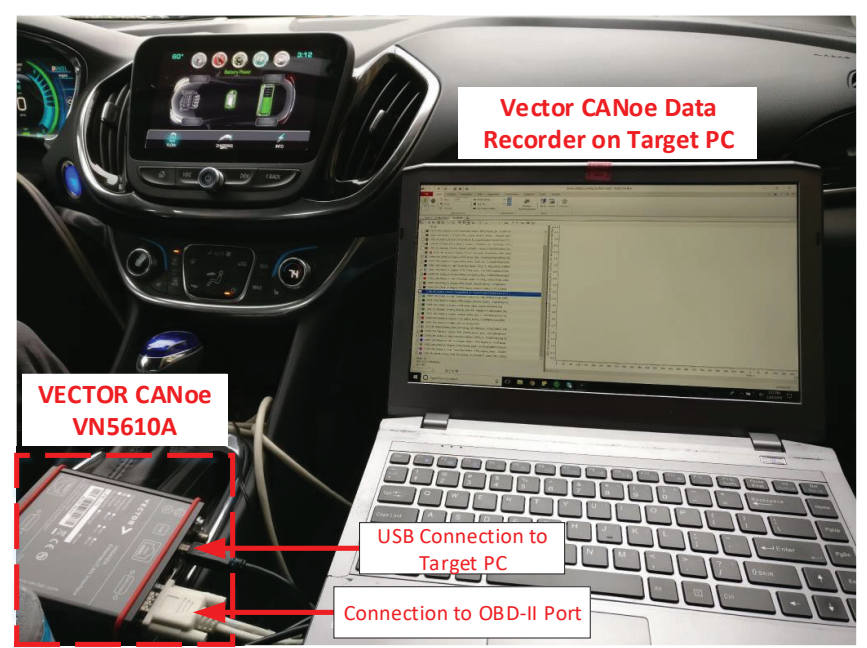

(a) Vector CANoe setup

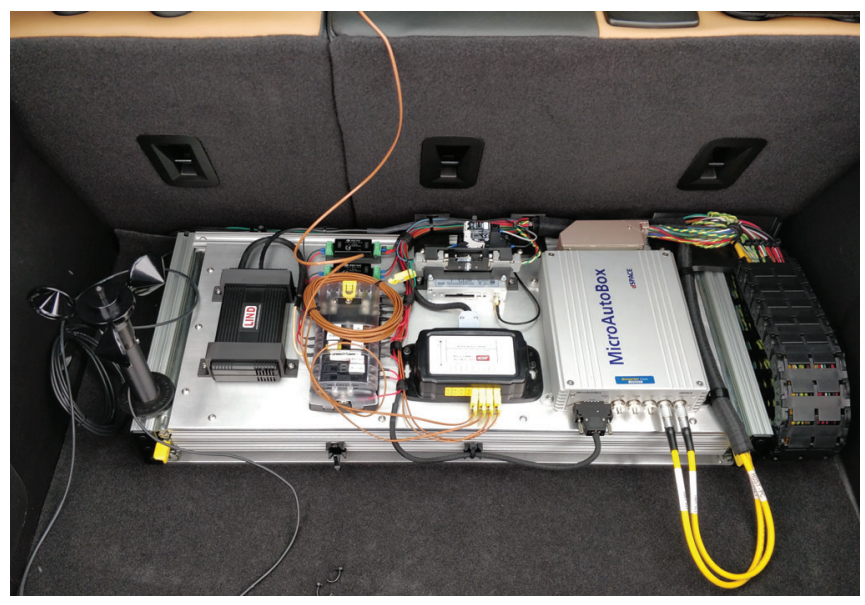

(b) dSpace MicroAutoBox setup

Figure 2.4: CAN data acquisition setup in test vehicle

manufacturer-specific CAN message IDs to access various available CAN signal data on the test vehicle. A Vector CANoe tool, CANdb++ Editor, was used to create specific test recorders for the VN5610A tool and the recorded data was exported as CSV files for model calibration and validation purposes. Similarly, after some test vehicles in the fleet were instrumented with dSpace MicroAutoBox for rapid controls implementation, required CAN signal data was recorded and stored using the dSpace 
Table 2.3

Specifications of Vector CAN tool (VN5610A) used for data acquisition

\begin{tabular}{ll}
\hline \hline Ethernet: Channels/transceiver & 2x BCM89811, 2x BCM54810 \\
Ethernet: Physical layer & 100 BASE-T1 (Broad-Reach) \\
& and 10BASE-T/100BASE-TX \\
Baudrates \% & 10Mbit/s ,100 Mbit/s ,1000 Mbit/s \\
CAN (FD) : Physical layer & CAN Highspeed(CAN FD capable) \\
CAN (FD) : Connectors & 1x D-SUB9 (dual channel) \\
Analog and Digital I/O & 1x Digital in/out, \\
& e.g. for DoIP Activation Line \\
Mean reaction time & $250 \mathrm{~s}$ \\
\hline
\end{tabular}

ControlDesk software.

\subsection{Argonne National Laboratory (ANL) Test}

\section{Data}

Researchers and technicians at Argonne National Laboratory (ANL) conducted several chassis dynamometer tests on the test vehicle and provided data to the MTU NEXTCAR team. This test data was used in conjunction with data from tests conducted on MTUDC to develop, calibrate and validate component and system models and to extract control logics implemented in the test vehicle. Table 2.4 shows a summary of tests conducted at ANL. 
Table 2.4

ANL vehicle data summary

\begin{tabular}{ll}
\hline \hline Number of test cycles & 25 \\
Climate control setpoint & $72^{\circ} \mathrm{F}$ \\
Drive cycles & UDDS \\
& HWFET \\
& US-06 \\
& Passing maneuvers \\
Performance test & Charge depleting \\
& Charge sustaining \\
Engine start conditions & Cold-start \\
& Warm-start \\
Ambient temperature & $-7^{\circ} \mathrm{C}$ \\
& $22^{\circ} \mathrm{C}-26^{\circ} \mathrm{C}$ \\
& $35^{\circ} \mathrm{C}-41^{\circ} \mathrm{C}$ \\
\hline
\end{tabular}




\section{Chapter 3}

\section{Modeling}

\subsection{Background}

The work done in this thesis focuses on the overall HVAC modeling and its integration with the VD\&PT model to enable optimization of the integrated operation of the HVAC and electric powertrain systems of a hybrid electric vehicle, specifically the test vehicle. Figure 3.1 shows an overview of the integrated VD\&PT and HVAC models that were developed for the purposes of this work. The VD\&PT model developed for this program, as referred to in Section 1.3, is capable of estimating vehicle dynamics and energy consumption within $5 \%$ of real-world test data.

Several HEVs including the test vehicle for this project have engine assisted heating 
wherein engine waste heat in the form of thermal energy of engine coolant is used along with the electric heater which is the primary heat source for cabin heating purposes. Additionally, some EVs and HEVs like the test vehicle also have shared cooling loops for battery and cabin cooling purposes. The thermal coupling evident between the vehicle HVAC and powertrain systems is important in evaluating optimal operating points for the proposed integrated system and is thus explained in detail in the following sections. 


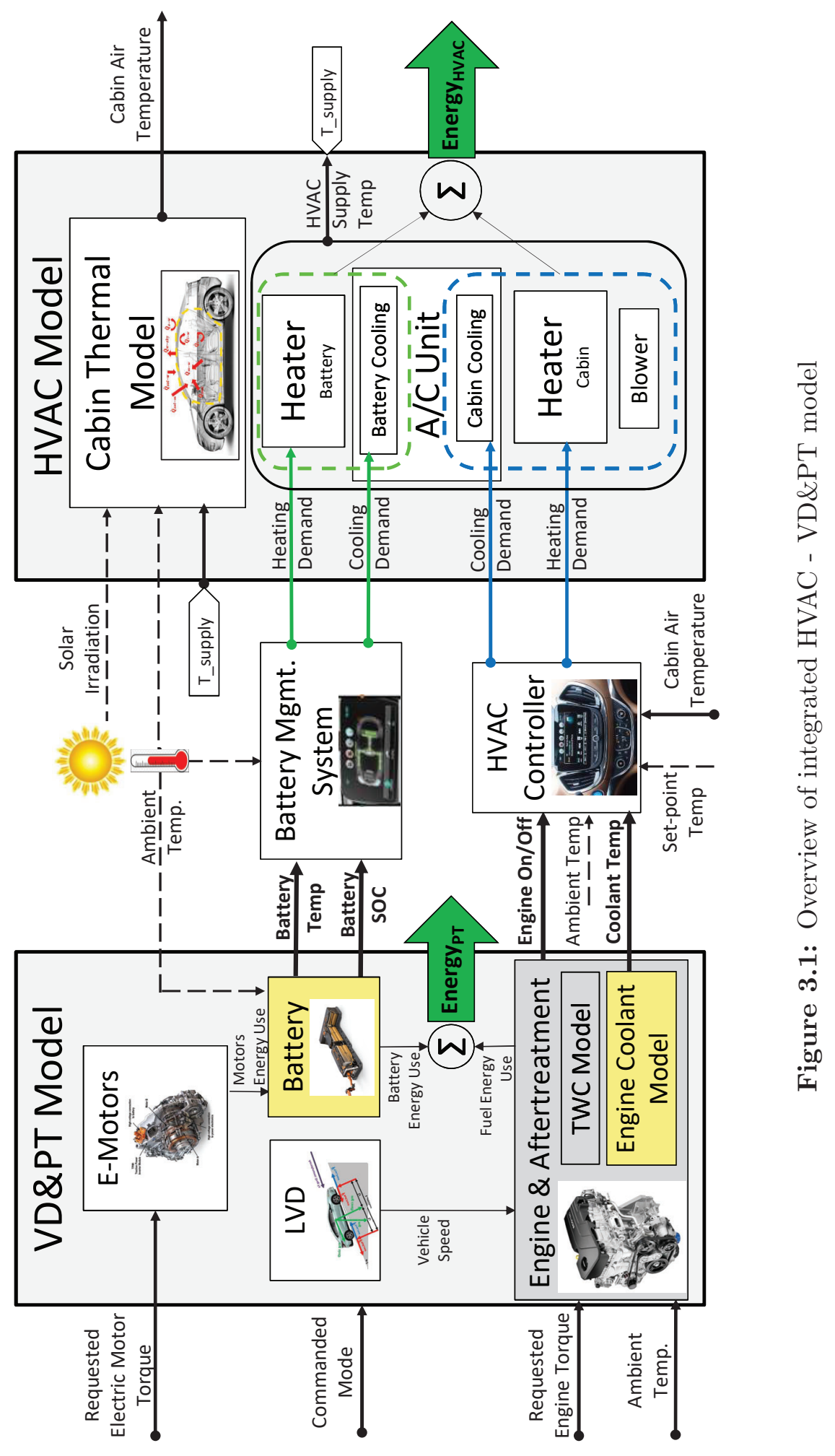




\subsubsection{HVAC Heating Loop}

The dual heating operation of the test vehicle is facilitated by the 2 integrated loops as shown by the schematic in Figure 3.2. The 2 loops are controlled by the flow control valve to allow heated engine coolant to be shared with the primary electric heater coolant when needed. This engine assisted heating operation is functional in the following cases:

$\dagger$ When the engine coolant is above a specified temperature threshold, and

$\dagger$ When cabin heating is required in cold ambient conditions below a specified temperature threshold.

\subsubsection{HVAC Cooling Loop}

The cooling loop for the test vehicle's high voltage battery and cabin conditioning are coupled via a common A/C compressor unit. In EVs and HEVs, the compressor must be electrically powered unlike the belt-driven compressors of conventional vehicles due to the absence of continuous engine operation. This integrated configuration allows for more flexibility in the HVAC controls framework since the compressor speed is independent of the engine speed. The schematic of this coupled HVAC cooling loop 


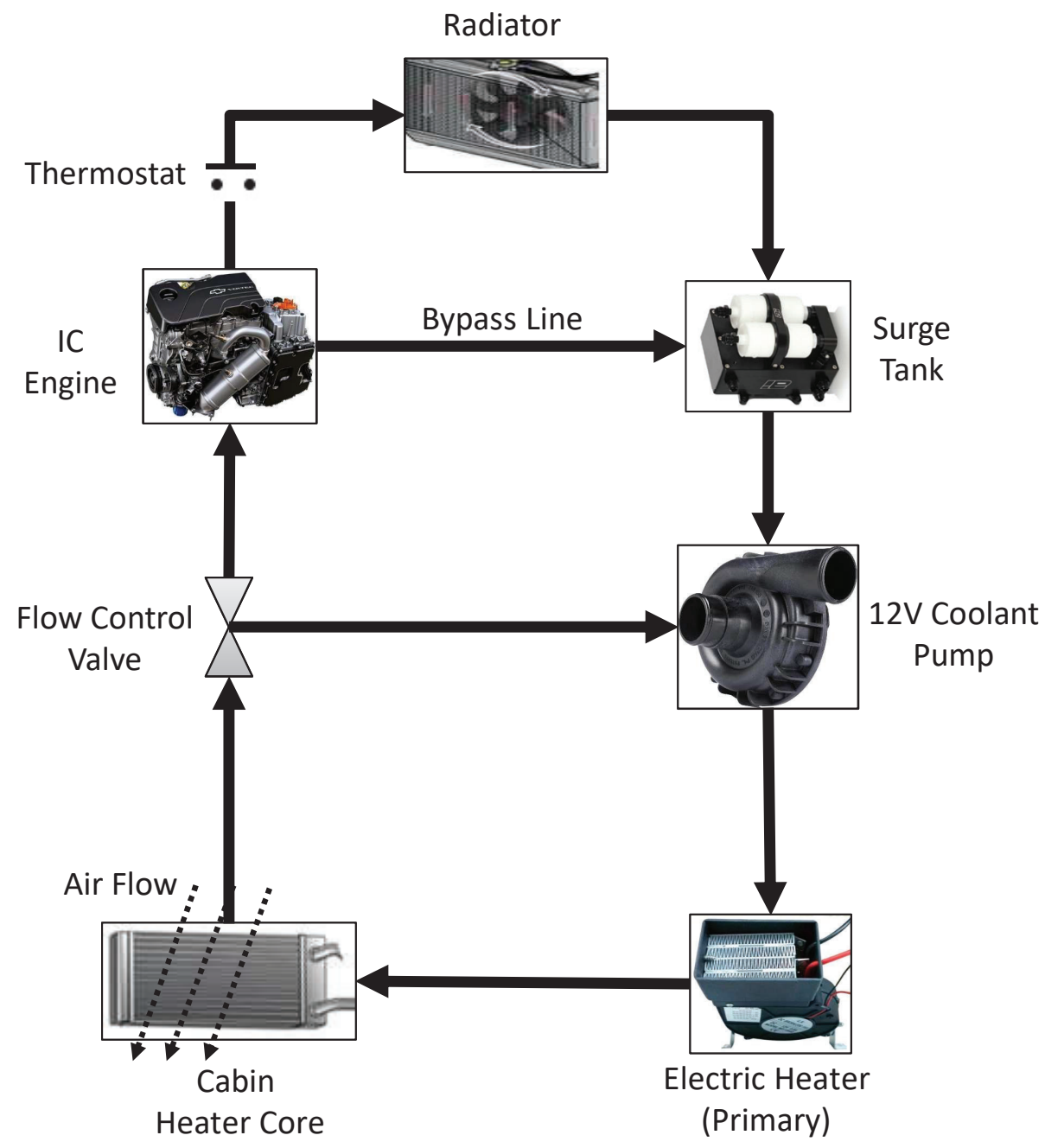

Figure 3.2: Test vehicle's cabin heating loop

in the test vehicle is shown in Figure 3.3.

The 3-way flow control valve, in the battery thermal management loop, is operated to maintain battery temperature within reasonable operating temperature range. Valve position 1 corresponds to battery heating, where a secondary electric heater is used to heat the coolant and consequently heat the battery through heat exchanger coils. (Note that the secondary electric heater for battery heating is independent of the 


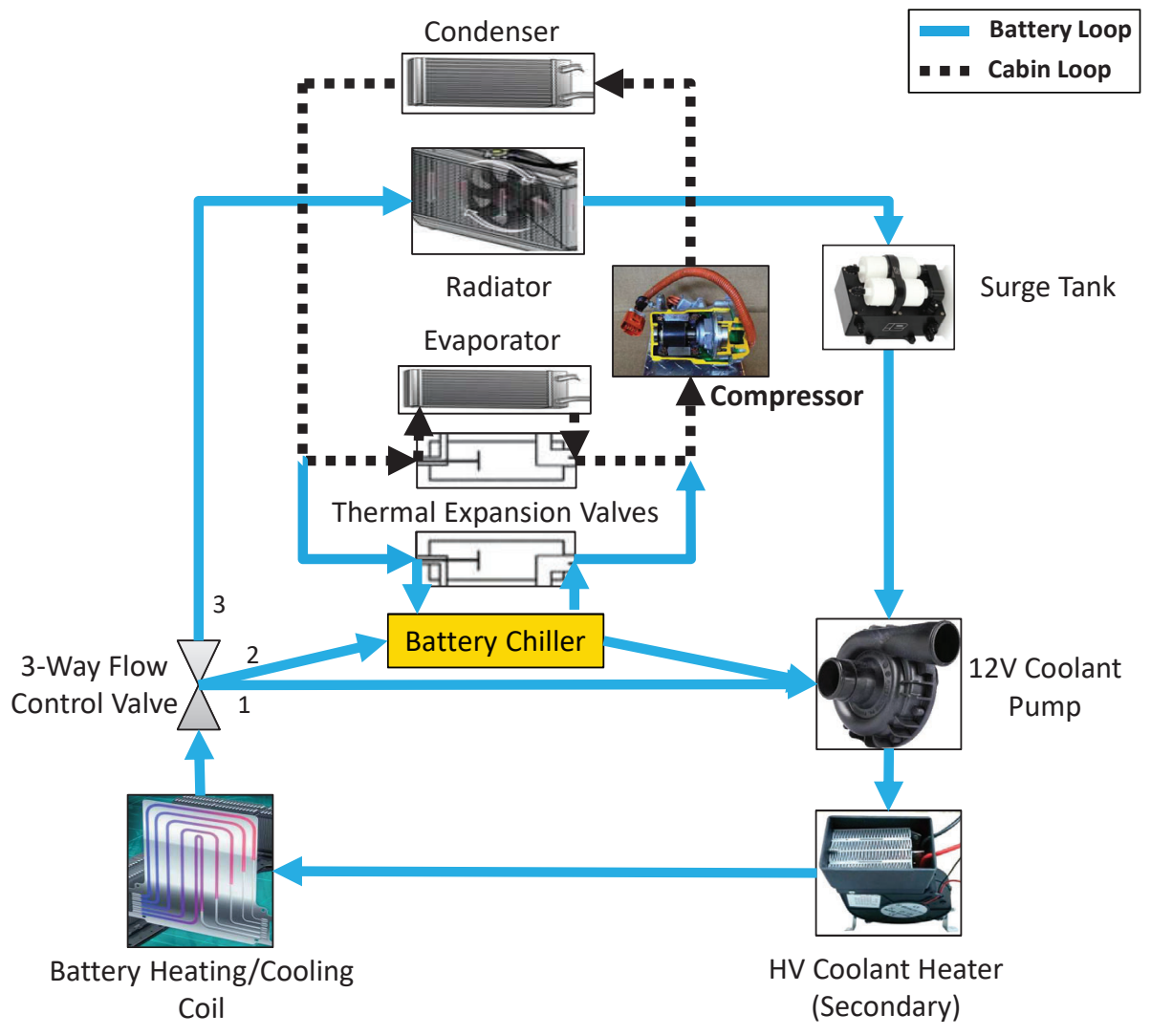

Figure 3.3: Test vehicle's integrated cooling loops

primary electric heater used for cabin heating referred to in Section 3.1.1) Valve position 2 corresponds to battery cooling, wherein the electric compressor is used to cool the refrigerant in the cabin cooling loop which cools the battery coolant in the battery chiller and finally cools the battery through heat exchanger coils. Finally, valve position 3 regulates battery temperature using pump control. In this loop the battery coolant flows through the radiator and the coolant pump. 


\subsection{Cabin Thermal Model}

A lumped capacitance transient thermal model of the cabin is developed to predict the mean cabin temperature by accurately capturing the temperature dynamics within the cabin. The test vehicle cabin is modeled as three distinct nodes namely; interior air, interior mass and cabin walls (shell). The interior air node comprises total air volume inside the cabin lumped together; the seats, center console and the dashboard form the interior mass node whereas the cabin doors, windows, roof, floor and the front and rear windshields comprise the cabin walls node. The heat transfer interactions including conduction, convection and radiation, between the three nodes as well as the solar heat transfer interactions are incorporated using heat transfer equations described in this section. A schematic of the cabin thermal model is shown in Figure 3.4.

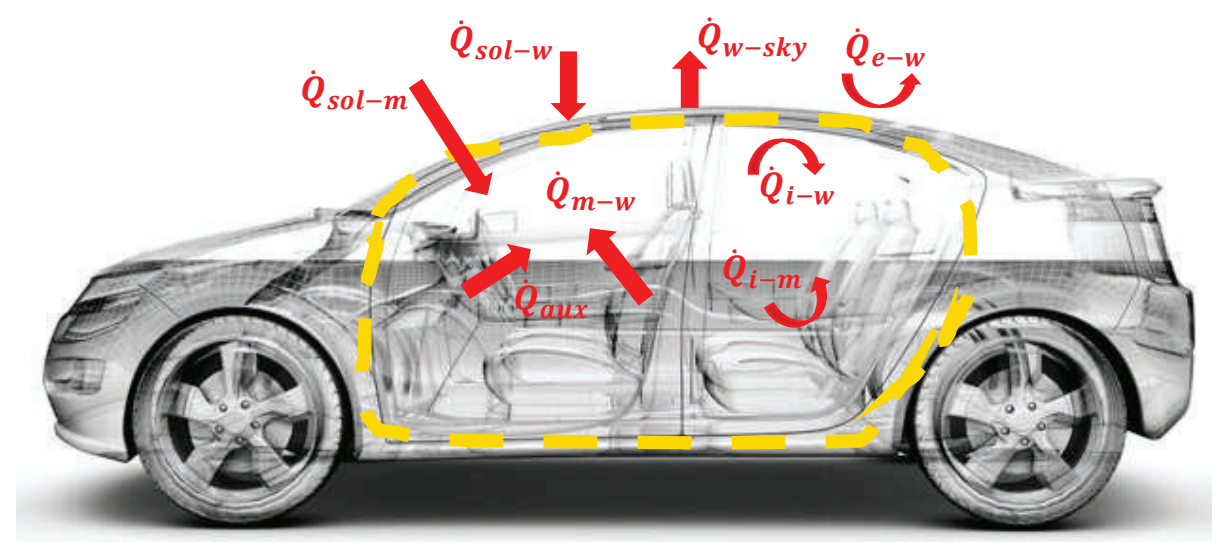

Figure 3.4: Cabin model control volume with heat loads 
Three governing heat transfer equations for the three nodes are developed using an energy balance approach. The equations for the interior air, interior mass and the cabin walls, shown in Eq. (3.1), (3.2), and (3.3) respectively, are implemented in our model to predict the temperatures of the respective nodes.

$$
\begin{aligned}
C_{i} \frac{d T_{i}}{d t}=\dot{Q}_{s u p}+\dot{Q}_{a u x}+\dot{Q}_{o c c}-\dot{Q}_{(i-m)}-\dot{Q}_{(i-w)} \\
C_{m} \frac{d T_{m}}{d t}=\dot{Q}_{(i-m)}+\dot{Q}_{(s o l-m)}-\dot{Q}_{(m-w)} \\
C_{w} \frac{d T_{w}}{d t}=\dot{Q}_{(i-w)}+\dot{Q}_{(e-w)}+\dot{Q}_{(s o l-w)}+\dot{Q}_{(m-w)} \\
-\dot{Q}_{(w-s k y)}
\end{aligned}
$$

where, $\dot{Q}$ is the heat flow rate, $C$ is heat capacity, $T$ is temperature and the subscripts denote the following; $i$ is interior air, $m$ is interior mass, $w$ is walls of the cabin, sup is supply air, aux is auxiliary, occ is occupant, sol is solar, $e$ is exterior (ambient) air and sky is ambient sky.

The individual heat flow rates(heat loads) taken into account in our model are detailed in the following sub-sections:

\subsubsection{HVAC supply heat flow rate}

The energy balance of cabin interior, shown in Eq. (3.4) and adopted from [21], represents the HVAC supply heat flow rate as a compensation for all thermal loads 
inside the cabin.

$$
\begin{aligned}
\dot{Q}_{\text {sup }}= & -\left[\dot{Q}_{a u x}+\dot{Q}_{\text {sol }}+\dot{Q}_{o c c}-\dot{Q}_{(i-w)}-\dot{Q}_{(i-m)}\right] \\
& -\left(c_{p, i} \dot{m}_{i}+c_{p, m} \dot{m}_{m}\right)\left[\frac{T_{i}-T_{s u p}}{t_{c}}\right]
\end{aligned}
$$

where, $c_{p}$ is specific heat capacity, $\dot{m}$ is mass flow rate, $T_{\text {sup }}$, is the supply air temperature desired from the HVAC system for cabin thermal comfort. This supply temperature is estimated using the methods described in Section 3.6 later. The pull-

down time constant, $t_{c}$, is the time required for the cabin temperature, $T_{i}$, to reach the supply temperature, within $1 \mathrm{~K}$.

\subsubsection{Heat transfer interactions}

These interactions include; cabin interior air with both interior mass and cabin walls, as well as ambient air with cabin walls. These three heat flow rates are summarized in Eq. (3.5).

$$
\dot{Q}_{i, e-x}=U_{i, e-x} A_{x}\left(T_{i, e}-T_{x}\right)
$$

where, $U$ is overall heat transfer coefficient which denotes the combined effect of convective and conductive heat transfer interactions between air and cabin surfaces and subscript $x$ denotes these surfaces. 


\subsubsection{Radiative heat transfer}

A first principles model of radiative heat transfer is used to model the interactions between the cabin interior mass, which is assumed to be a black body, and the interior cabin walls, as shown in Eq. (3.6).

$$
\dot{Q}_{m-w}=\sigma \epsilon_{m} A_{m} F_{m-w}\left(T_{m}^{4}-T_{w}^{4}\right)
$$

where, $\sigma$ is Stefan-Boltzmann constant, $\epsilon$ is the emissivity of the cabin mass and shell and is dependent on the color of the cabin interiors and exterior, $A$ is surface area and $F_{m-w}$ is the view factor from the interior mass to the walls and is assumed to be unity.

Similarly, the interaction between the exterior cabin walls and the sky is also modeled by the Stefan-Boltzmann law assuming that the cabin walls are a small convex object in a large cavity, thereby acting as a black body. This relationship is illustrated in Eq. (3.7).

$$
\dot{Q}_{w-s k y}=\sigma \epsilon_{w} A_{w}\left(T_{w}^{4}-T_{s k y}^{4}\right)
$$




\subsubsection{Heat from occupants}

Both latent and sensible heat flow rates from human occupants are taken into consideration. According to ASHRAE standards [39], one seated person accounts for approximately $35 \mathrm{~W}$ of sensible heat and $70 \mathrm{~W}$ of latent heat.

$$
\dot{Q}_{\text {occ,sensible }}=n \cdot 35 \quad \dot{Q}_{\text {occ,latent }}=n \cdot 70
$$

where, $n$ is number of occupants.

\subsubsection{Auxiliary heat}

The primary sources of auxiliary heat inside the cabin are vehicle electrical auxiliaries as well as supplementary electronic devices like laptops used during testing. This was assumed to be a constant value of $400 \mathrm{~W}$ for the purposes of this work.

\subsubsection{Solar heat flow rate}

The heat flow rate from solar irradiation consists of component energy gains by the cabin walls and the cabin interior mass as shown in Eq. (3.9). 


$$
\dot{Q}_{s o l-w}=\alpha_{w} \sum G_{s i d e}^{\prime} A_{s i d e, w}
$$

where, $\alpha$ is the wall absorptivity and it depends on vehicle color and $G^{\prime}$ is the global solar irradiance. The heat gained by cabin walls is due to the incident solar radiation on each cabin wall ( side = right, left, front, back, roof) depending on the incident surface area and wall absorptivity.

The heat gained by interior mass due to incident radiation penetrating through the glass windows, is dependent on glass transmissivity in addition to the incident surface area and interior mass absorptivity as summarized in Eq. (3.10).

$$
\dot{Q}_{\text {sol-m }}=\alpha_{m} \tau_{g} \sum G_{\text {side }}^{\prime} A_{\text {side }, g}
$$

where, $\tau$ is transmissivity and subscript $g$ denotes glass. This is applied to front and rear windshields, front and rear windows on both driver and passenger sides and if applicable, to the sun roof.

\subsubsection{Solar irradiation load}

Solar irradiation data is available from solar sensors like pyranometers, in the form of global horizontal irradiation measurement. The cabin thermal model developed for this work employs decomposition models which estimate direct and diffuse irradiance from the available global irradiance data. We implement the decomposition model 
proposed by Reindl et al. to calculate the diffuse fraction based on clearness index values [40]. Then, the global irradiance on tilted surfaces, $G_{\text {side }}^{\prime}$, is estimated using transposition models proposed in [41]. Finally, the solar heat loads, described in Eq. (3.9) and (3.10) are calculated. This process gives our model the capability of representing the actual solar irradiance on each exterior cabin wall (shell) and on interior mass through windows by using the solar elevation and azimuth angles based on time of day, angle of tilt of vehicle surfaces, heading angle, latitude and longitude position of the vehicle from Global Positioning System (GPS), surface albedo and clearness index as inputs. The decomposition and transposition equations implemented in this model are shown in Eq. (3.11) and (3.12) respectively.

$$
G H I=D H I+D N I \cdot \cos (z)
$$

where, GHI is global horizontal irradiance, DHI is diffuse horizontal irradiance, $D N I$ is direct normal irradiance and $z$ is zenith angle.

$$
Q_{\text {tilted }}=D N I \cdot \cos (\theta)+D H I \cdot R_{d}+\rho \cdot G H I \cdot R_{r}
$$

where, $\theta$ is angle of incidence of the vehicle surface, $\rho$ is surface albedo, $R_{d}$ is diffuse transposition factor and $R_{r}$ is ground reflection transposition factor. 


\subsection{Engine Coolant Temperature Model}

The engine coolant temperature plays an important role in determining cabin heating operation as discussed in Section 3.1.1. A lumped coolant model is developed for the purposes of this work based on the energy balance illustrated in Figure 3.5. The fundamental equation representing the thermal energy gained by the engine coolant from engine waste heat and thermal energy lost to ambient air through convection is shown in Eq. (3.13).

$$
\alpha \dot{m}_{f} Q_{L H V}=m_{\text {coolant }} c_{p, \text { coolant }} \frac{d T_{\text {coolant }}}{d t}+h A \Delta T
$$

where, $\alpha$ is fraction of burnt fuel energy transferred to coolant, $\dot{m}_{f}$ is fuel flow rate, $Q_{L H V}$ is lower heating value of gasoline, $m_{\text {coolant }}$ is mass, $c_{p, \text { coolant }}$ is specific heat capacity and $T_{\text {coolant }}$ is temperature of the coolant, $h$ is convective heat transfer coefficient, $A$ is the area of coolant exposed to air, $\Delta T$ is the difference between coolant and ambient air temperatures.

The rate of thermal energy loss to ambient air is dependent on multiple factors depicted in Figure 3.5. These influencing variables are incorporated as look-up tables in the engine coolant temperature model based on test data. Among these factors, modeling the effect of vehicle speed is critical because of the following reasons: 
i The rate of convective heat loss to ambient air is highly dependent on vehicle speed, and

ii Preview of future vehicle speed profile in connected vehicle scenarios can be exploited to further optimize HVAC energy consumption.

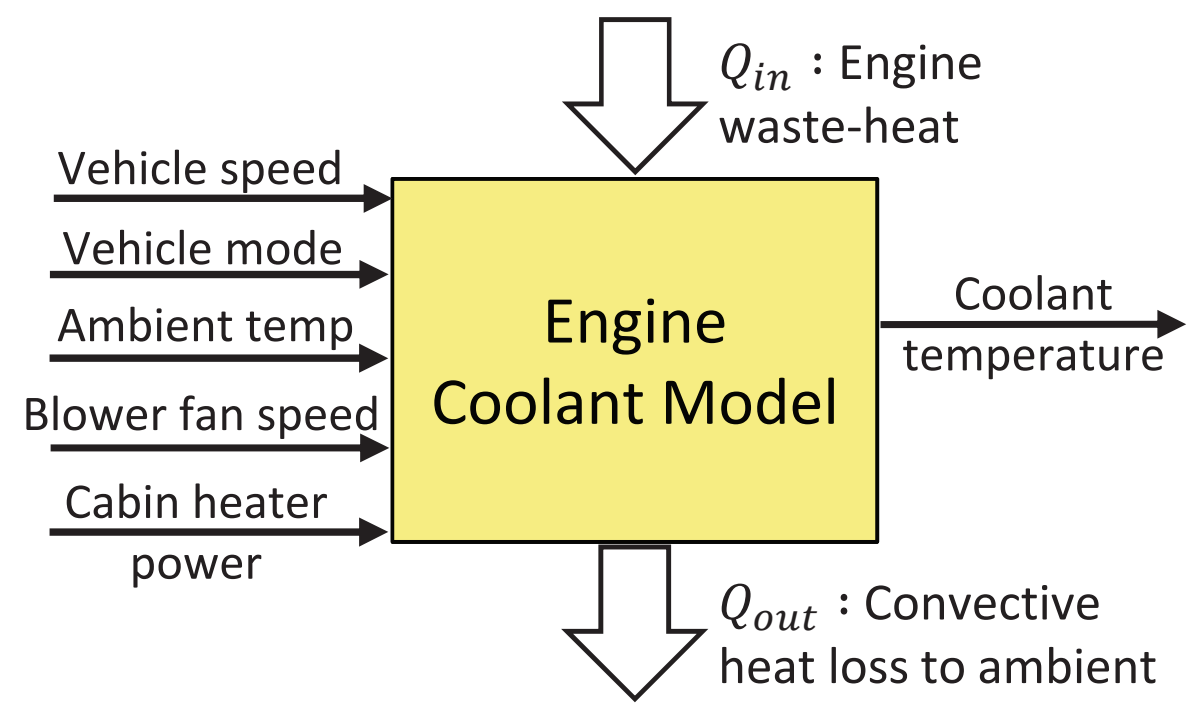

Figure 3.5: Schematic of lumped engine coolant temperature model

\subsection{Cabin Electric Heater Model}

A rule-based controller based on the control logic extracted from both vehicle test data and ANL researchers' analysis in [22] is implemented in the cabin electric heater model to determine heater energy consumption. The baseline control logic is extracted 
for different operating modes of the test vehicle. When the engine coolant temperature is maintained high enough to independently meet cabin heating requirements through engine assisted heating, the electric heater is not used. However, during cold start conditions when ambient temperature is below the user-specified temperature threshold (either $35^{\circ} \mathrm{F}$ or $15^{\circ} \mathrm{F}$ ), the engine is turned on and the electric heater is used alone for cabin heating until coolant is heated to $60^{\circ} \mathrm{C}$ due to engine waste heat. Then, the electric heater turns off and engine continues until coolant temperature is at least $65^{\circ} \mathrm{C}$ or until engine is no longer needed for providing traction power to the vehicle. At this point, the engine coolant is hot enough to provide engine assisted heating and hence electric heater is not used. However, as the engine coolant temperature drops, the electric heater turns on intermittently between $52^{\circ} \mathrm{C}$ and $49^{\circ} \mathrm{C}$ at reduced power level to supplement the heated engine coolant for cabin heating purposes.

It is important to note that during the periods when electric heater is supplementing engine coolant heat, due to the sharing of engine coolant and electric heater coolant loops described in Section 3.1.1, the rate of engine coolant heat loss is reduced. This leads to a longer time period until coolant reaches the lower temperature threshold for the engine to be started again and consequently allows the electric heater to be used as the sole provider of cabin heat. 


\subsection{Battery Electric Heater Model}

The battery electric heater described in Section 3.1.2 is used to independently meet the heating requirements of the vehicle's high voltage battery. The energy consumption model of this electric heater is dependent on ambient and battery temperatures

only. A simple model developed from experimental test data for the purposes of this work shows a constant heater operating power when the battery temperature is below the lower temperature threshold. The battery electric heater model estimates a constant $2.5 \mathrm{~kW}$ supply power when battery temperature is below $3^{\circ} \mathrm{C}$.

\subsection{Cabin Heater Core Model}

The $\varepsilon$-NTU method for counter-flow heat exchanger, theorized in [42], is used to model the test vehicle cabin heater core. The heat exchange takes place from the hot coolant entering the heater core to the cold ambient air which is consequently heated and supplied to the vehicle cabin for cabin heating. Figure 3.6 shows a schematic of the heater core model developed for the purposes of this work.

Since, the test vehicle heater core specifications are unknown, experimental test data is used to characterize the heater core effectiveness using Eq. (3.14) - (3.19). 


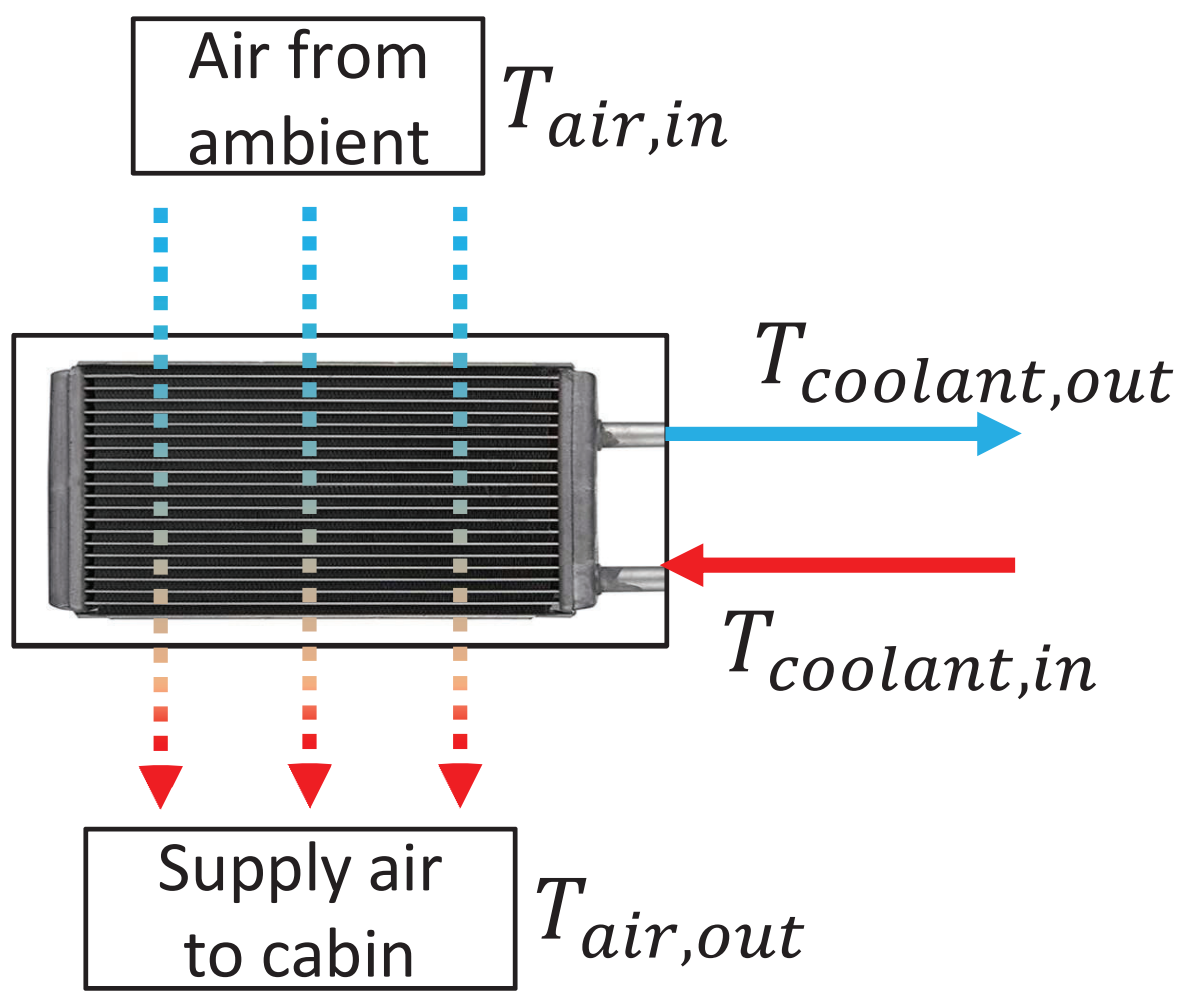

Figure 3.6: Schematic of cabin heater core model

$$
\begin{gathered}
C_{\text {air }}=\dot{m}_{\text {air }} \cdot c_{p, \text { air }} \\
C_{\text {coolant }}=\dot{m}_{\text {coolant }} \cdot c_{p, \text { coolant }} \\
C_{\text {min }}=\min \left(C_{\text {air }}, C_{\text {coolant }}\right) \quad C_{\text {max }}=\max \left(C_{\text {air }}, C_{\text {coolant }}\right) \\
\dot{Q}_{\text {air }}=\dot{m}_{\text {air }} \cdot c_{p, \text { air }}\left(T_{\text {air }, \text { out }}-T_{\text {air }, \text { in }}\right) \\
\dot{Q}_{\text {max }}=C_{\text {min }}\left(T_{\text {coolant }, \text { in }}-T_{\text {air }, \text { in }}\right) \\
\varepsilon=\dot{Q}_{\text {air }} / \dot{Q}_{\text {max }}
\end{gathered}
$$




$$
T_{\text {coolant }, \text { out }}=T_{\text {coolant }, \text { in }}-\varepsilon\left(\dot{Q}_{\max } / C_{\max }\right)
$$

where, $\varepsilon$ is the heater core effectiveness.

Different combinations of the dual heating operation of the integrated electric heater and engine assisted heating leads to the heating of the coolant entering the cabin heater core. Based on experimental data, another model is developed for varying operating conditions to estimate temperature of coolant entering the cabin heater core, $T_{\text {coolant,in }}$. Then, temperature of air supplied to cabin, $T_{\text {air,out }}$, can be calculated using the heat-exchanger model developed earlier. Given the ambient air temperature, $T_{a i r, i n}$, Eq. (3.20) can be used to calculate the temperature of hot air entering the vehicle cabin during cabin heating.

$$
T_{a i r, o u t}=T_{a i r, i n}-\varepsilon\left(T_{\text {coolant }, \text { in }}-T_{a i r, i n}\right)
$$

The cabin temperature dynamics modeled in Section 3.2 then accurately predict the air temperature inside the cabin for the calculated temperature of air entering the cabin i.e. supply air. 


\subsection{Catalyst Temperature Model}

The catalyst temperature is significant in evaluating emissions in vehicles. Although the effects of emissions have not been explicitly considered in this work, it is still important to understand the catalyst temperature evolution and to take into account the impact of emissions albeit to a limited extent for the purposes of this work. The test vehicle has a three-way catalyst (TWC), close-coupled catalytic converter located next to the engine block and insulated within heat-shields. To characterize the TWC, several high-fidelty models based on catalyst chemistry are available [43, 44]. However, to build a first-order, control-oriented TWC model independent of the chemical reaction mechanics, collected test data on ambient temperature, vehicle speed, and engine speed is used to build a catalyst temperature model as shown in

Figure 3.7.

The cool-down characteristics of catalyst temperature are modeled as a convective heat loss to the ambient air flowing past the heat-shields covering the catalytic converter. Hence, during cool-down, the catalyst temperature is a function of ambient temperature and vehicle speed as illustrated by Eq. (3.21).

$$
m_{\text {catalyst }} c_{p, \text { catalyst }} \frac{d T_{\text {catalyst }}}{d t}=-h A \Delta T
$$

where, $h$ is convective heat transfer co-efficient dependent on ambient temperature 
Three-way Catalyst Model

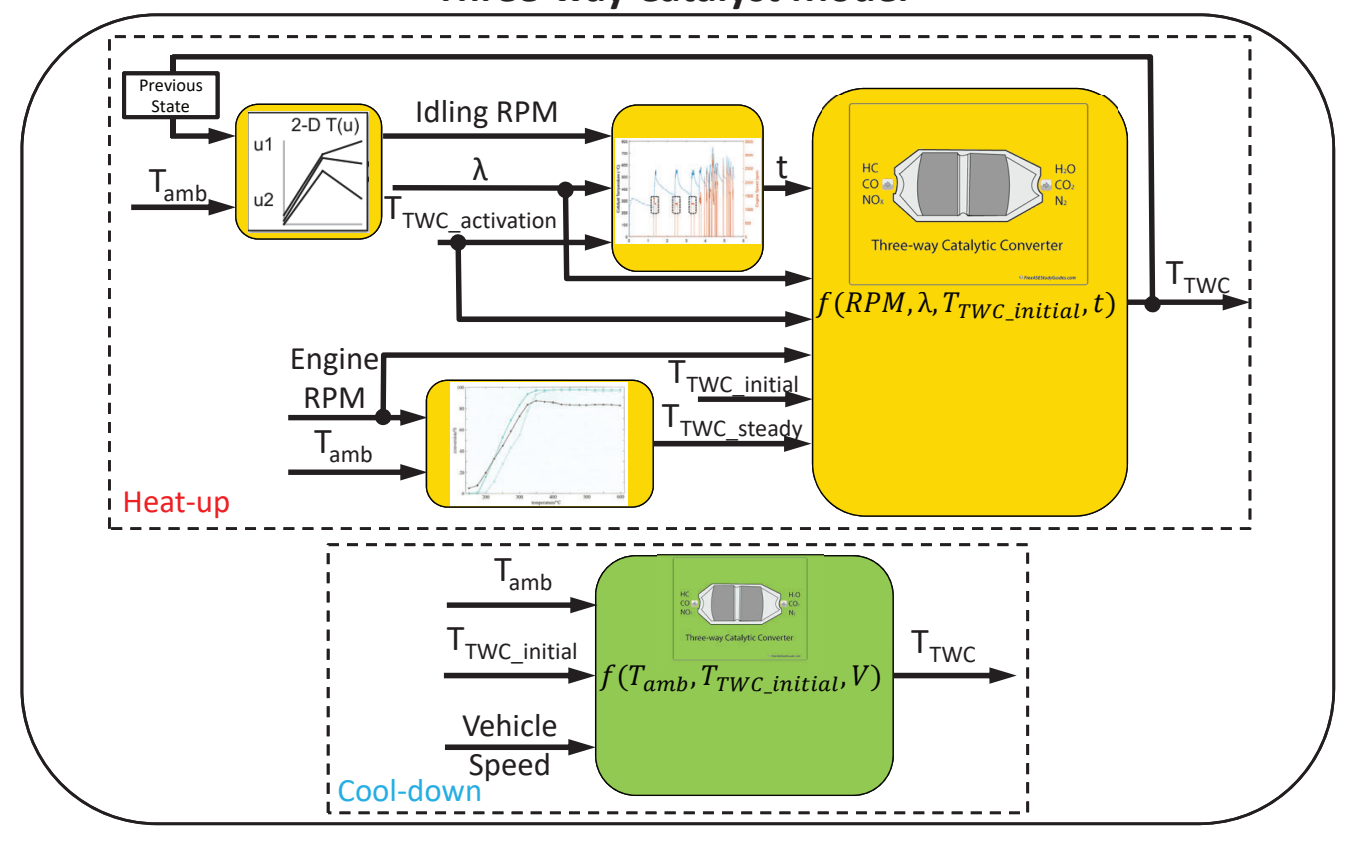

Figure 3.7: Schematic of three-way catalyst temperature model

and vehicle speed, $A$ is the surface area of TWC catalytic converter and $\Delta T$ is the temperature differential between catalyst and ambient air.

The heat-up characteristics of catalyst temperature are modeled as two separate stages i.e. activation stage and exothermic reaction stage. The activation stage refers to the initial heat-up of the catalyst until it reaches the light-off temperature. After the catalyst light-off, exothermic reactions lead to rapid increase in the catalyst temperature. The Eq. (3.22) shows the two stages in catalyst heat-up contingent on light-off temperature. 


$$
T_{\text {catalyst }}= \begin{cases}C_{1} t^{C_{2}}+T_{T W C, \text { initial }}, & T_{\text {catalyst }} \leq T_{\text {light-off }} \\ C_{3} t^{C_{4}}+C_{5} e^{-C_{6} t} \omega_{e}+C_{7} \lambda+C_{8}, & T_{\text {catalyst }}>T_{\text {light-off }}\end{cases}
$$

where, $C_{1-8}$ represent parameters estimated from test data, $t$ is the time in seconds, $\omega_{e}$ is the engine speed in rpm and $\lambda$ is the factor influencing the time needed to achieve light-off temperature.

\subsection{Compressor Model}

The A/C compressor unit used for test vehicle cabin and battery cooling, described in Section 3.1.2, is an electric compressor. Due to lack of technical specifications of compressor used by test vehicle manufacturer and infeasibility of disassembling the test vehicle cooling loop to identify or instrument the $\mathrm{A} / \mathrm{C}$ compressor unit and subsequently develop physics-based models, a system identification methodology forming an artificial neural network is adopted. The ambient air temperature and temperature of air entering the vehicle cabin i.e. supply air temperature are measured in available test data. Since, the energy consumption of A/C compressor is proportional to the temperature differential between ambient air and supply air, they are used as inputs to the artificial neural network as illustrated by Figure 3.8. The neural network toolbox in MATLAB is used to design the compressor neural network using Levenberg-Marquardt algorithm with 10 hidden layers for 6 different test datasets for 
hot weather $\left(22-41^{\circ} \mathrm{C}\right)$ provided by ANL, amounting to $1.7 \mathrm{e} 5$ data points.

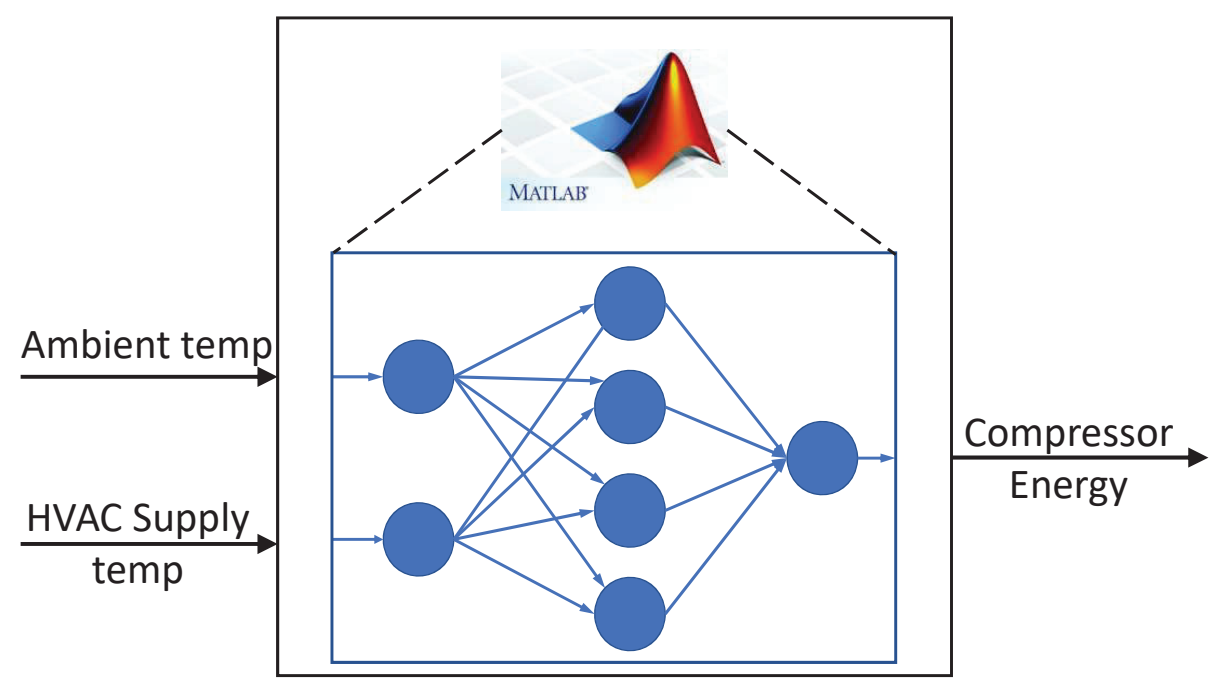

Figure 3.8: Schematic of A/C compressor neural network model

The neural network performance was evaluated using the metrics shown in Figure 3.9. Additionally, cross-validation tests were conducted to ensure independence of the trained neural network from initial conditions. Cross-validation tests entail rerunning the neural network toolbox multiple times with different initial conditions and enabling different sampling of data into training, testing and validation data. Figure 3.10 shows the cross-validation test results with negligible spread of the mean square error (MSE) which means repeatibility of the neural network training and hence independence from initial conditions. 

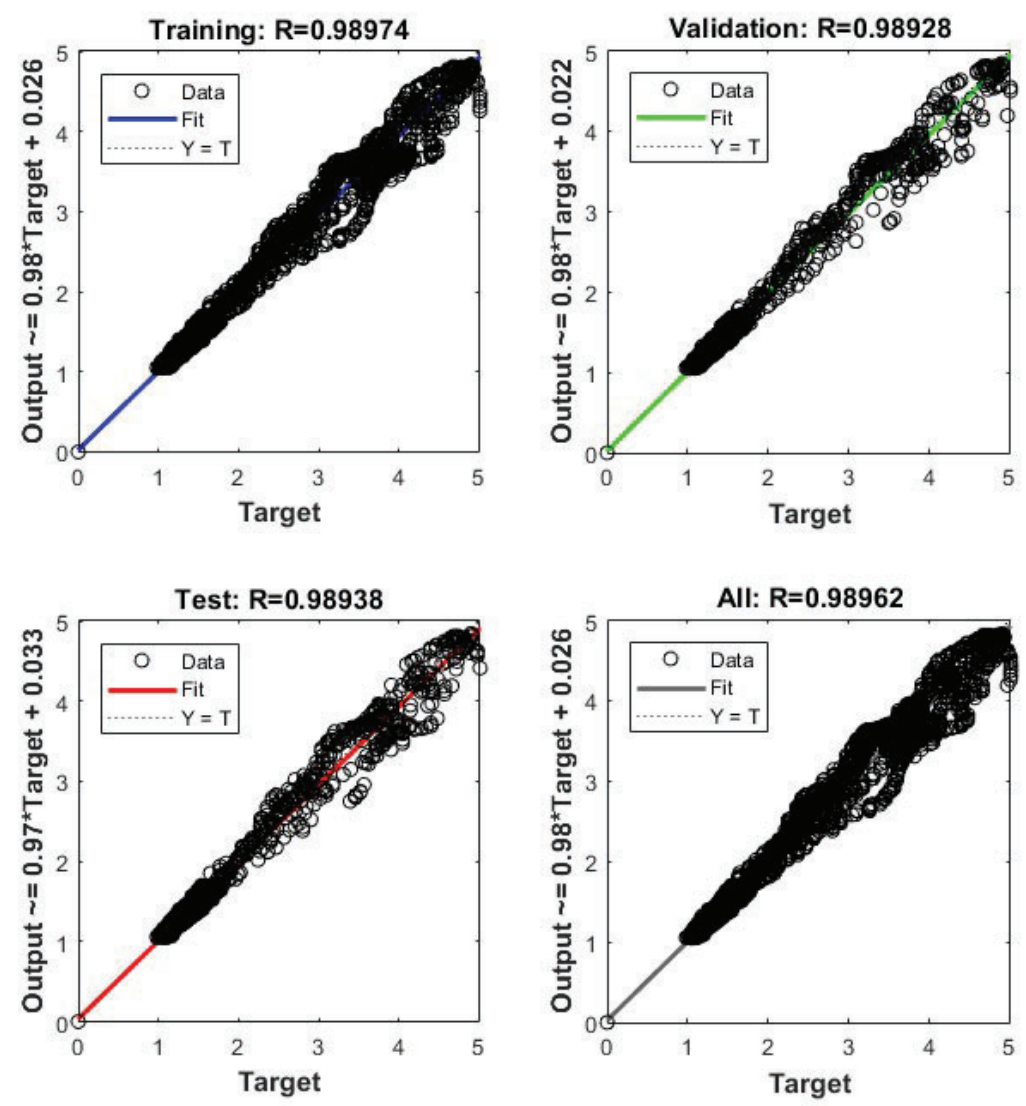

Figure 3.9: Performance R-values for trained compressor neural network 


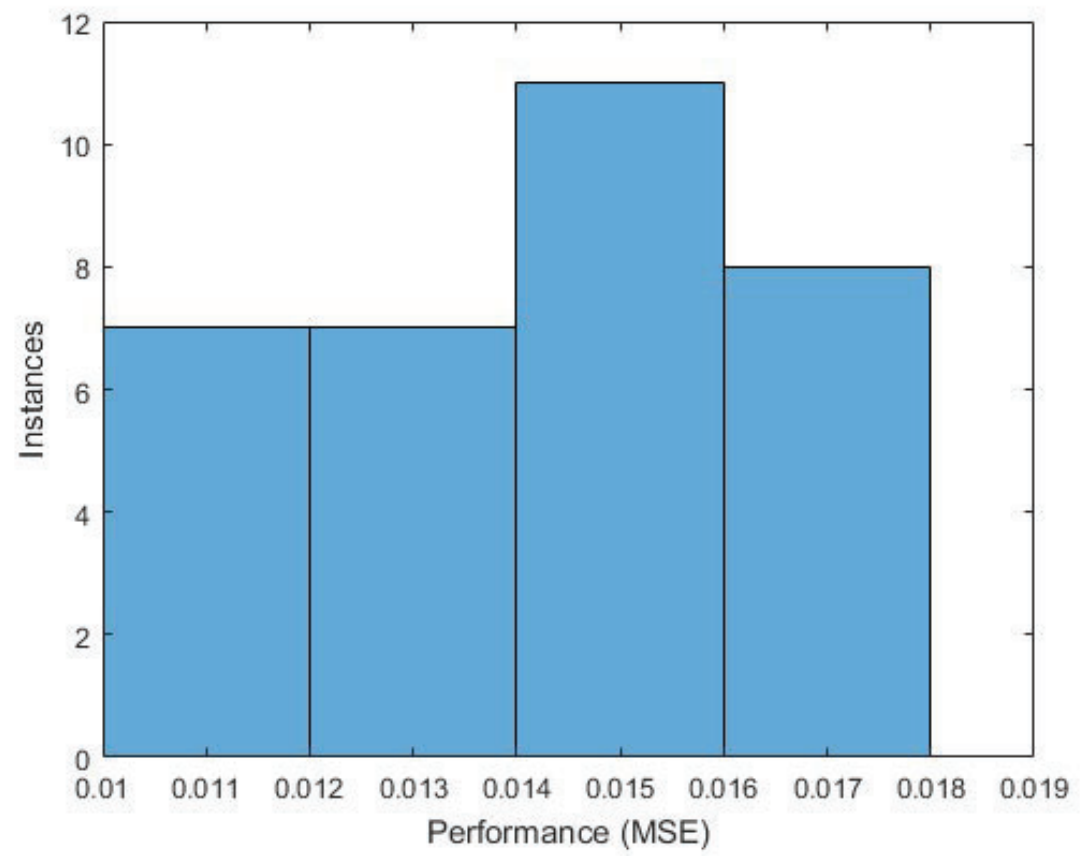

Figure 3.10: Cross-validation test results for trained neural network 



\section{Chapter 4}

\section{Model Validation}

\subsection{Characterization of Cabin Thermal Dynamics}

The thermal masses of the 3 nodes defined by the cabin thermal model were characterized using the test setup described in Chapter 2 Section 2.5. The electric heater is turned on for $1 \mathrm{hr}$. to allow heat-up of the cabin followed by $1 \mathrm{hr}$. cool-down period with the heater turned off. The temperature measurement from the thermocouple sensors in the vehicle cabin was used for parameter estimation by minimizing mean square errors between the measured data and simulated data from the cabin thermal model. The Table 4.1 shows the values of the thermal masses for each node which 
minimizes the errors. Figure 4.1 shows the comparison between measured and simulated temperature modeled by the cabin thermal model for the calculated thermal mass parameters.

Table 4.1

Cabin Thermal Masses

\begin{tabular}{ll}
\hline \multicolumn{1}{c}{ Parameters } & Values \\
\hline Cabin Interior Air & $12 \mathrm{~kg}$ \\
Cabin Shell (Wall) & $280 \mathrm{~kg}$ \\
Cabin Interior Mass & $20 \mathrm{~kg}$ \\
\hline
\end{tabular}

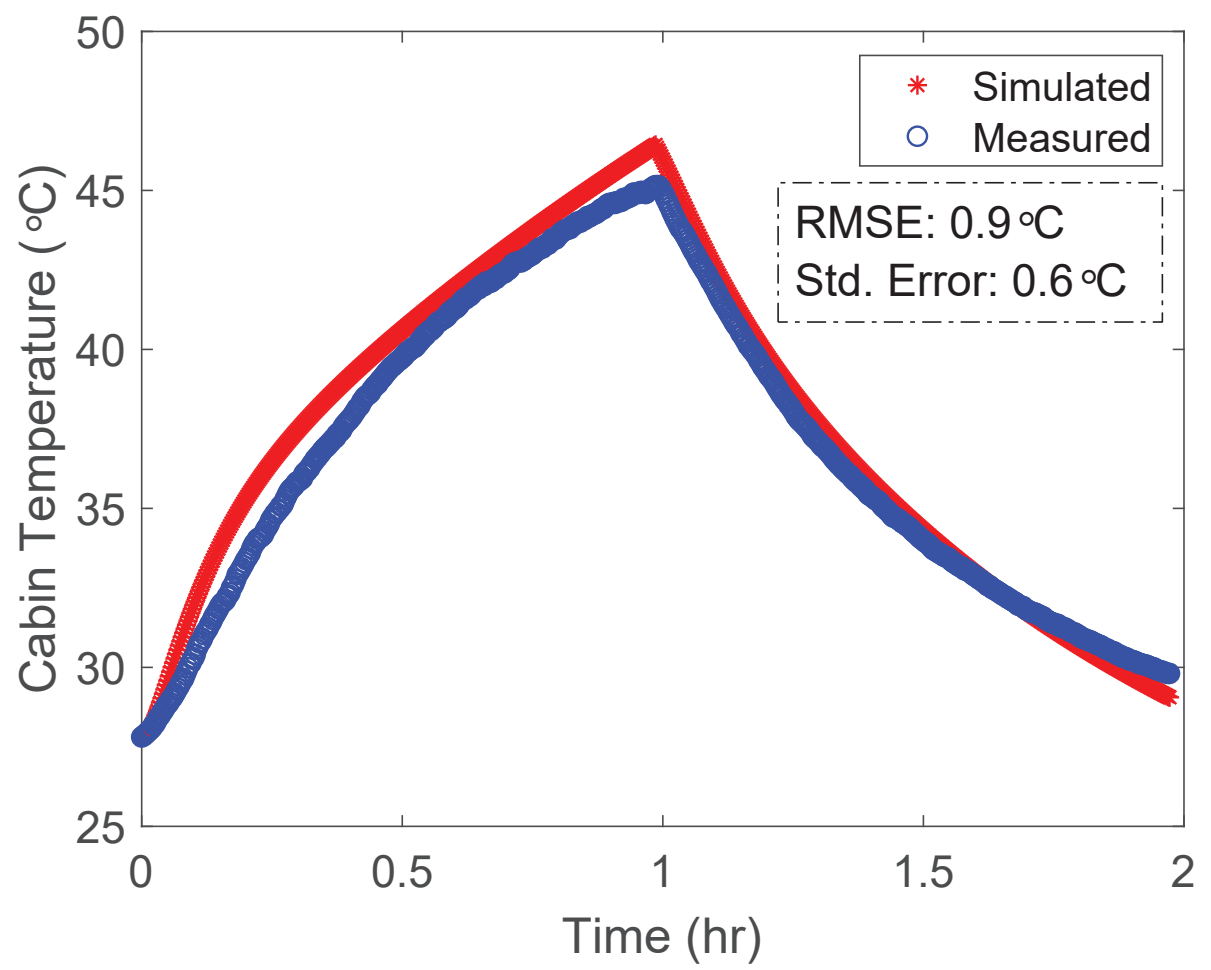

Figure 4.1: Results of cabin thermal mass characterization test

It is important to note that the thermal masses are not representative of the physical masses or volumes, rather they are indicative of the magnitudes of thermal energy 
possessed or transferred by the respective nodes.

\subsection{Cabin Blower Characterization}

The air volume flow rate into the test vehicle cabin is characterized using the test setup described in Chapter 2 Section 2.4. The test vehicle blower fan is turned on at varying fan speed settings. The pressure differential at each setting is measured at the oil manometer setup and then used to calculate the volume flow rate of air entering the cabin using an iterative solver scheme adopted from [38]. Figure 4.2 shows experimental results for different cabin air vent positions i.e. forward only or defrost, and engine status. 


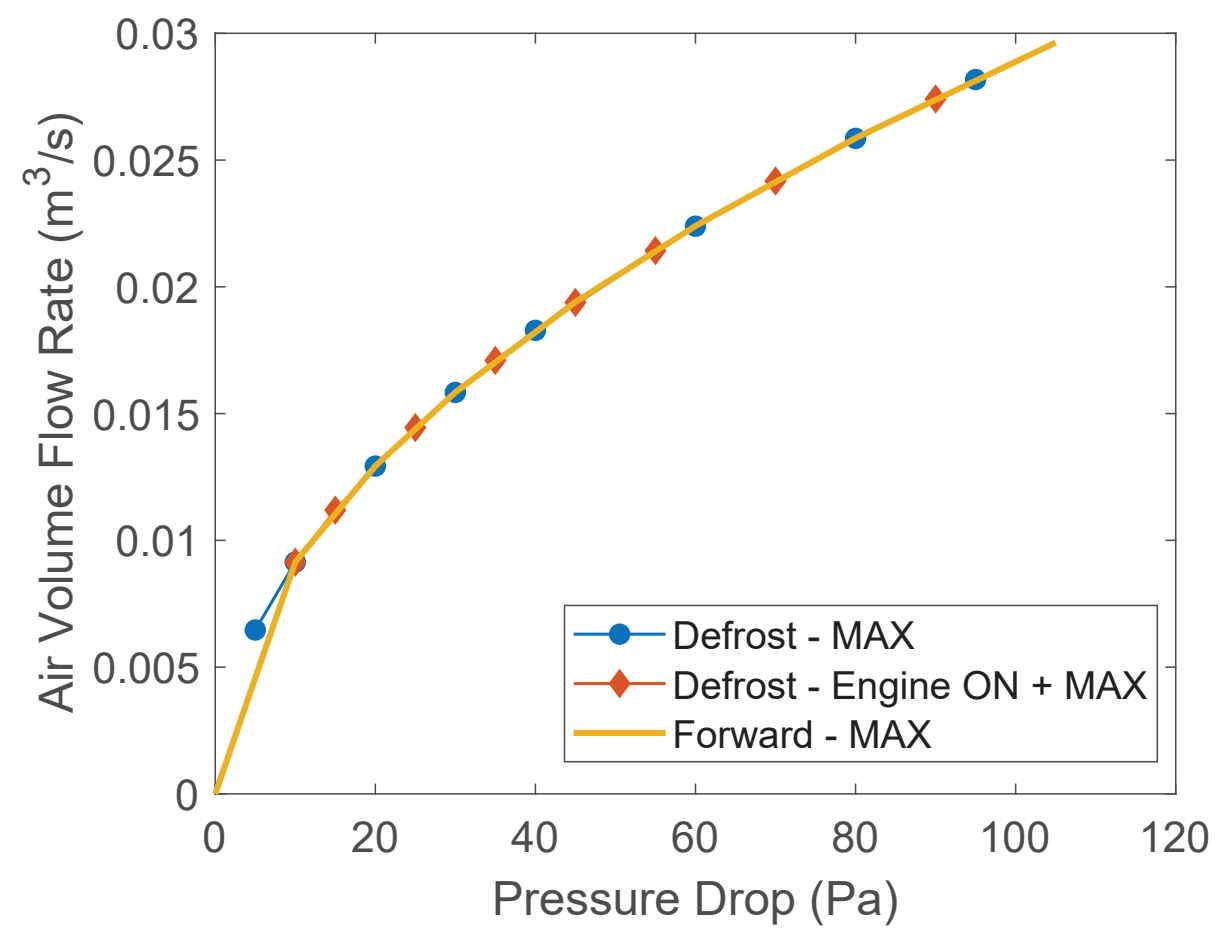

Figure 4.2: Results of cabin blower characterization test

\subsection{Cabin Temperature}

The thermocouple sensors instrumented inside the vehicle cabin were used to examine the temperature distribution inside the test vehicle cabin. Figure 4.3 shows the distribution of temperature during a $2 \mathrm{hr}$. test consisting of $1 \mathrm{hr}$. each periods of heat-up and cool-down. The temperature measured by the instrument panel sensor is used for vehicle HVAC control and hence denoted as the measured uniform cabin air temperature in future model validation results.

After incorporating the cabin thermal masses and cabin blower fan characteristics 


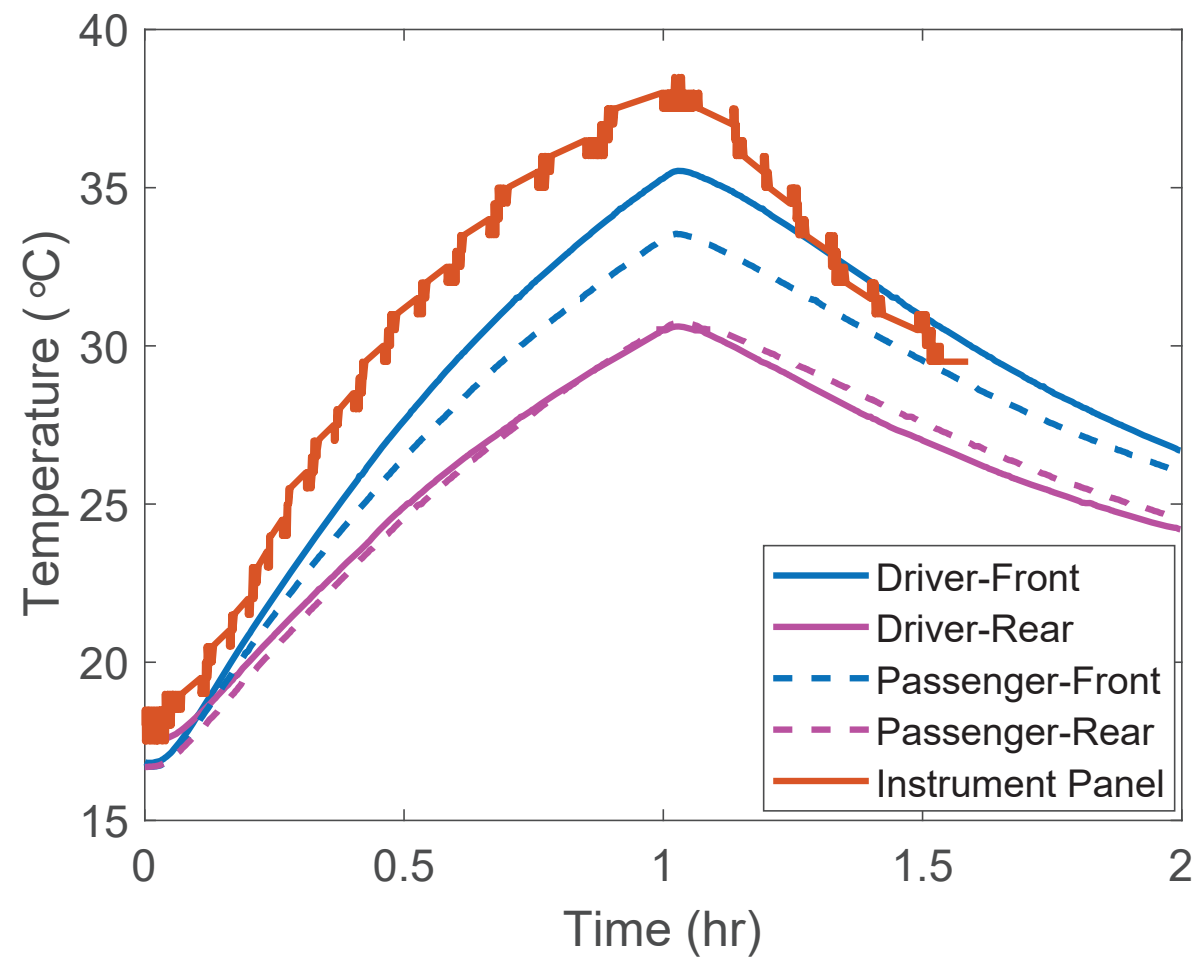

Figure 4.3: Temperature distribution inside test vehicle cabin

into the cabin thermal model, the cabin air temperature is validated against test data provided by ANL as well as data from tests conducted at APSRC Labs. Figures 4.4(a) and 4.4(b) show validation results for a cabin heat-up and cool-down test respectively conducted at APSRC Labs. 


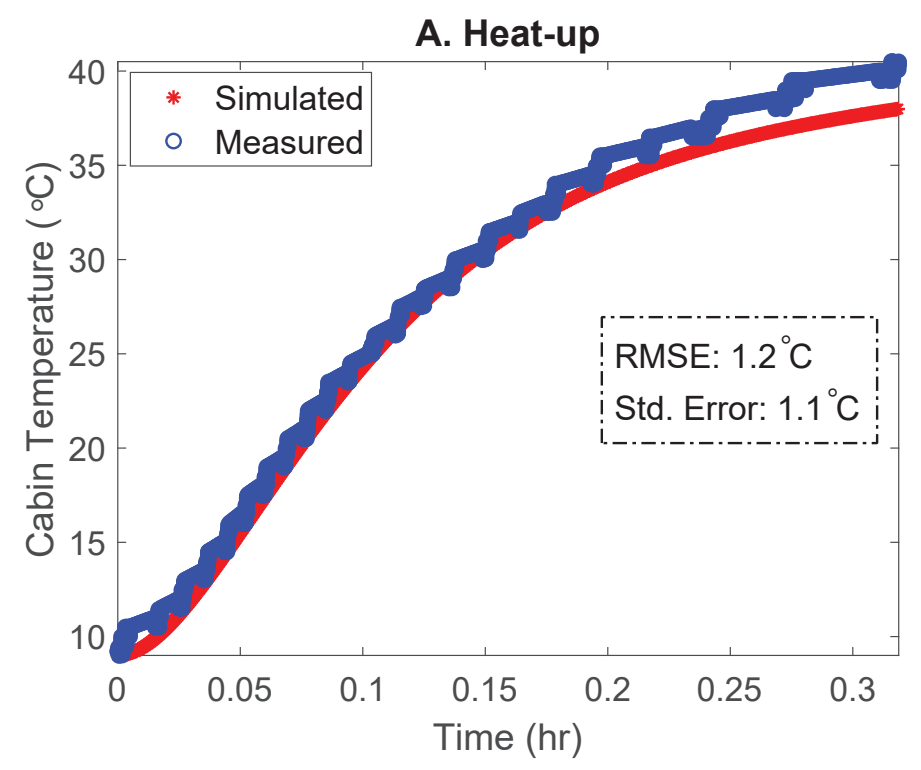

(a) Cabin heating validation

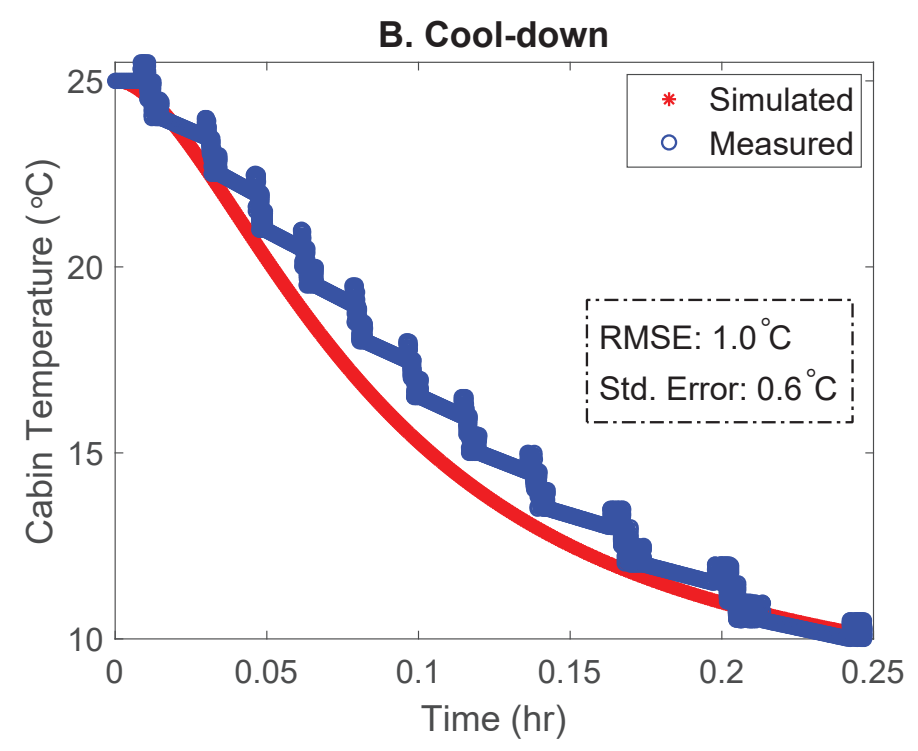

(b) Cabin cooling validation

Figure 4.4: Validation of cabin temperature during heating and cooling

Additionally, the solar irradiation model described in Chapter 3 Section 3.2 is independently validated using the test setup described in Chapter 2 Section 2.3. The test vehicle is stationed at $\mathrm{KRC}$ near the pyranometer setup with doors and windows shut 
and vehicle turned off. The thermocouple sensors inside the vehicle cabin measure the cabin air temperature during the $24 \mathrm{hr}$. test period. The test was conducted on a clear, sunny day with ambient conditions ranging from $8^{\circ} \mathrm{C}$ to $22^{\circ} \mathrm{C}$ during the test period. Figure 4.5 shows the model validation results for the solar irradiation loads in the cabin thermal model.

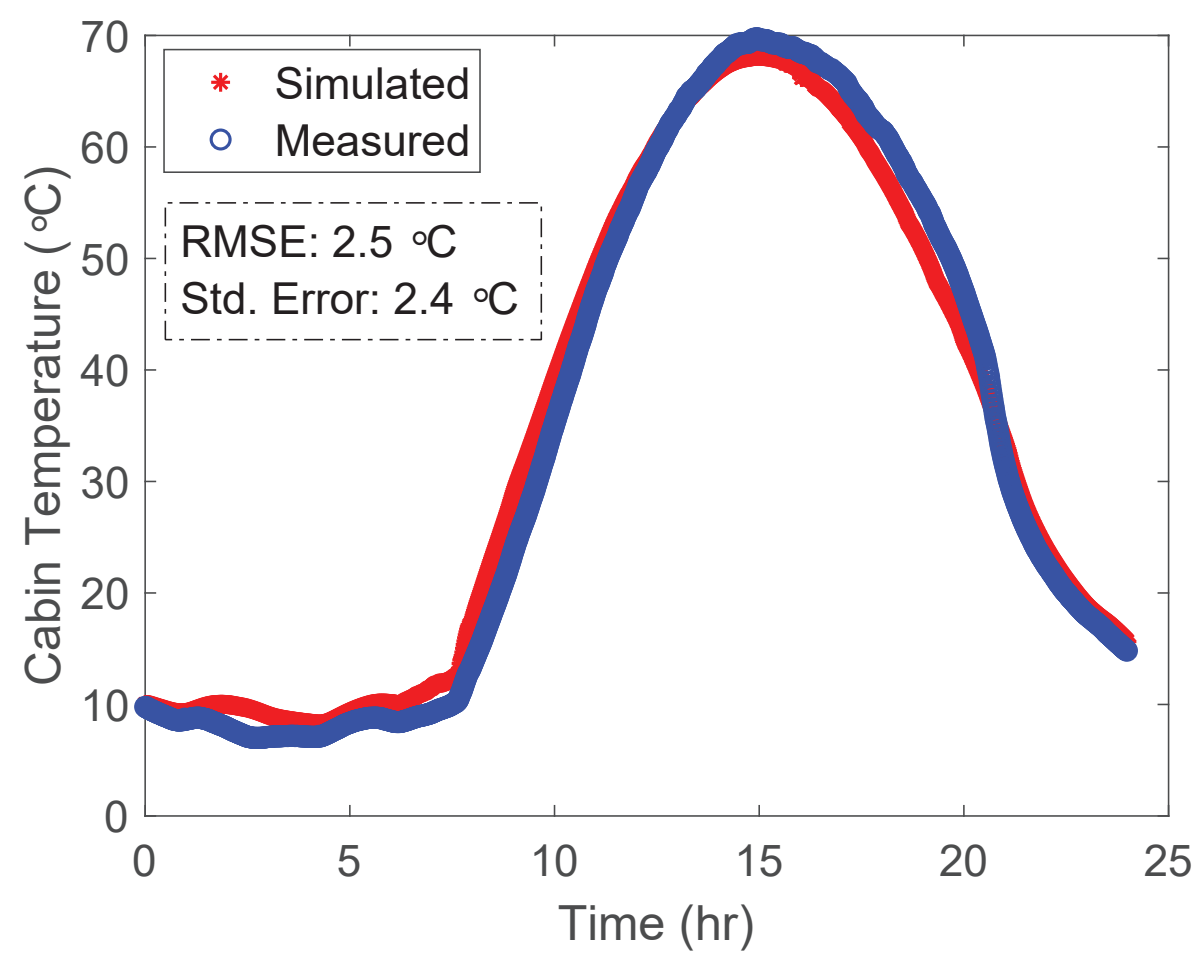

Figure 4.5: Validation of solar irradiation model during a 24hr. test

\subsection{Coolant Temperature}

In order to model the effect of vehicle speed on rate of thermal energy lost by engine coolant, described in Chapter 3 Section 3.3, engine coolant temperature data from 
vehicle CAN bus is recorded along with vehicle speed, ambient temperature, fuel flow rate and engine speed for several tests. To isolate the effect of vehicle speed on coolant temperature, tests at varying cruising speeds were conducted in the $\mathrm{CD}$ mode of operation to avoid engine turning on and consequently heating up the coolant.

Figures 4.6 and 4.7 show two instances of these cruising speed tests for characterizing effect of vehicle speed on coolant temperature.

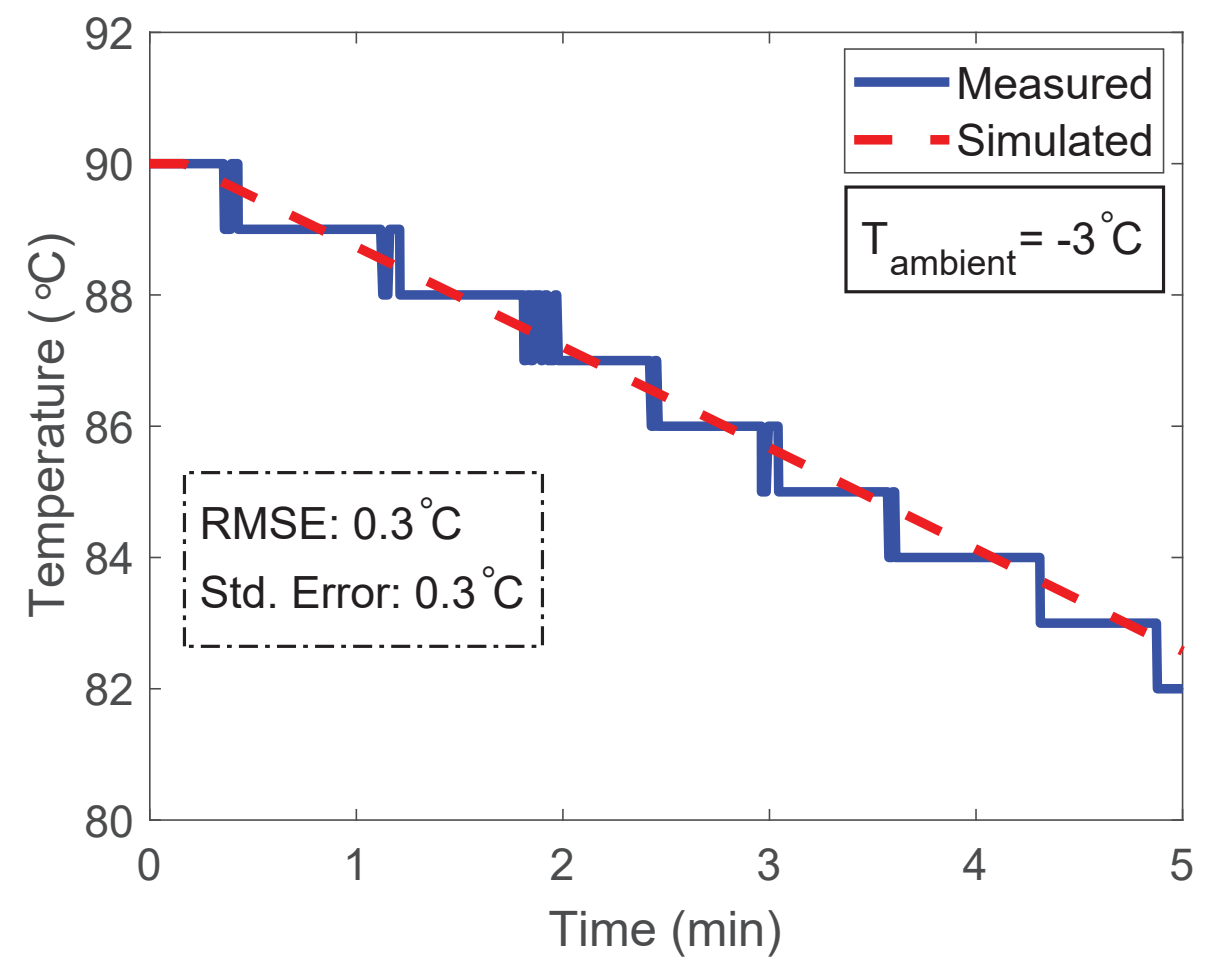

Figure 4.6: Effect of vehicle speed on coolant temperature at 20mph cruising speed 


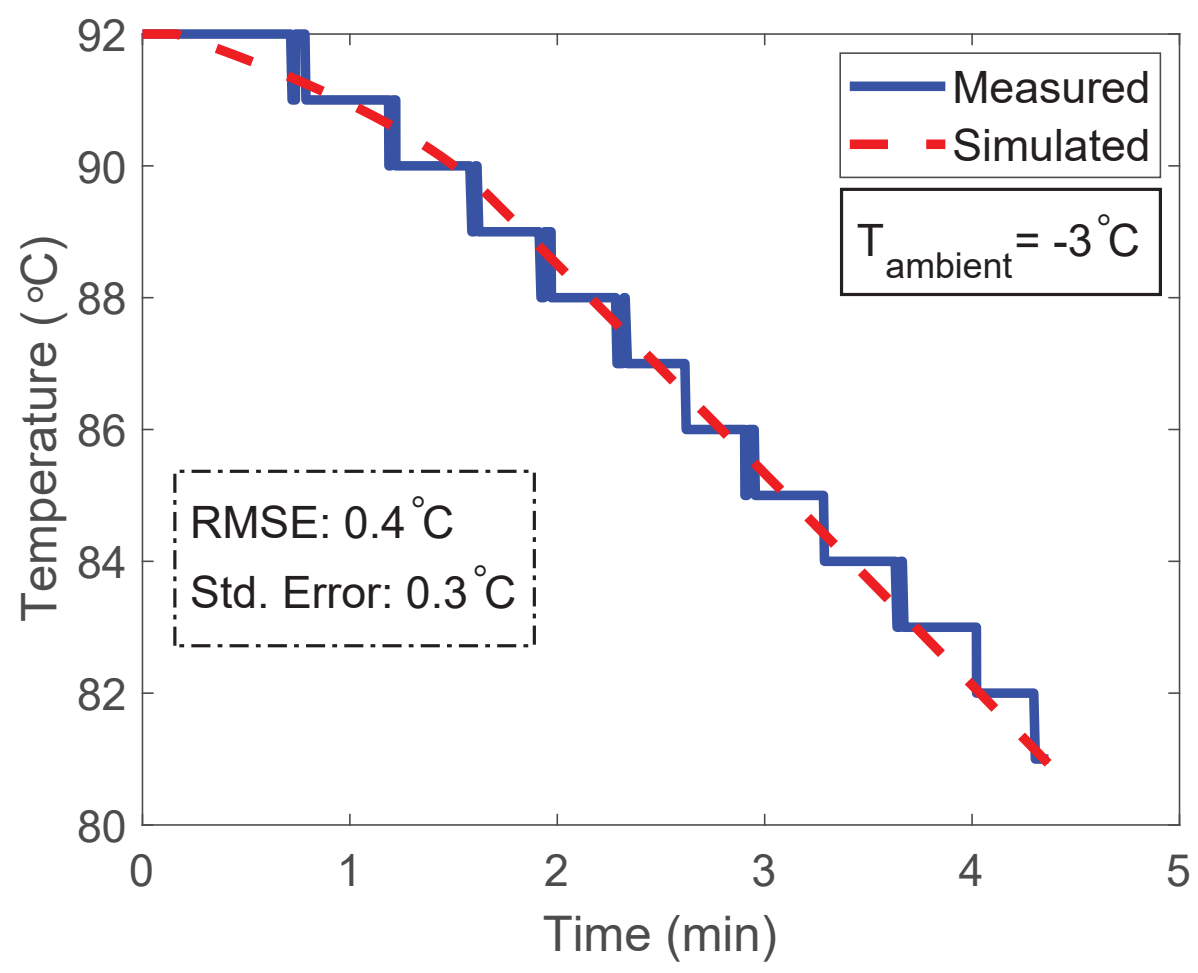

Figure 4.7: Effect of vehicle speed on coolant temperature at 55mph cruising speed

Other tests were conducted to incorporate effects of blower fan speeds and electric heater operation on rate of coolant temperature cool-down. Additionally, the effect of engine fuel flow rate on coolant heating was incorporated to develop the overall coolant temperature model. Figure 4.8 shows the validation results for the overall coolant temperature model against measured data from tests conducted at APSRC Labs. 


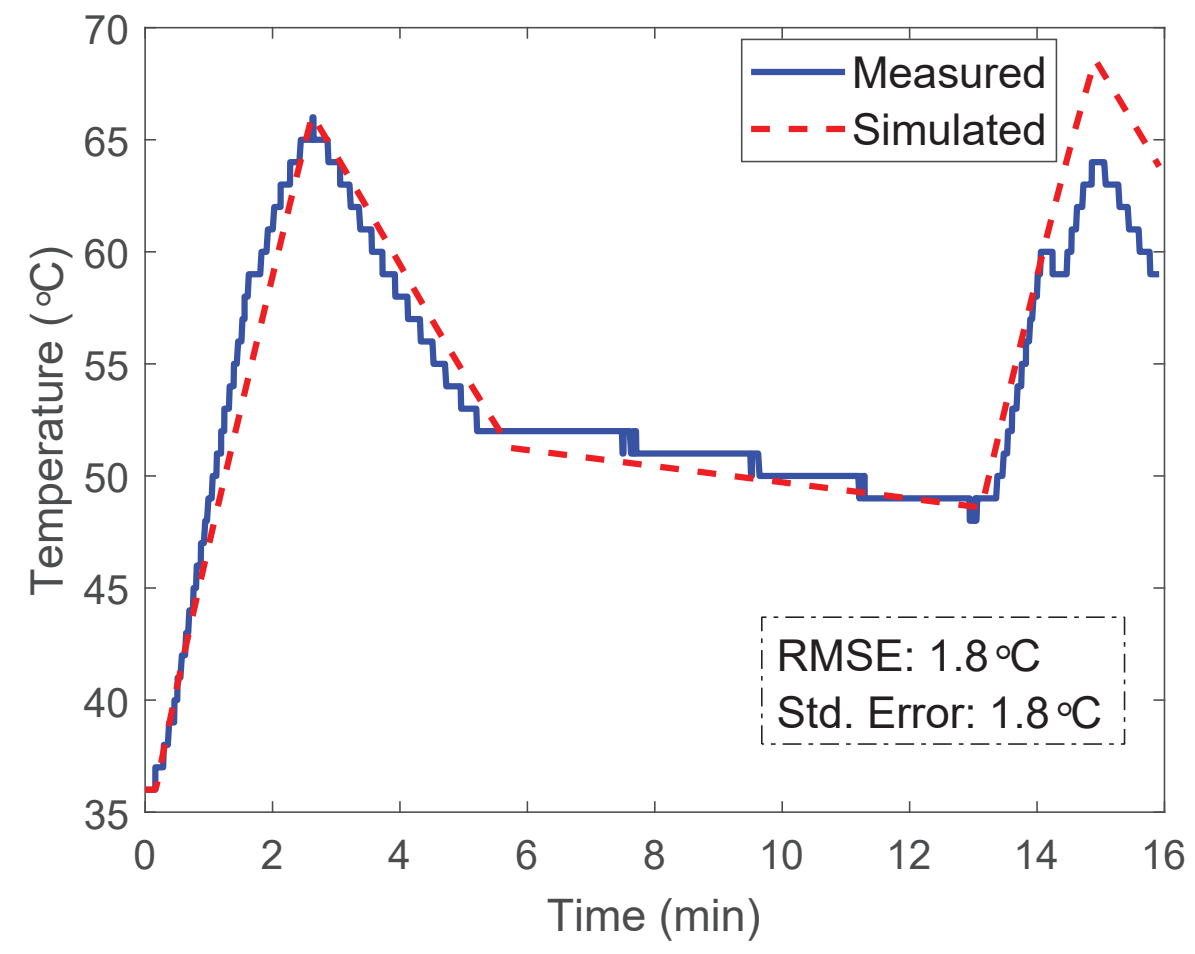

Figure 4.8: Validation of coolant temperature model at $T_{\text {ambient }}=-4^{\circ} \mathrm{C}$

\subsection{Catalyst Temperature}

The catalyst temperature model developed in Chapter 3 Section 3.7 is validated for both heat-up and cool-down test scenarios. As explained earlier, the cool-down characteristics of catalyst temperature are only modeled as functions of ambient temperature and vehicle speed. The nature of cool-down curve of catalyst temperature in available test data increased confidence in our assumption. Figure 4.9 shows two validation results at different ambient temperatures and vehicle speeds. The heat-up characteristics of catalyst temperature, on the other hand, are modeled in two stages 
with comparatively complex functions. Figure 4.10 shows two validation results for catalyst temperature during heat-up. The light-off temperature is assumed to be $300^{\circ} \mathrm{C}$ for the purposes of this work.

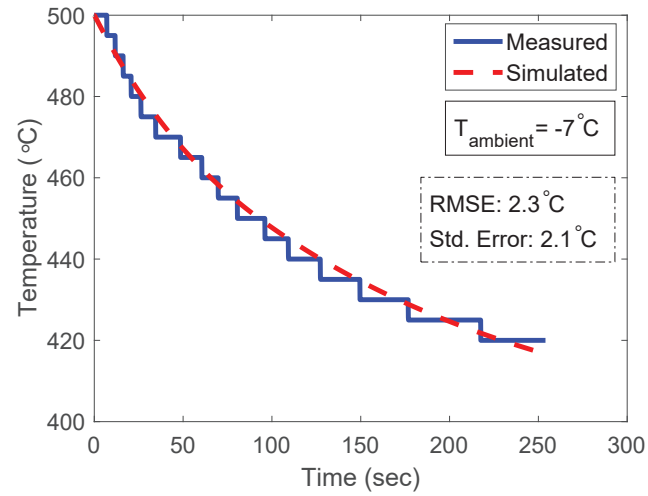

(a) Validation at $T_{\text {ambient }}=-7^{\circ} \mathrm{C}$

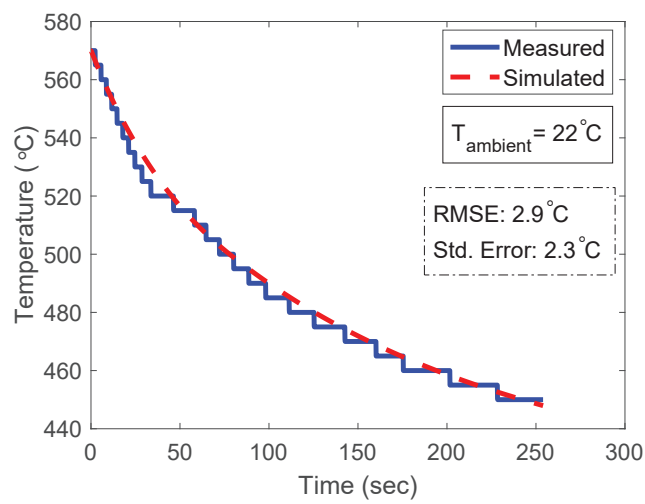

(b) Validation at $T_{\text {ambient }}=22^{\circ} \mathrm{C}$

Figure 4.9: Validation of catalyst temperature during cool-down in 2 different operating conditions

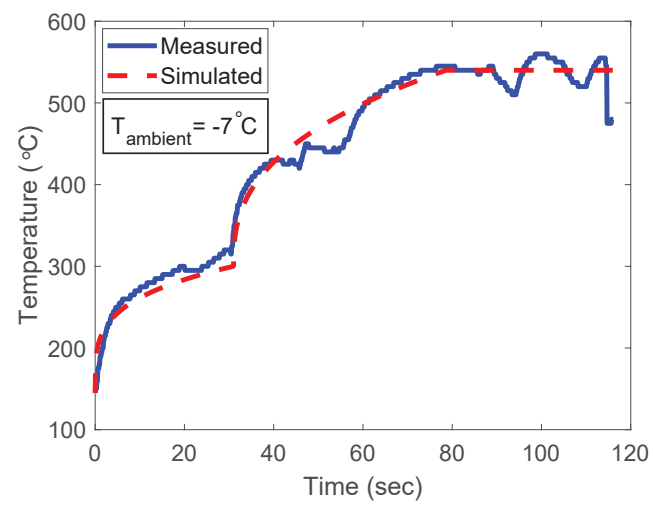

(a) Validation at $T_{\text {ambient }}=-7^{\circ} \mathrm{C}$

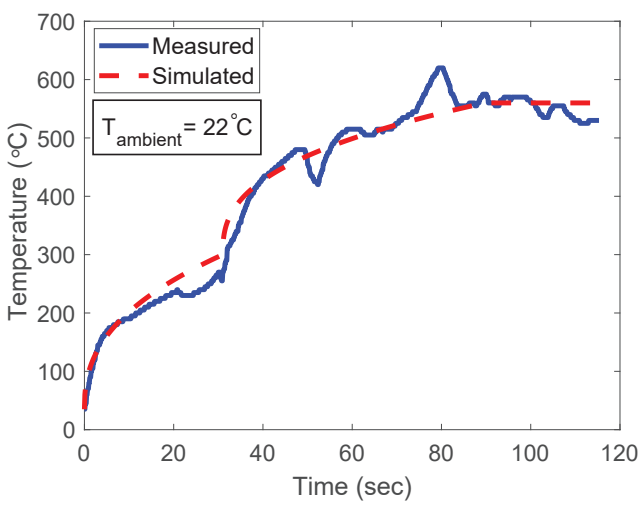

(b) Validation at $T_{\text {ambient }}=22^{\circ} \mathrm{C}$

Figure 4.10: Validation of catalyst temperature during heat-up in 2 different operating conditions 


\subsection{Cabin Electric Heater Energy}

The control logic extracted for the cabin electric heater operation in Chapter 3 Section 3.4 is used to predict heater energy consumption. Test data for electric heater power consumption is available on vehicle CAN bus and recorded according to Chapter 2 Sections 2.6 and 2.7. Figure 4.11 shows validation results for cabin electric heater's cumulative energy consumption. Although the instantaneous behavior of electric heater power consumption is difficult to capture, the model is capable of predicting cumulative energy consumption within $5 \%$.

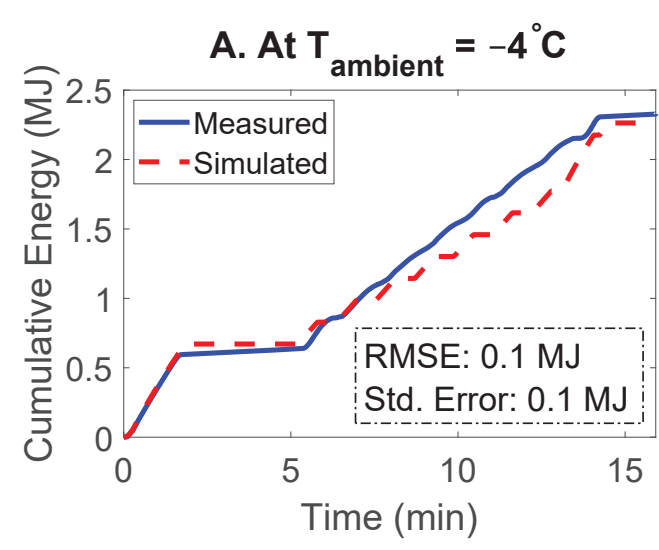

(a) Validation at $T_{\text {ambient }}=-4^{\circ} \mathrm{C}$

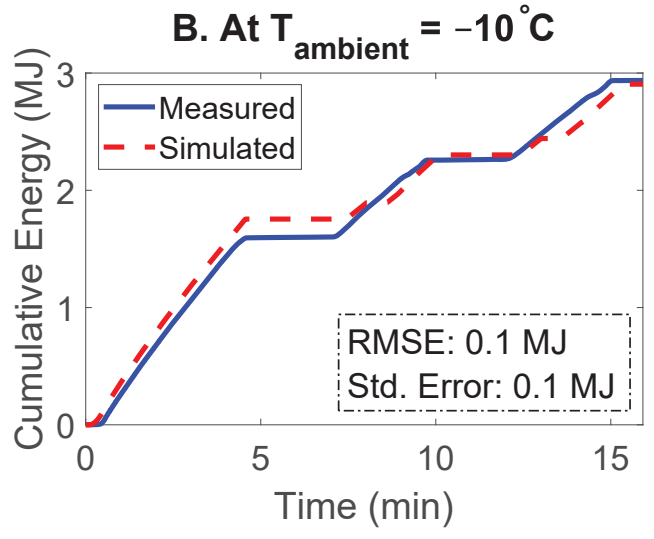

(b) Validation at $T_{\text {ambient }}=-10^{\circ} \mathrm{C}$

Figure 4.11: Validation of cabin electric heater energy consumption 


\subsection{A/C Compressor Energy}

The electric compressor energy consumption is modeled using an artificial neural network described in Chapter 3 Section 3.8. The neural network was trained on $70 \%$ of the data available from the ANL datasets, while $15 \%$ each was used for validation and testing. The validation results for compressor power consumption are shown in Figure 4.12 .

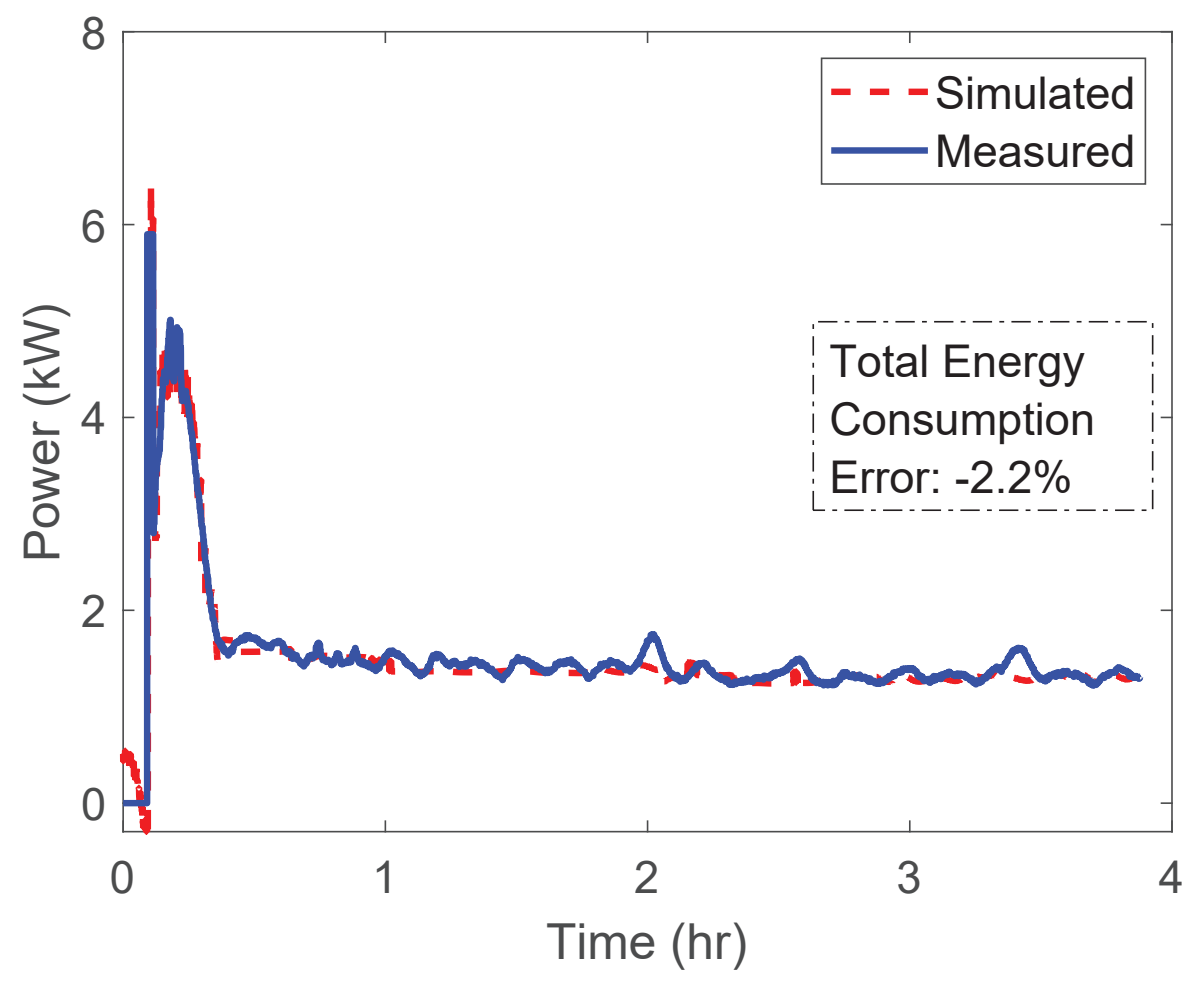

Figure 4.12: Validation of electric compressor energy consumption 



\section{Chapter 5}

\section{Vehicle Energy Consumption}

\section{Reduction Strategies}

\subsection{Integrated HVAC - Powertrain Operation}

The thermal coupling between the cabin electric heater and engine coolant, explained in Chapter 3 Section 3.1.1, in the form of engine assisted heating can be leveraged in a connected vehicle scenario for optimal cabin thermal management. The goal of minimizing impact of cabin heating on usable electric range dictates optimally supplying thermal energy to the coolant via engine and electric heater. A modelbased optimization tool can be developed to enable calibration of operating points of 
this integrated HVAC - Powertrain operation.

In connected vehicles, trip duration can be estimated using driver schedule, traffic information, signal phasing and timing data and information available from other connected vehicles. To illustrate the concept behind optimization of integrated HVAC - Powertrain operation for cabin heating purposes, a sample simulation is illustrated in Figure 5.1. The test conditions indicate cold ambient conditions with fully charged battery leading to CD mode of operation of the test vehicle. The engine coolant temperature dependence on cabin heating operation during the CD mode in cold ambient conditions, seen earlier in Chapter 3 Section 3.4, helps us identify three configurable parameters, $P_{1}, P_{2}$ and $P_{3}$, shown in Figure 5.1. In this case, consider the following concept to help reduce vehicle energy consumption: If the engine and cabin electric heater are operated in a manner that the engine coolant temperature is just above $P_{3}$ at the end of the trip, then engine restart can be avoided for this particular trip duration, as alluded to in Chapter 3 Section 3.4. This allows for reduced energy consumption by eliminating an engine on event with the help of information available in a connected vehicle framework. Note that earlier, in Chapter 1 Section 1.4, it was reported that in the test vehicle the engine operates to meet cabin thermal conditioning requirements.

Figure 5.2 shows the test vehicle during a testing day at APSRC Labs in cold ambient conditions which helped us characterize the baseline cabin heating operation 


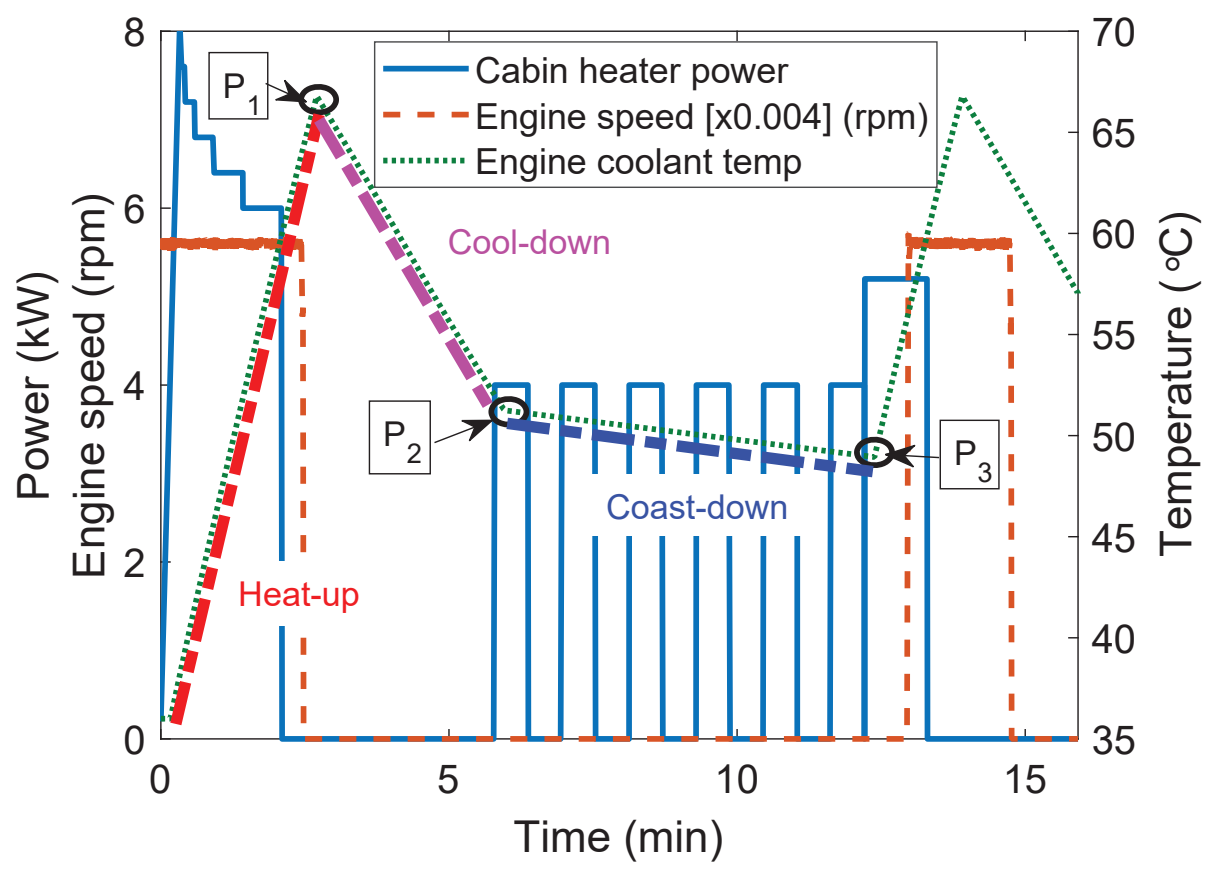

Figure 5.1: Sample simulation example to illustrate integrated HVAC - Powertrain operation for cabin heating

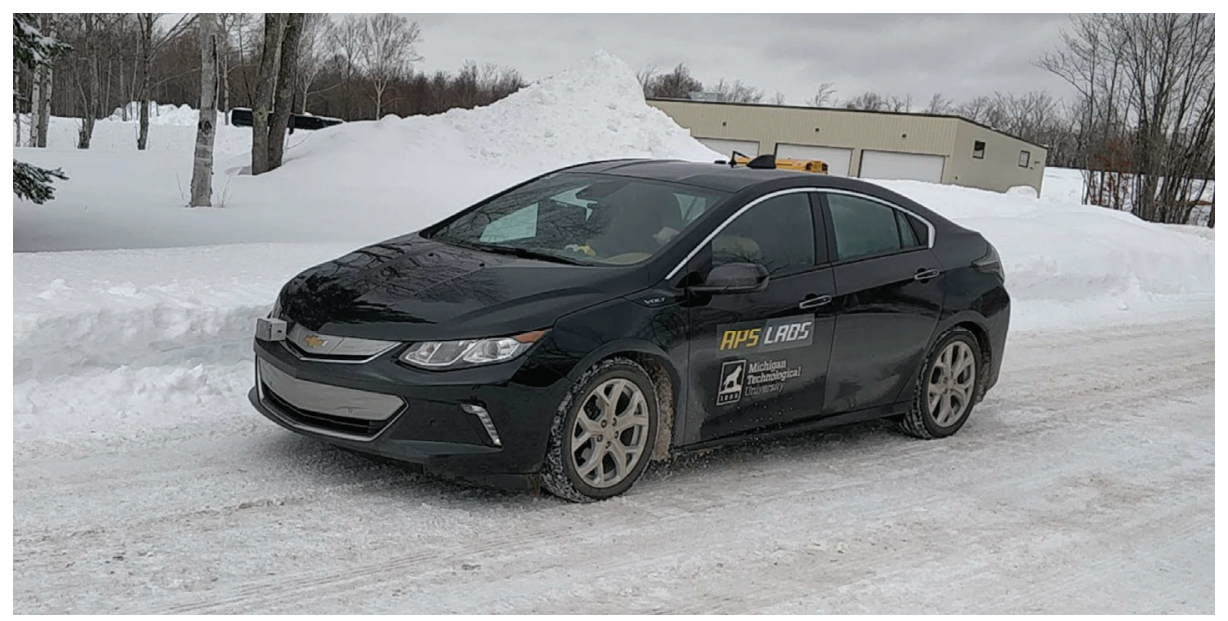

Figure 5.2: Sample test data collection at APSRC Labs to illustrate baseline cabin heating operation in cold ambient conditions

illustrated in Figure 5.1. In Figure 5.1, $P_{1}$ is the upper threshold of engine coolant temperature in CD mode of operation, where the engine turns off after the initial 
"heat-up" stage. Between $P_{1}$ and $P_{2}$, during the "cool-down" stage, thermal energy gained by the engine coolant during the "heat-up" stage is used alone for cabin heating. $P_{2}$ is the point where cabin electric heater turns on intermittently, at reduced power level leading to the "coast-down" stage. This represents the electric heater supplementing engine coolant heat for cabin heating and it continues until $P_{3}$, which is the lower threshold of engine coolant temperature. At this point the engine turns on and begins the "heat-up" stage once again. Table 5.1 shows the 3 configurable parameters for the test vehicle with their baseline values.

Table 5.1

Engine Coolant Temperature Parameters for Cabin Heating

\begin{tabular}{|c|c|c|}
\hline Parameters & Description & Values \\
\hline$P_{1}$ & Upper Threshold (Engine turns OFF) & $65^{\circ} \mathrm{C}$ \\
$P_{2}$ & Electric heater supplementing engine coolant & $52^{\circ} \mathrm{C}$ \\
$P_{3}$ & Lower Threshold (Engine turns ON) & $49^{\circ} \mathrm{C}$ \\
\hline
\end{tabular}

\subsubsection{Case Study}

The optimization problem is defined for the custom MTUDC: 45 min trip with 91\% initial battery state-of-charge and $\mathrm{CD}$ mode of operation in $-10^{\circ} \mathrm{C}$ ambient conditions, cold-start with cabin set-point of $22^{\circ} \mathrm{C}\left(72^{\circ} \mathrm{F}\right)$. With 10 equally-spaced points for each parameter, $P_{1}, P_{2}$ and $P_{3}$, an optimization domain comprising of $1 \mathrm{e} 3$ combinations of calibration parameters is generated. The 3-way trajectory optimization 
works with the integrated HVAC - VD\&PT model developed for the purposes of this work to estimate total vehicle energy consumption in the optimization domain. The thermal comfort constraints, defined by the ASHRAE Standard 55 [45], determine the feasibility of the solutions obtained by the trajectory optimization. The Standard states passenger comfort as cabin temperature approximately between $67^{\circ} \mathrm{F}\left(19^{\circ} \mathrm{C}\right)$ and $82^{\circ} \mathrm{F}\left(27^{\circ} \mathrm{C}\right)$. Hence the model-based optimization tool, illustrated in Figure 5.3, enables co-optimization of the vehicle HVAC and powertrain systems by meeting the goals of minimizing total vehicle energy consumption whilst maintaining passenger comfort inside the cabin. 


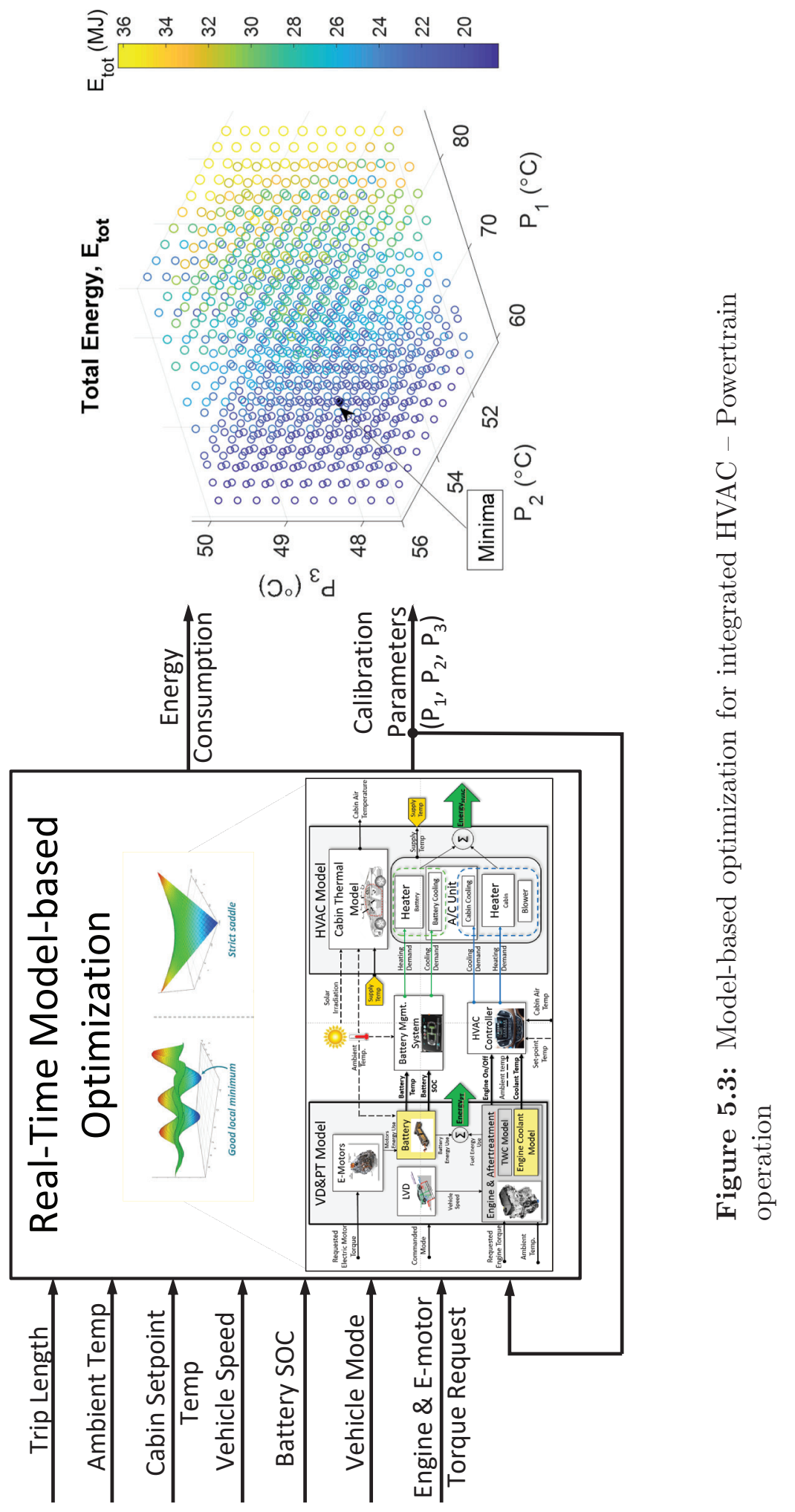


The various inputs, shown in Figure 5.3, including trip duration available in the connected hybrid electric test vehicle are used by the integrated HVAC - VD\&PT model to generate the total vehicle energy consumption in the optimization domain shown in Figure 5.3. The minima corresponds to the combination of the calibration parameters which gives minimum total vehicle energy. As described earlier, the constraint imposed by thermal comfort is implemented to determine the optimal combination of calibration parameters. Figure 5.4 shows that cabin temperature evolution for the optimal solution is within the ASHRAE Standard temperature limits. The baseline case corresponds to the test vehicle operation in the absence of the model-based optimization tool. Figure 5.5 shows a comparison of cabin electric heater power and engine coolant temperature between baseline and optimal operation. 


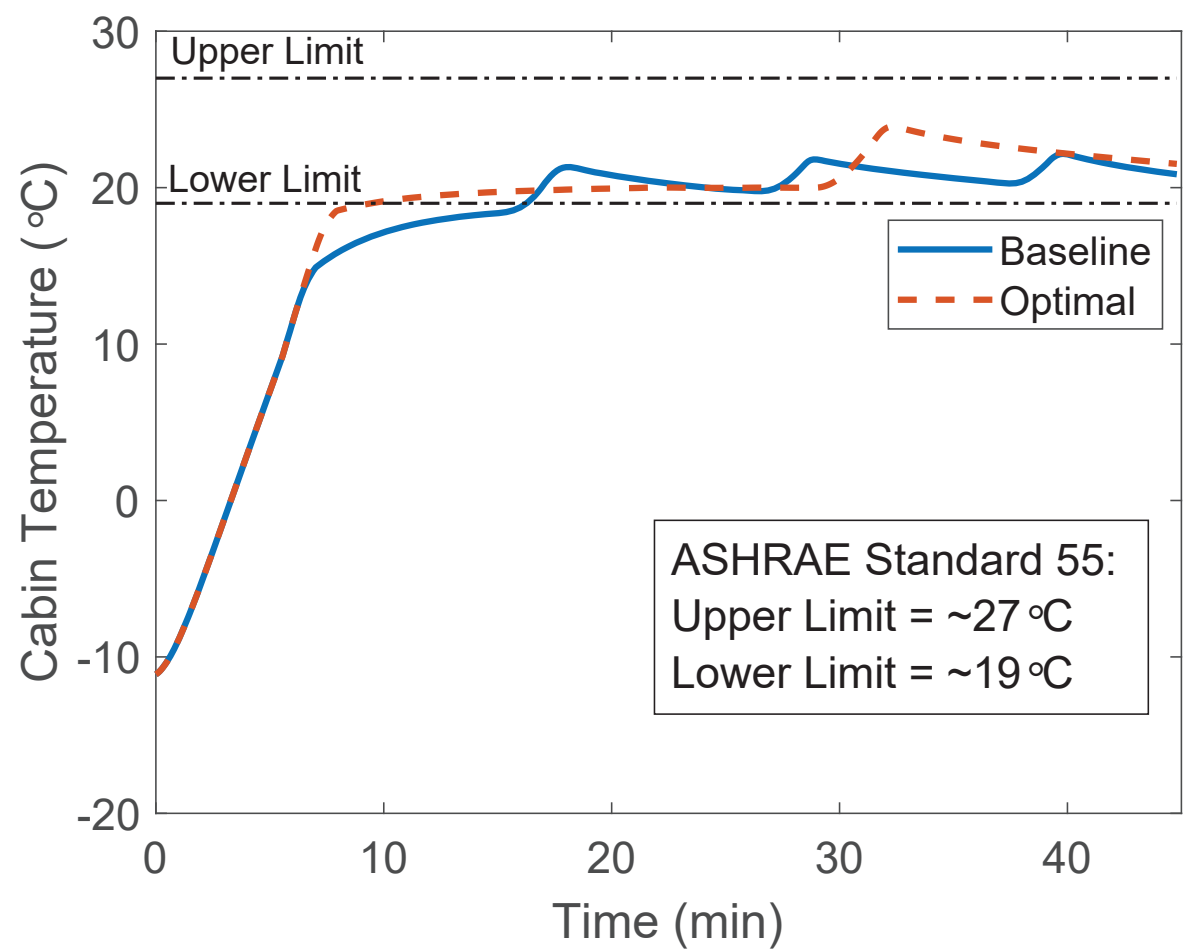

Figure 5.4: Comparison of cabin air temperature between baseline and integrated HVAC - Powertrain operation

We observe that the optimization tool reduces number of engine on events from four to one by allowing initial engine on period to be longer and subsequently heating engine coolant to a higher temperature. We also note that in baseline test vehicle, engine coolant temperature is high at the end of the trip, indicating thermal energy waste for cabin heating. In contrast, the optimal solution operates cabin electric heater at the optimal time in the trip and for an optimal duration to compensate for the heating requirement of the vehicle cabin. In this manner, the optimization tool is able to minimize energy consumption for cabin heating while maintaining cabin temperature within ASHRAE bounds. Table 5.2 shows an energy consumption summary for both baseline and optimal calibration solution. We observe that the electric heater energy 


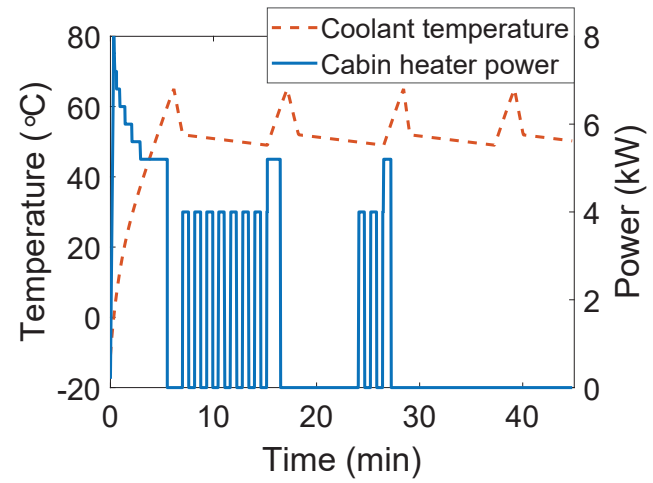

(a) Baseline operation

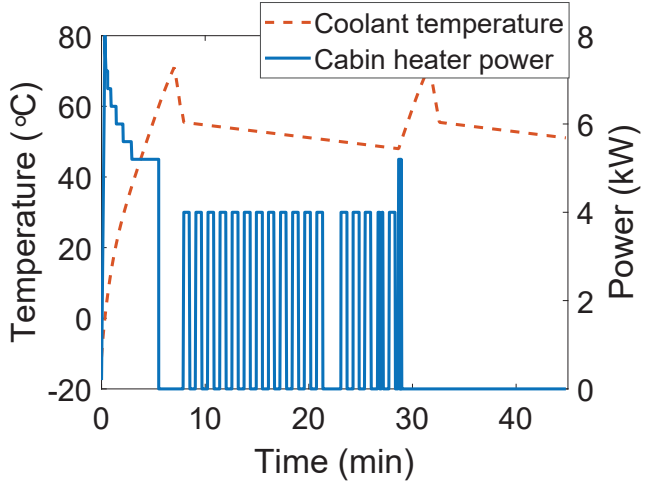

(b) Optimal operation

Figure 5.5: Comparison of cabin heating operation between baseline and optimal solution

consumption is higher in the optimal solution than in baseline case but the optimal solution reduces total HVAC energy consumption by $14 \%$ compared to the baseline test vehicle operation.

Table 5.2

Energy Consumption Summary

\begin{tabular}{|c|c|c|c|c|}
\hline Case & $\begin{array}{c}\text { Heater } \\
\text { Energy[MJ] }\end{array}$ & $\begin{array}{c}\text { Fuel } \\
\text { Energy[MJ] }\end{array}$ & $\begin{array}{c}\text { HVAC } \\
\text { Energy[MJ] }\end{array}$ & $\begin{array}{c}\Delta \text { HVAC } \\
\text { Energy[\%] }\end{array}$ \\
\hline \hline Baseline & 3.8 & 29.9 & 33.7 & - \\
Optimal & 4.2 & 24.8 & 29 & -14 \\
\hline
\end{tabular}

The HVAC energy consumed by the test vehicle is a portion of the total vehicle energy consumption. As seen in Chapter 1 Section 1.4, for MTUDC test cycle under similar operating conditions as analyzed in this case study, the HVAC energy is $54 \%$ of the total vehicle energy. Hence, we infer that optimal solution producing $14 \%$ energy savings in HVAC energy corresponds to $7.6 \%$ total vehicle energy savings. 


\subsection{Coordinated Thermal Management}

The fuel supplied to the engine to meet engine torque requirements is modeled to incorporate changes in the fuel flow rate due to thermal and emission considerations of the test vehicle. The engine coolant temperature has a lower threshold defined to avoid cold-start conditions which incur a penalty on the fuel flow rate to the engine. Similarly, catalyst temperature has a light-off temperature threshold defined to indicate activation of the catalyst. Turning on the engine when catalyst is below this lower temperature threshold also incurs a penalty to compensate for increased emissions by increasing exhaust temperature. The lower temperature thresholds for cold-start and light-off are set to $49^{\circ} \mathrm{C}$ and $300^{\circ} \mathrm{C}$ respectively for the test vehicle. It has been reported in [5], that the engine fuel penalty for catalyst light-off is 10 times higher than that for engine cold-start. Hence, a coordinated thermal management strategy can be developed for optimal allowance of one or both or no fuel penalties for a known trip duration to minimize overall vehicle energy consumption whilst maintaining cabin comfort levels.

Consider the following example, illustrated in Figure 5.6, in warm ambient condition with warmed-up vehicle, fully charged battery and CD mode of operation. The trip duration, estimated as described before in Section 5.1, is such that vehicle battery charge will be depleted before the end of trip i.e. charge sustaining (CS) mode of 
operation will be required before end of trip. During the trip, as the engine coolant temperature reaches the lower threshold, engine is turned on to allow heating of the coolant and avoid cold-start conditions in the future. Note that the catalyst temperature during this time also changes. Instead of engine cold-start temperature threshold, if catalyst light-off is the primary control parameter for engine status, then number of engine on events for thermal conditioning can be reduced from two to one while incurring one additional cold-start penalty during the CD mode of operation of the trip. However, fuel energy consumption, shown in Table 5.3, illustrates a reduction in energy consumption even with added fuel penalty. Additionally, if the engine status is commanded such that before the start of CS mode, engine coolant is just above its lower temperature threshold, additional energy savings can be achieved due to reduced duration of engine on event.

Table 5.3

Energy Consumption Summary

\begin{tabular}{|c|c|c|c|}
\hline Case & Description & $\begin{array}{c}\text { Fuel } \\
\text { Energy[MJ] }\end{array}$ & $\begin{array}{c}\Delta \text { Fuel } \\
\text { Energy[\%] }\end{array}$ \\
\hline \hline Baseline & $\begin{array}{c}\text { 3 Engine ON } \\
\text { 0 Fuel penalty }\end{array}$ & 13.8 & - \\
\hline Improved & $\begin{array}{c}\text { 2 Engine ON + } \\
\text { 1 Fuel penalty (Cold-start) }\end{array}$ & 12.2 & -1.2 \\
\hline
\end{tabular}




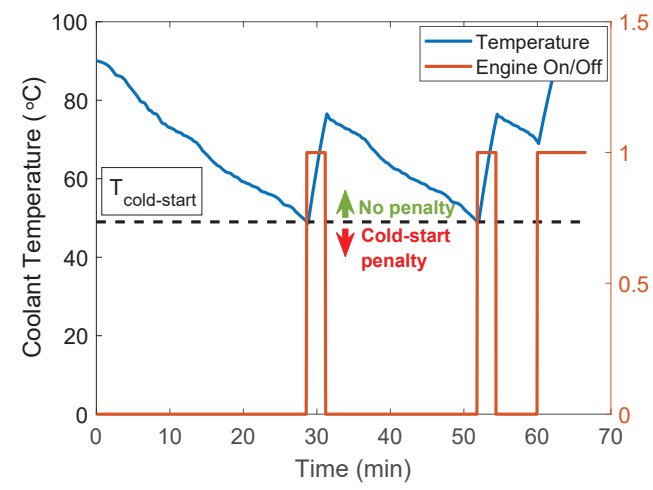

(a) Coolant temperature-Baseline

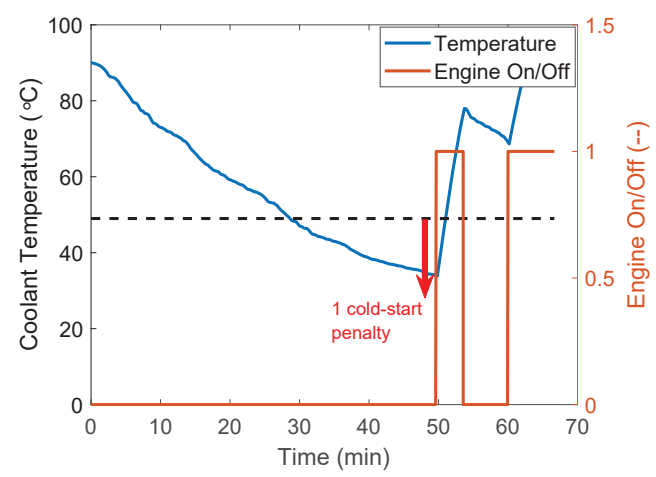

(c) Coolant temperature-Improved

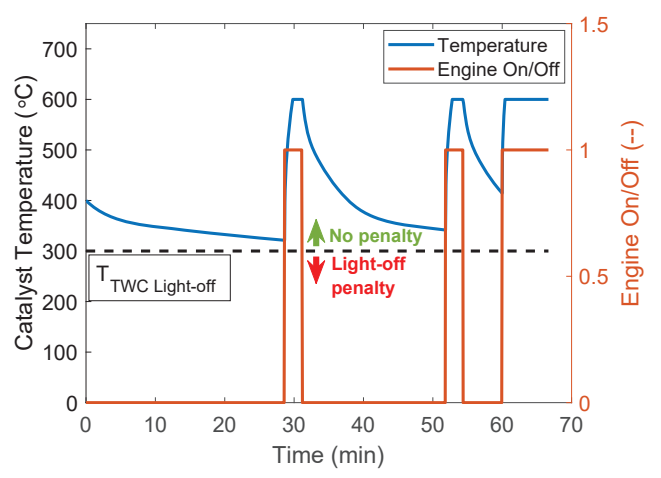

(b) Catalyst temperature-Baseline

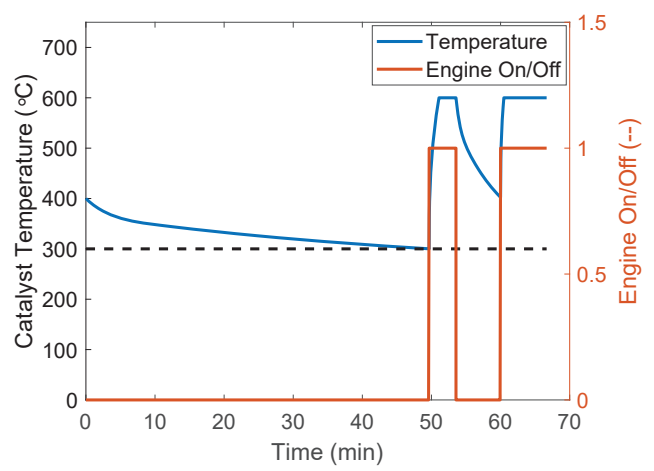

(d) Catalyst temperature-Improved

Figure 5.6: Sample simulation example of coordinated thermal management at $T_{\text {ambient }}=22^{\circ} \mathrm{C}$

\subsubsection{Case Study}

The test conditions are defined for a custom MTUDC: 45 min trip with $91 \%$ initial battery state-of-charge, $-10^{\circ} \mathrm{C}$ ambient conditions, warm-start with pre-conditioned cabin at set-point of $22^{\circ} \mathrm{C}\left(72^{\circ} \mathrm{F}\right)$. Figure 5.7 represents Case A which shows the engine status commanded by the engine coolant temperature to avoid cold-starts. This case represents the baseline operation of the test vehicle wherein engine is used 
for cabin thermal management in cold ambient conditions, as noted earlier in Chapter 1 Section 1.4. We observe the combination of cabin electric heater and 4 instances of engine turning on in the test vehicle maintaining cabin air temperature within passenger comfort limits. However, again it can be seen that engine turns on near end of trip as noted earlier in Section 5.1. Note that when engine is running, the test vehicle is assumed to be in its fixed-gear mode of operation for the purposes of this case study.

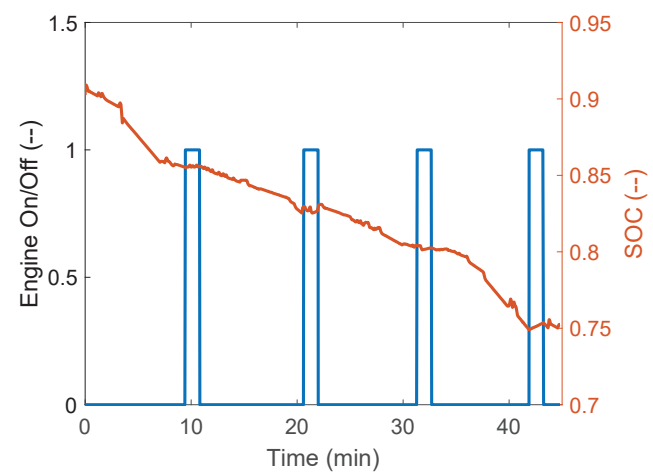

(a) Engine and battery state

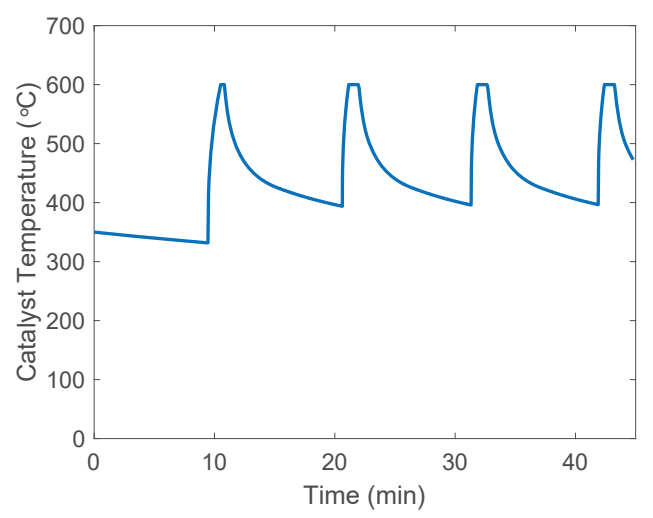

(c) Catalyst temperature

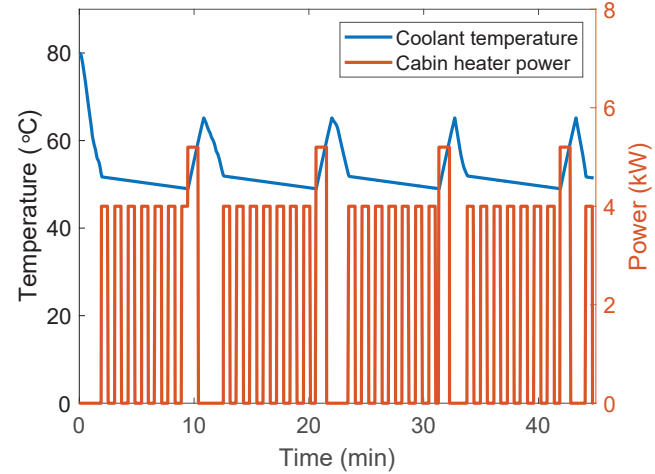

(b) Coolant temperature and electric heater

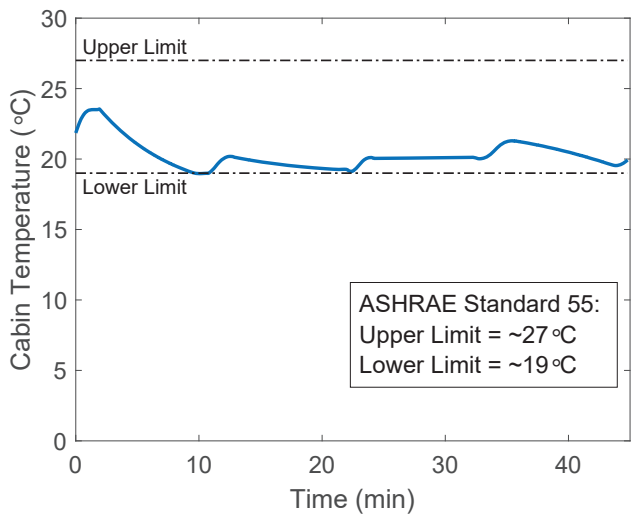

(d) Cabin Temperature

Figure 5.7: Case A: Baseline operation without coordinated thermal management 
Along with the energy saving potential observed in Section 5.1, which reduces the number of engine on events by optimizing integrated electric heater and engine heatassist operation, the catalyst thermal management strategy described in Section 5.2 can be implemented together to reduce energy consumption. This is represented as Case B in Figure 5.8. The cabin air temperature is again maintained within passenger comfort limits.

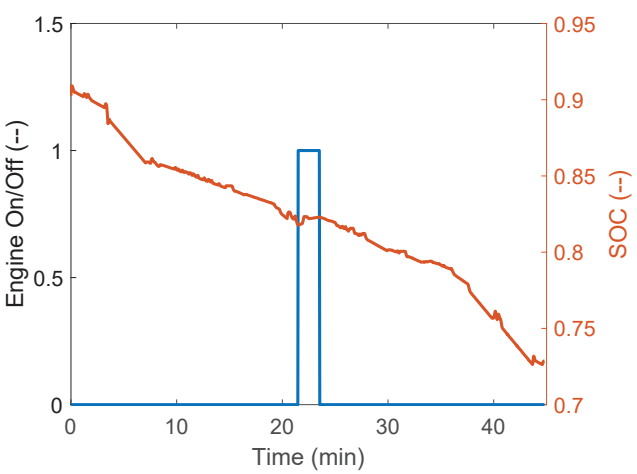

(a) Engine and battery state

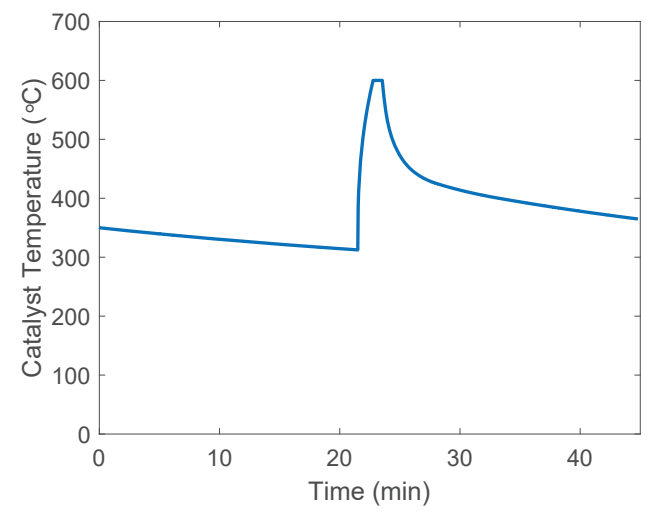

(c) Catalyst temperature

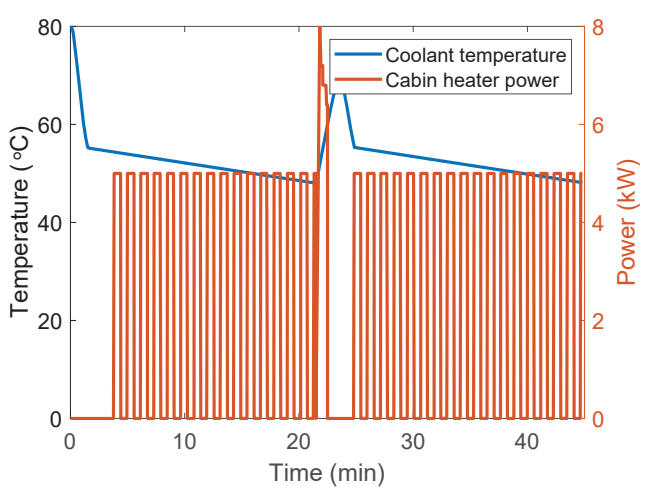

(b) Coolant temperature and electric heater

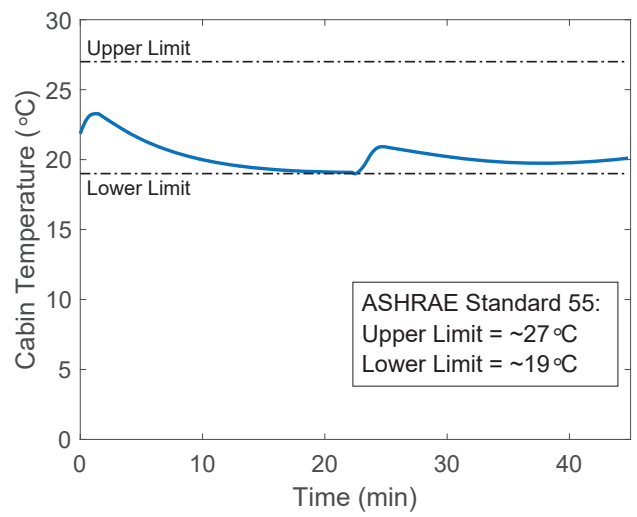

(d) Cabin Temperature

Figure 5.8: Case B: Optimal operation with coordinated thermal management 
The engine status is commanded by a combination of engine cold-start and catalyst light-off temperature thresholds to minimize fuel consumption by taking into account their respective fuel penalties. We observe that, for the trip duration of the test cycle under study, allowing for cold-start penalty while incurring a catalyst light-off penalty does not eliminate any more engine on events when implemented in conjunction with the integrated HVAC - powertrain optimal operation. Thus, the operation illustrated in Figure 5.8 is the optimal operation.

Table 5.4 summarizes the total vehicle energy consumption for the baseline and optimal solution. The fuel energy and battery energy together represent the energy consumed for traction purposes. The total vehicle energy savings observed in this case study are the result of a synergistic combination of the integrated HVAC - Powertrain operation and powertrain thermal management for catalyst light-off. 


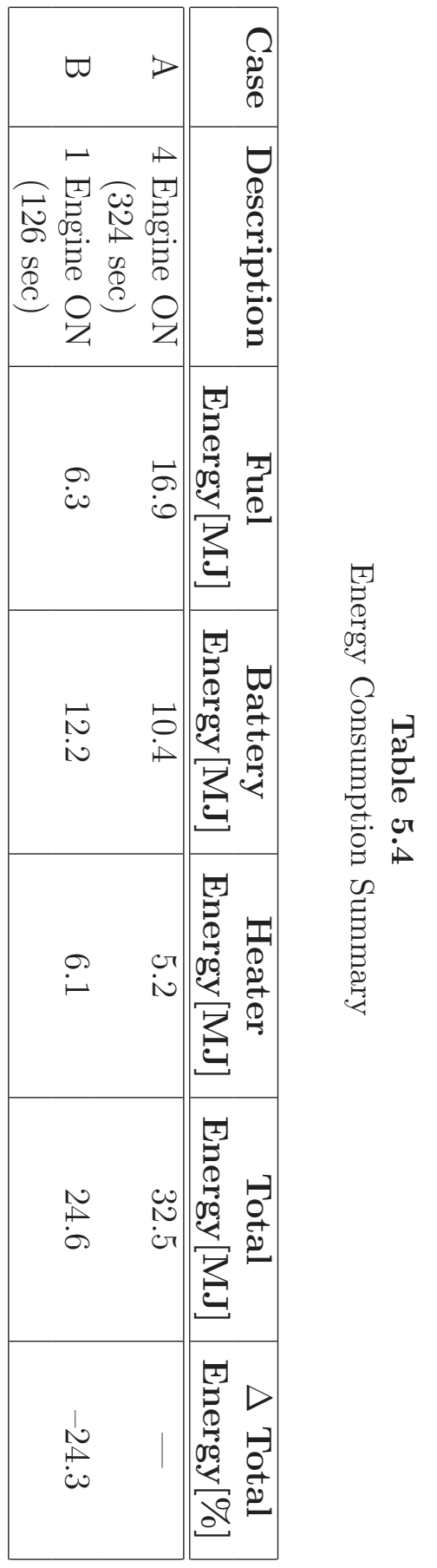




\subsection{Monte Carlo Simulations}

Monte Carlo simulations provide a great solution when dealing with random variables in various business and engineering applications. The process of predicting energy consumption reduction by the strategies proposed in this work has significant inherent variability which needs a better statistical definition to evaluate the performance of these strategies.

The ambient temperature, solar irradiation, trip duration, initial battery SOC, cabin set-point temperature among several other random variables introduce variations in the forecast of energy savings. In this section, one such random variable i.e. ambient temperature is analyzed under the Monte Carlo simulation approach to provide a better estimate of the energy savings potential. The ambient temperature in the town of Houghton, MI for the winter months of October to May in the year 2017 is extracted from historical data available on the National Renewable Energy Laboratory (NREL) National Solar Radiation Database (NSRDB) [4]. The ambient temperature in 30-min intervals for the desired location and time of year is shown in Figure 5.9.

A sample of 50 ambient temperatures is selected as a normal/Gaussian distribution from the available data with a mean value of $0.1^{\circ} \mathrm{C}$ and standard deviation of $6.5^{\circ} \mathrm{C}$. 


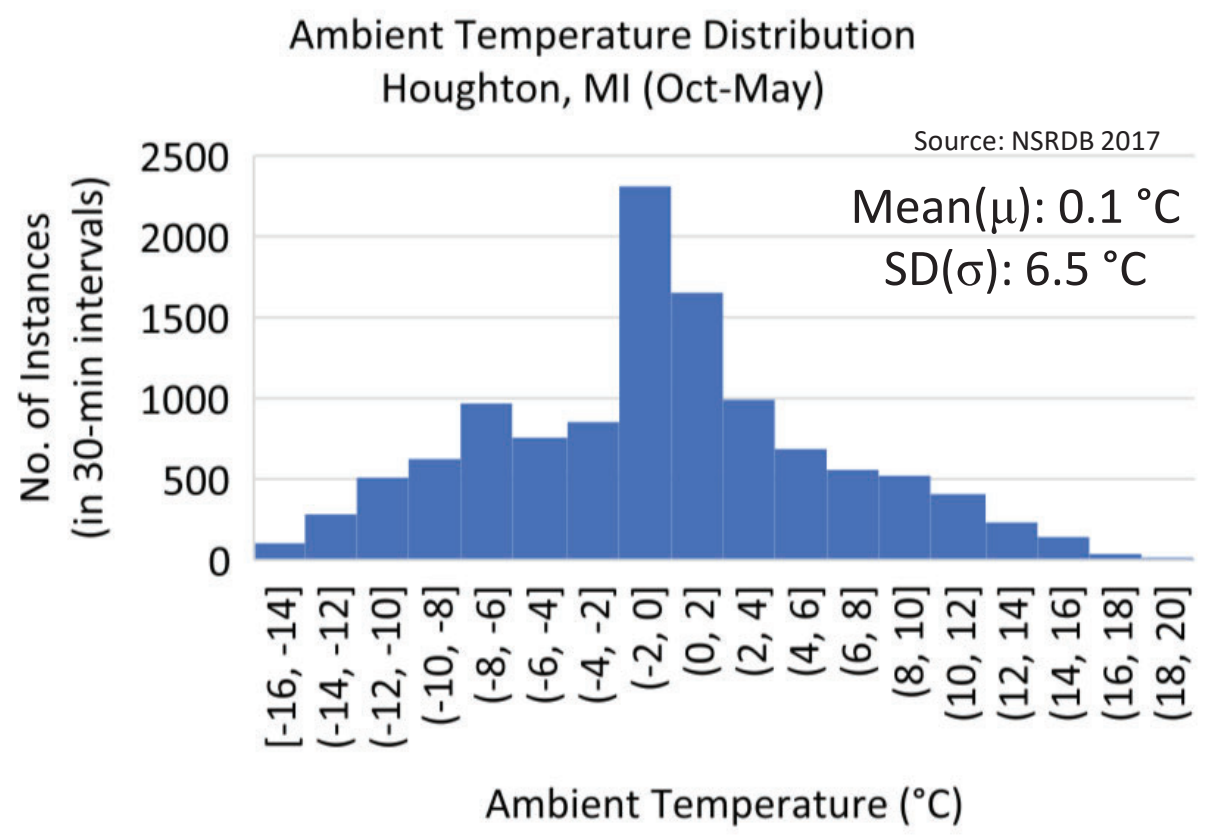

Figure 5.9: Distribution of ambient temperature [4]

This sample, shown in Figure 5.10, represents a normal distribution of ambient temperatures in Houghton, MI during the months of October - May and hence is assumed to accurately capture the probability distribution function for energy consumption reduction by the proposed strategies. 


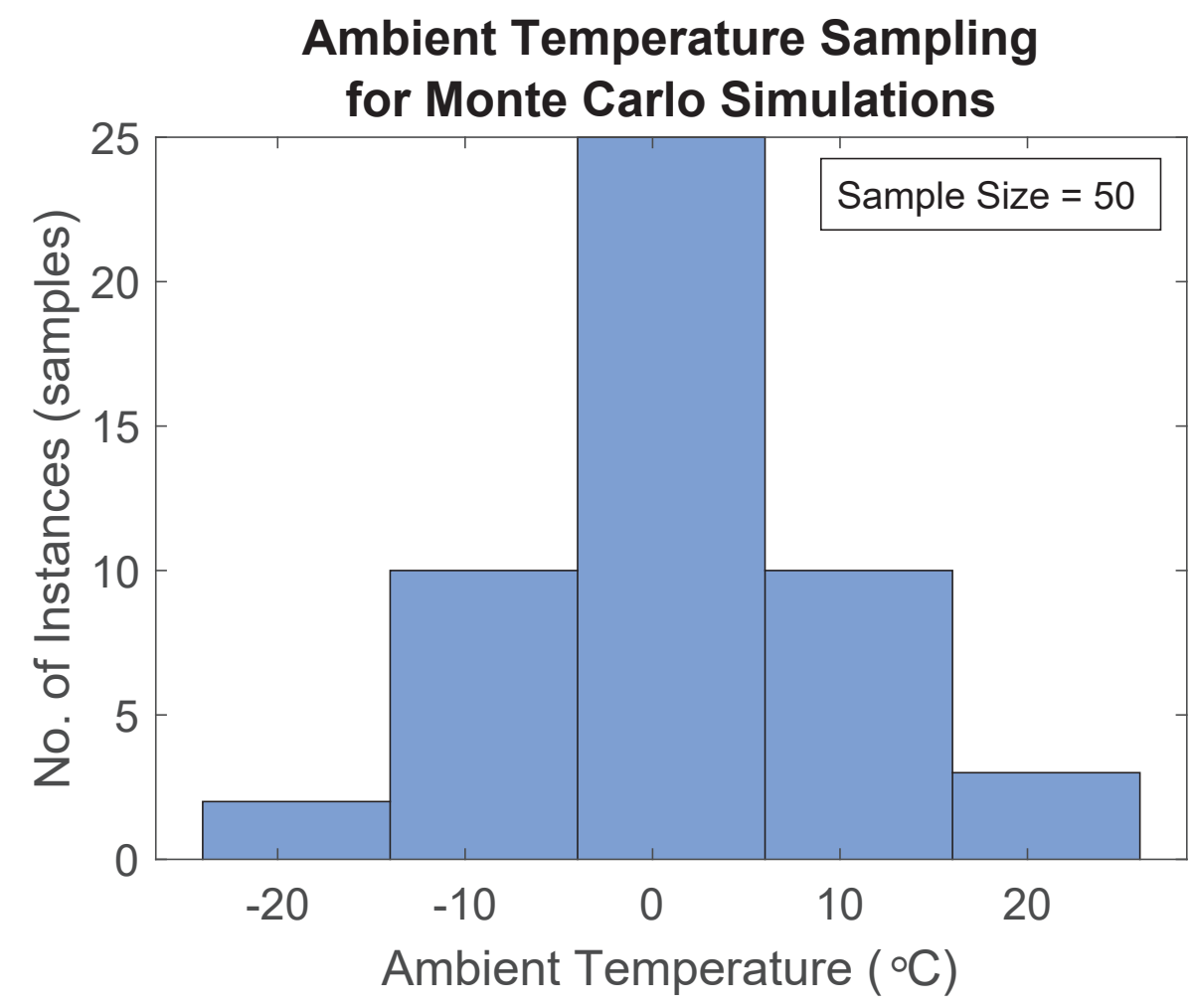

Figure 5.10: Normally distributed sample of ambient temperature data

\subsubsection{Integrated HVAC - Powertrain Operation}

Monte Carlo simulations (sample size: 50) for evaluating variability with respect to ambient temperature show that the maximum HVAC energy savings possible by implementing this strategy is $16 \%$. The probability distribution has a mean value of $6 \%$ energy savings in HVAC. It must be noted that for the test vehicle, the engine heatassist operation is only available for ambient temperature below $35^{\circ} \mathrm{F}\left(2^{\circ} \mathrm{C}\right)$. Hence, for all ambient temperature inputs in the sample which are above this threshold, this strategy is ineffective i.e. the energy saving potential is $0 \%$ since the electric heater 
alone is used for cabin thermal management and no optimal selection of the operating points for cabin electric heater and engine heat-assist is possible. As noted earlier in Section 5.1.1, the total vehicle energy savings is a fraction of the maximum HVAC energy savings possible. Hence, maximum total vehicle energy savings possible by implementing this strategy is $9 \%$ and the total vehicle energy savings distribution, shown in Figure 5.11, has a mean value of $3 \%$.

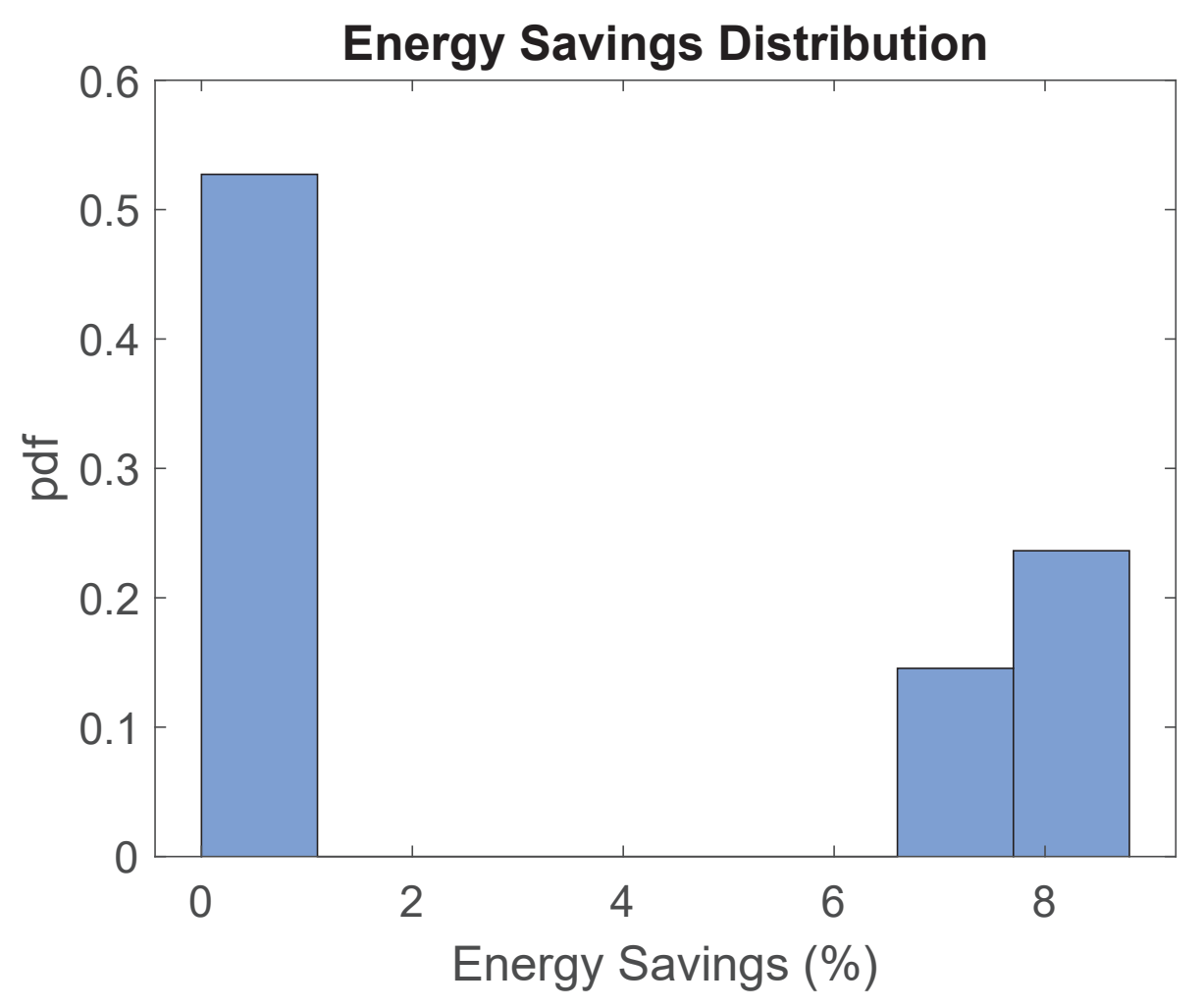

Figure 5.11: Total vehicle energy savings distribution for Integrated HVAC - Powertrain Operation 


\subsubsection{Coordinated Thermal Management}

Similarly, Monte Carlo simulations for the coordinated thermal management strategy show that the ambient temperature variability results in a $14 \%$ mean variation in total vehicle energy savings. The probability distribution of total vehicle energy savings is illustrated in Figure 5.12.

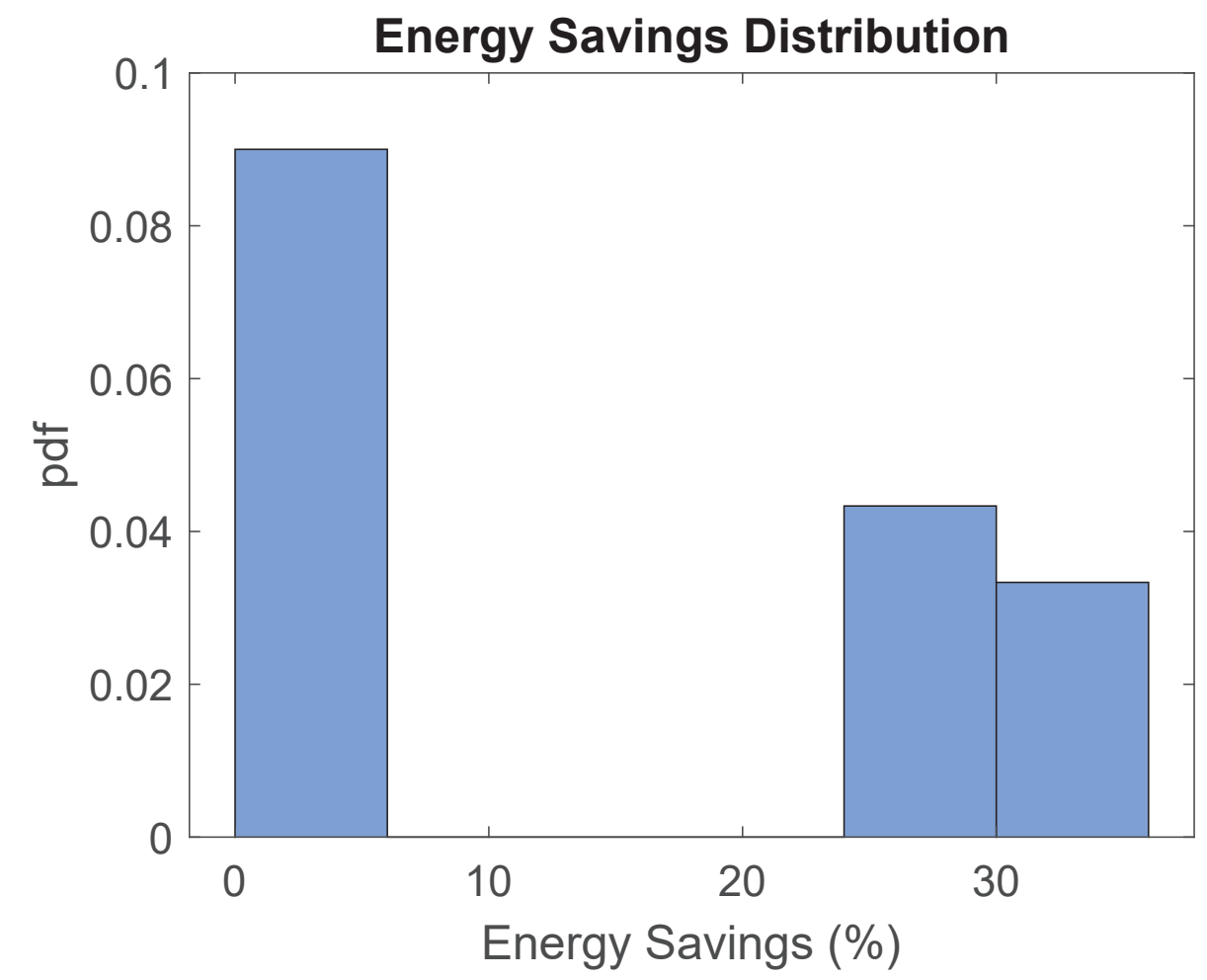

Figure 5.12: Total vehicle energy savings distribution for Coordinated Thermal Management strategy 
We observe a bi-modal distribution for the probability distribution of energy savings in Figures 5.11 and 5.12, because of the test vehicle HVAC operation in ambient conditions above and below $35^{\circ} \mathrm{F}\left(2^{\circ} \mathrm{C}\right)$ as explained earlier. This results in the following: at higher ambient temperatures, the potential energy saving by the proposed strategies is low and concentrated around $0 \%$, whereas at lower ambient temperatures the potential energy saving is much higher. 


\section{Chapter 6}

\section{Conclusion and Future Work}

An experimentally validated model of the GM Chevrolet Volt Gen II hybrid electric vehicle's HVAC system is developed using MATLAB/Simulink tools. The experimental test data used for validation was either provided by ANL or collected from tests conducted at APSRC Labs. The individual components of the vehicle's HVAC system and the sub-systems integrating the vehicle powertrain and HVAC systems were tested, modeled, validated and analyzed to evaluate potential energy savings opportunities. 


\subsection{Conclusion}

The findings of the work done as part of this thesis under the MTU NEXTCAR team project are summarized below:

$\dagger$ A transient thermal model of the vehicle cabin is developed and augmented with a blower fan model, solar irradiation model to accurately predict mean cabin air temperature with an average error of $1.2^{\circ} \mathrm{C}$.

$\dagger$ Component models for integrating HVAC and powertrain systems by estimating catalyst and engine coolant temperatures are developed and validated to predict temperature with an average error of $2.2^{\circ} \mathrm{C}$ and $1.8^{\circ} \mathrm{C}$ respectively.

$\dagger$ Cabin heating operation is modeled by incorporating engine coolant temperature and cabin electric heater models. The electric heater control logic implemented in this work is capable of predicting cumulative energy consumption within $4 \%$ for charge depleting mode of operation.

$\dagger$ An artificial neural network to predict A/C compressor energy consumption is also developed to help evaluate potential energy savings with coordinated battery and cabin cooling operation.

$\dagger$ A model-based optimization tool is developed for integrated HVAC - Powetrain 
operation which achieves up to $16 \%$ energy consumption reduction in HVAC energy in a given connected vehicle scenario whilst maintaining passenger comfort level inside the cabin during cabin heating operation. The energy savings distribution from Monte Carlo simulations show a range of $0-9 \%$ with a mean of $3 \%$ reduction in total vehicle energy using this strategy.

$\dagger$ A coordinated thermal management strategy is presented in this work which results in $14 \%$ mean reduction in overall vehicle energy consumption for a specific connected vehicle scenario. Monte Carlo simulations show 0-34\% total vehicle energy savings resulting from a synergistic combination of the proposed control strategies.

\subsection{Future Work}

$\dagger$ The main focus of the energy savings opportunities analyzed in this work has been on cabin heating operation for connected vehicle scenarios. In future work, the $\mathrm{A} / \mathrm{C}$ compressor model developed and validated in this thesis can be used to further develop battery cooling and battery management models to evaluate the potential energy savings opportunities with coordinated cooling operations of the battery and vehicle cabin. The compressor operation can be optimized by leveraging the thermal coupling between battery and cabin and thereby show 
reduction in vehicle energy consumption.

$\dagger$ In addition, the battery heating operation in cold ambient conditions using the secondary heater should be studied to optimize coordinated HVAC, battery and powertrain thermal management.

$\dagger$ The evaluation of cabin thermal dynamics can be further improved by incorporating humidity calculations and human physiological thermal models and thereby increase fidelity of cabin thermal model. Then cabin comfort levels can consider the effects of both mean air temperature and humidity ratio to give a better estimate of passenger comfort inside the vehicle cabin.

$\dagger$ A higher fidelity model can be developed for the catalyst temperature based on the chemical reaction mechanisms involved.

$\dagger$ The proposed optimization framework can be extended to a multi-objective model predictive feedback control (MPC) framework to determine optimal control actions for total vehicle energy reduction while addressing human comfort, powertrain operational constraints, and HVAC actuators constraints.

$\dagger$ In the proposed coordinated thermal management strategy, the test vehicles mode of operation during engine on events needs to be examined for further optimization.

$\dagger$ An iterative learning procedure can be employed to understand driver-specific patterns of vehicle and HVAC usage in terms of average daily trip lengths and 
desired passenger comfort levels to better tailor the vehicle operating strategies for optimal control.

$\dagger$ The impact of pre-conditioning vehicle cabin using grid energy must be evaluated to better estimate the overall energy consumption and its impact on EV range.

$\dagger$ Further statistical analysis can be carried out to understand the frequency of occurrence of specific scenarios stated in the case studies presented in this work. This will help us characterize effect of different random variables and thereby better estimate the potential energy savings under different operating conditions in a connected vehicle infrastructure of the near future. 



\section{References}

[1] The Outlook for Energy: A View to 2040. Technical report, ExxonMobil, 2016. URL http://cdn.exxonmobil.com/ /media/global/files/ outlook-for-energy/2016/2016-outlook-for-energy ·pdf.

[2] Connected Car Market Analysis By Application (Vehicle Management, Driver Assistance, Mobility Management, Safety, Entertainment) And Segment Forecasts To 2022. Technical Report 978-1-68038-648-6, May 2016. URL https:// wWW.grandviewresearch.com/industry-analysis/connected-car-market.

[3] How Software Will Dominate the Automotive Industry, URL https://www.toptal.com/insights/innovation/ how-software-will-dominate-the-automotive-industry.

[4] NREL National Solar Radiation Database, . URL https://sam.nrel.gov/ weather-data.html.Accessed:07/19/19.

[5] R. Yadav. Modeling and Analysis of Energy Consumption in Chevrolet Volt 
Gen II Hybrid Electric Vehicle. MS Thesis, Michigan Technological University, Houghton, MI, 2018. URL https://digitalcommons.mtu.edu/etdr/633.

[6] Corporate Average Fuel Economy. Technical report, United States Department of Transportation, 2018. URL https://www.nhtsa.gov/laws-regulations/ corporate-average-fuel-economy.

[7] Connected Vehicles. Technical report, IEEE, . URL http://sites.ieee.org/ connected-vehicles/ieee-connected-vechicles/connected-vehicles/.

[8] U.S. Department of Energy, ARPA-E NEXTCAR Program, . URL https:

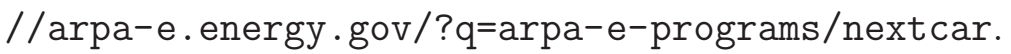

[9] Jeffrey D. Gonder. Route-Based Control of Hybrid Electric Vehicles. April 2008. doi: 10.4271/2008-01-1315. URL https://www.sae.org/content/ $2008-01-1315 /$.

[10] Baisravan HomChaudhuri, Runing Lin, and Pierluigi Pisu. Hierarchical control strategies for energy management of connected hybrid electric vehicles in urban roads. Transportation Research Part C: Emerging Technologies, 62:7086, January 2016. ISSN 0968090X. doi: 10.1016/j.trc.2015.11.013. URL https://linkinghub.elsevier.com/retrieve/pii/S0968090X15004131.

[11] Xuewei Qi, Guoyuan Wu, Kanok Boriboonsomsin, and Matthew J. Barth. A Novel Blended Real-Time Energy Management Strategy for Plug-in Hybrid Electric Vehicle Commute Trips. In 2015 IEEE 18th International Conference 
on Intelligent Transportation Systems, pages 1002-1007, Gran Canaria, Spain, September 2015. IEEE. ISBN 978-1-4673-6596-3. doi: 10.1109/ITSC.2015.167. URL http://ieeexplore.ieee.org/document/7313259/.

[12] Guoyuan Wu, Kanok Boriboonsomsin, and Matthew J. Barth. Development and Evaluation of an Intelligent Energy-Management Strategy for Plug-in Hybrid Electric Vehicles. IEEE Transactions on Intelligent Transportation Systems, 15 (3):1091-1100, June 2014. ISSN 1524-9050, 1558-0016. doi: 10.1109/TITS.2013. 2294342. URL http://ieeexplore.ieee.org/document/6717001/.

[13] Matthew A. Jeffers, Larry Chaney, and John P. Rugh. Climate Control Load Reduction Strategies for Electric Drive Vehicles in Cold Weather. SAE International Journal of Passenger Cars - Mechanical Systems, 9(1):75-82, April 2016. ISSN 1946-4002. doi: 10.4271/2016-01-0262. URL https://www.sae.org/content/ 2016-01-0262/.

[14] Matthew A. Jeffers, Larry Chaney, and John P. Rugh. Climate Control Load Reduction Strategies for Electric Drive Vehicles in Warm Weather. April 2015. doi: 10.4271/2015-01-0355. URL https://www. sae.org/content/2015-01-0355/.

[15] Henning Lohse-Busch, Michael Duoba, Eric Rask, Kevin Stutenberg, Vivek Gowri, Lee Slezak, and David Anderson. Ambient Temperature (20F, 72F and 95F) Impact on Fuel and Energy Consumption for Several Conventional Vehicles, Hybrid and Plug-In Hybrid Electric Vehicles and Battery Electric Vehicle. 
April 2013. doi: 10.4271/2013-01-1462. URL https://www.sae.org/content/ 2013-01-1462/

[16] Hao Wang, Ilya Kolmanovsky, Mohammad Reza Amini, and Jing Sun. Model Predictive Climate Control of Connected and Automated Vehicles for Improved Energy Efficiency. In 2018 Annual American Control Conference (ACC), pages 828-833, Milwaukee, WI, June 2018. IEEE. ISBN 978-1-5386-5428-6. doi: 10.23919/ACC.2018.8431051. URL https://ieeexplore.ieee.org/document/ $8431051 /$.

[17] Julian Eckstein, Christopher Lke, Frederik Brunstein, Patrick Friedel, Ulrich Khler, and Ansgar Trchtler. A Novel Approach Using Model Predictive Control to Enhance the Range of Electric Vehicles. Procedia Technology, 26:177184, 2016. ISSN 22120173. doi: 10.1016/j.protcy.2016.08.024. URL https: //linkinghub.elsevier.com/retrieve/pii/S2212017316303711.

[18] Quansheng Zhang, Stephanie Stockar, and Marcello Canova. Energy-Optimal Control of an Automotive Air Conditioning System for Ancillary Load Reduction. IEEE Transactions on Control Systems Technology, 24(1):67-80, January 2016. ISSN 1063-6536, 1558-0865. doi: 10.1109/TCST.2015.2418322. URL http://ieeexplore. ieee.org/document/7104126/. 
[19] David Marcos, Francisco J. Pino, Carlos Bordons, and Jos J. Guerra. The development and validation of a thermal model for the cabin of a vehicle. $A p$ plied Thermal Engineering, 66(1-2):646-656, May 2014. ISSN 13594311. doi: 10.1016/j.applthermaleng.2014.02.054. URL https://linkinghub.elsevier . com/retrieve/pii/S135943111400146X.

[20] Brbara Torregrosa-Jaime, Filip Bjurling, Jos M. Corbern, Fausto Di Sciullo, and Jorge Pay. Transient thermal model of a vehicle's cabin validated under variable ambient conditions. Applied Thermal Engineering, 75:45-53, January 2015. ISSN 13594311. doi: 10.1016/j.applthermaleng.2014.05.074. URL https: //linkinghub.elsevier.com/retrieve/pii/S1359431114004505.

[21] Mohammad Ali Fayazbakhsh and Majid Bahrami. Comprehensive Modeling of Vehicle Air Conditioning Loads Using Heat Balance Method. April 2013. doi: 10.4271/2013-01-1507. URL https://www. sae.org/content/2013-01-1507/.

[22] Jongryeol Jeong, Sungwook Choi, Namdoo Kim, Heeyun Lee, Kevin Stutenberg, and Aymeric Rousseau. Model Validation of the Chevrolet Volt 2016. April 2018. doi: 10.4271/2018-01-0420. URL https://www.sae.org/content/ 2018-01-0420/.

[23] Brendan M. Conlon, Trevor Blohm, Michael Harpster, Alan Holmes, Margaret Palardy, Steven Tarnowsky, and Leon Zhou. The Next Generation Voltec Extended Range EV Propulsion System. SAE International Journal 
of Alternative Powertrains, 4(2):248-259, April 2015. ISSN 2167-4205. doi: 10.4271/2015-01-1152. URL https://www.sae.org/content/2015-01-1152/.

[24] Sinisa Jurkovic, Khwaja Rahman, Nitin Patel, and Peter Savagian. Next Generation Voltec Electric Machines; Design and Optimization for Performance and Rare-Earth Mitigation. SAE International Journal of Alternative Powertrains, 4(2):336-342, April 2015. ISSN 2167-4205. doi: 10.4271/2015-01-1208. URL https://www. sae.org/content/2015-01-1208/.

[25] Jeffrey Jocsak, David White, Cedric Armand, and Richard S. Davis. Development of the Combustion System for General Motors' High-Efficiency Range Extender Ecotec Small Gas Engine. SAE International Journal of Engines, 8 (4):1587-1601, April 2015. ISSN 1946-3944. doi: 10.4271/2015-01-1272. URL https://www. sae.org/content/2015-01-1272/.

[26] Lili Feng and Predrag Hrnjak. Experimental Study of an Air Conditioning-Heat Pump System for Electric Vehicles. April 2016. doi: 10.4271/2016-01-0257. URL https://www. sae.org/content/2016-01-0257/.

[27] Chung-Won Cho, Ho-Seong Lee, Jong-Phil Won, and Moo-Yeon Lee. Measurement and Evaluation of Heating Performance of Heat Pump Systems Using Wasted Heat from Electric Devices for an Electric Bus. Energies, 5(3): 658-669, March 2012. ISSN 1996-1073. doi: 10.3390/en5030658. URL http: //www.mdpi.com/1996-1073/5/3/658. 
[28] John J. Meyer, Jason Lustbader, Nicos Agathocleous, Antonio Vespa, John Rugh, and Gene Titov. Range Extension Opportunities While Heating a Battery Electric Vehicle. April 2018. doi: 10.4271/2018-01-0066. URL https: //www.sae.org/content/2018-01-0066/.

[29] Fei Qin, Qingfeng Xue, Guiying Zhang, Huiming Zou, and Changqing Tian. Experimental Investigation on Heat Pump for Electric Vehicles with different Refrigerant Injection Compressors. Energy Procedia, 75:1490-1495, August 2015. ISSN 18766102. doi: 10.1016/j.egypro.2015.07.281. URL https://linkinghub . elsevier.com/retrieve/pii/S1876610215010498.

[30] Jae Hwan Ahn, Hoon Kang, Ho Seong Lee, Hae Won Jung, Changhyun Baek, and Yongchan Kim. Heating performance characteristics of a dual source heat pump using air and waste heat in electric vehicles. Applied Energy, 119:1-9, April 2014. ISSN 03062619. doi: 10.1016/j.apenergy.2013.12.065. URL https: //linkinghub.elsevier.com/retrieve/pii/S0306261914000051.

[31] Ziqi Zhang, Wanyong Li, Junye Shi, and Jiangping Chen. A Study on Electric Vehicle Heat Pump Systems in Cold Climates. Energies, 9(11):881, October 2016. ISSN 1996-1073. doi: 10.3390/en9110881. URL http://www.mdpi.com/ $1996-1073 / 9 / 11 / 881$.

[32] James Jeffs, Andrew McGordon, Alessandro Picarelli, Simon Robinson, and W. Dhammika Widanage. System level heat pump model for investigations into 
thermal management of electric vehicles at low temperatures. pages 107-116, February 2019. doi: 10.3384/ecp19157107. URL http://www.ep.liu.se/ecp/ article. asp?issue $=157 \% 26 \operatorname{article}=11$.

[33] Antti Lajunen. Energy Efficiency and Performance of Cabin Thermal Management in Electric Vehicles. March 2017. doi: 10.4271/2017-01-0192. URL https://www. sae.org/content/2017-01-0192/.

[34] John P. Rugh, V. Hovland, and S. O. Andersen. Significant Fuel Savings and Emission Reductions by Improving Vehicle Air Conditioning. Washington D.C., June 2014. URL http://www.nrel.gov/transportation/pdfs/fuel_ savings_ac.pdf.

[35] Online Casio Calculator, . URL https://keisan. casio.com.Accessed:05/22/ 2018.

[36] Jan Pokorn, Filip Polek, Milo Fojtln, Jan Fier, and Miroslav Jcha. Measurement of airflow and pressure characteristics of a fan built in a car ventilation system. EPJ Web of Conferences, 114:02097, 2016. ISSN 2100-014X. doi: 10.1051/epjconf/201611402097. URL http://www.epj-conferences.org/10. 1051/epjconf/201611402097.

[37] Milo Fojtln, Michal Planka, Jan Fier, Jan Pokorn, and Miroslav Jcha. Airflow Measurement of the Car HVAC Unit Using Hot-wire Anemometry. EPJ Web of Conferences, 114:02023, 2016. ISSN 2100-014X. doi: 10.1051/epjconf/ 
201611402023. URL http://www.epj-conferences.org/10.1051/epjconf/ 201611402023.

[38] Measurement of Fluid Flow in Pipes Using Orifice, Nozzle, and Venturi. Standard MFC-3M-2004, American Society of Mechanical Engineers (ASME), 2004.

[39] 2017 ASHRAE handbook. Technical report, American Society of Heating, Refrigerating and Air-Conditioning Engineers, 2017. URL https://app. knovel.com/hotlink/toc/id:kpASHRAEP2/ashrae-handbook-fundamentals/ ashrae-handbook-fundamentals.

[40] D.T. Reindl, W.A. Beckman, and J.A. Duffie. Diffuse fraction correlations. Solar Energy, 45(1):1-7, 1990. ISSN 0038092X. doi: 10.1016/0038-092X(90)90060-P. URL https://linkinghub.elsevier.com/retrieve/pii/0038092X9090060P.

[41] Christian Gueymard. An anisotropic solar irradiance model for tilted surfaces and its comparison with selected engineering algorithms. Solar Energy, 38(5): 367-386, 1987. ISSN 0038092X. doi: 10.1016/0038-092X(87)90009-0. URL https://linkinghub.elsevier.com/retrieve/pii/0038092X87900090.

[42] Frank P. Incropera and Frank P. Incropera, editors. Fundamentals of heat and mass transfer. John Wiley, Hoboken, NJ, 6th ed edition, 2007. ISBN 978-0-47145728-2. OCLC: ocm62532755.

[43] J.Carlos Zavala, Pannag R. Sanketi, M. Wilcutts, T. Kaga, and J.K. Hedrick. 
SIMPLIFIED MODELS OF ENGINE HC EMISSIONS, EXHAUST TEMPERATURE AND CATALYST TEMPERATURE FOR AUTOMOTIVE COLDSTART. IFAC Proceedings Volumes, 40(10):199-205, 2007. ISSN 14746670. doi: 10.3182/20070820-3-US-2918.00028. URL https://linkinghub.elsevier. com/retrieve/pii/S1474667015319261.

[44] Byron T. Shaw, Gerald D. Fischer, and J. Karl Hedrick. A SIMPLIFIED COLDSTART CATALYST THERMAL MODEL TO REDUCE HYDROCARBON EMISSIONS. IFAC Proceedings Volumes, 35(1):307-312, 2002. ISSN 14746670. doi: 10.3182/20020721-6-ES-1901.01519. URL https://linkinghub. elsevier.com/retrieve/pii/S1474667015399407.

[45] Thermal Environmental Conditions for Human Occupancy. Standard 55-2013, American Society of Heating, Refrigerating and Air-Conditioning Engineers, 2013. 


\section{Appendix A}

\section{Publication from thesis}

$\dagger$ The work presented in this thesis has been accepted and will be presented at the ASME Dynamic Systems and Control Conference on October 8 11, 2019 at Park City, UT. The accepted paper is titled as follows:

Doshi N., Hanover D., Hemmati S., Morgan C. and Shahbakhti M., "Modeling of Thermal Dynamics of a Connected Hybrid Electric Vehicle for Integrated HVAC and Powertrain Optimal Operation"

$\dagger$ The work will also be presented at the SAE Thermal Management Systems Symposium on October 15 - 17, 2019 at Plymouth, MI. 



\title{
Appendix B
}

\section{Summary of Model and Data Files}

\author{
B.1 Chapter 1
}

Table B.1

MTUDC Energy Distribution Data

\begin{tabular}{lc}
\hline \multicolumn{1}{c}{ File name } & File description \\
\hline hvac_energy_distribution_formatted.xlsx & Energy distribution data \\
& for Figures 1.7 and 1.8(b) \\
Test1008.mat & MTUDC test data for Figure 1.8(a) \\
\hline
\end{tabular}


Table B.2

CAD Files

\begin{tabular}{cc}
\hline File name & File description \\
\hline cabin_model_final.sldprt & Data in Table 2.1 is extracted from \\
& test vehicle CAD model developed using \\
& measurements made at APSRC \\
\hline
\end{tabular}

\section{B.2 Chapter 2}

Table B.3

Vector CAN Files

\begin{tabular}{cc}
\hline File name & File description \\
\hline CAN_1_HVAC_Signals.dbc & $\begin{array}{c}\text { Database Container file of HVAC signals } \\
\text { for use with Vector VN5610A tool }\end{array}$ \\
Drew_configuration_mar_3.cfg & Configuration file for HVAC CAN signals \\
\hline
\end{tabular}

Table B.4

ANL Data Files

\begin{tabular}{cc}
\hline File name & File description \\
\hline 2016_Chevrolet_Volt_AVTA & Details of test data \\
_Test_Summary_10062016.xlsx & tabulated in Table 2.4 \\
\hline
\end{tabular}




\section{B.3 Chapter 3}

Solar irradiation model described in Chapter 3 Section 3.2.7 is detailed in depth here. Based on a simplified model dependent on only clearness index, $k_{t}$ and solar elevation angle, $\alpha_{s}$, the diffuse fraction, $k$ is calculated as shown in Equation B.1.

$$
k= \begin{cases}\min \left(1,1.02-0.254 * k_{t}+0.0123 * \sin \left(\alpha_{s}\right)\right), & \text { if } k_{t} \leq 0.3 \\ \min \left(0.97,1.4-1.749 * k_{t}+0.177 * \sin \left(\alpha_{s}\right)\right), & \text { if } k_{t}<0.78 \\ \max \left(0.1,0.486 * k_{t}-0.183 * \sin \left(\alpha_{s}\right)\right), & \text { if } k_{t} \geq 0.78\end{cases}
$$

The diffuse fraction, $k$, helps decompose $G H I$ into its components, $D H I$ and $D N I$, as shown below:

$$
D H I=k * G H I \quad D N I=\frac{(1-k)}{\sin \left(\alpha_{s}\right)} * G H I
$$

The angle of incidence, $\theta$, diffuse transposition factor, $R_{d}$ and ground reflection transposition factor, $R_{r}$ for each side of the vehicle cabin are calculated as follows:

$$
\theta_{\text {side }}=\cos ^{-1}\left(\cos \left(90-\alpha_{s}\right) * \cos \left(\Theta_{\text {side }}\right)+\sin \left(90-\alpha_{s}\right) * \sin \left(\Theta_{\text {side }}\right) * \cos \left(\alpha_{z}-\gamma\right)\right)
$$


where, $\Theta$ is the angle of tilt of each side of vehicle cabin, $\alpha_{z}$ is solar azimuth angle and $\gamma$ is heading angle of the vehicle.

$$
\begin{gathered}
R_{r, \text { side }}=\frac{1-\cos \left(\Theta_{\text {side }}\right)}{2} \\
R_{d, \text { side }}=r_{b, \text { side }} * \frac{D N I}{S_{o}}+C_{\phi, \text { side }} * \frac{S_{o}-D N I}{S_{o}}
\end{gathered}
$$

where, $S_{o}$ is a solar constant $=1367 \mathrm{~W} / \mathrm{m}^{2} . r_{b, \text { side }}$ and $C_{\phi, \text { side }}$ are defined below:

$$
\begin{gathered}
r_{b, \text { side }}=\max \left(0, \cos \left(\frac{\theta_{\text {side }}}{\cos \left(90-\alpha_{s}\right)}\right)\right) \\
C_{\phi, \text { side }}=1.0115-0.20293 * \Theta_{\text {side }}-0.080823 * \Theta_{\text {side }}^{2}
\end{gathered}
$$

\section{B.4 Chapter 4}

Table B.5

Cabin Thermal Mass Characterization Data and Model

\begin{tabular}{lc}
\hline \multicolumn{1}{c}{ File name } & File description \\
\hline may_9th_test_data.mat & Test data for Figure 4.1 \\
may_9th_model_int_mass.m & MATLAB script file for thermal mass validation \\
\hline
\end{tabular}


Table B.6

Cabin Blower Characterization Data and Model

\begin{tabular}{lc}
\hline \multicolumn{1}{c}{ File name } & File description \\
\hline FAN_Workspace.mat & Test data for Figure 4.2 \\
FAN_Profiles.m & MATLAB script file for \\
& characterizing cabin blower fan \\
\hline
\end{tabular}

Table B.7

Cabin Temperature Distribution Data Files

\begin{tabular}{lc}
\hline \multicolumn{1}{c}{ File name } & File description \\
\hline april12_workspace.mat & Test data for Figure 4.3 \\
temperature_dist.m & MATLAB script file for \\
& plotting temperature distribution \\
\hline
\end{tabular}

Table B.8

Cabin Temperature Validation Data and Model

\begin{tabular}{lc}
\hline \multicolumn{1}{c}{ File name } & File description \\
\hline mar_3_workspace.mat & Test data for Figure 4.4 \\
may11th_heatup.m & MATLAB script file for validation during heat-up \\
may11th_cooldown.m & MATLAB script file for validation during cool-down \\
\hline
\end{tabular}

\section{B.5 Chapter 5}


Table B.9

Solar Irradiation Validation Data and Model

\begin{tabular}{lc}
\hline \multicolumn{1}{c}{ File name } & File description \\
\hline may_23_solar_test_data.mat & Test data for Figure 4.5 \\
solarangles_may22.mat & Solar angles data for Figure 4.5 \\
Rev_3.m & MATLAB script file for \\
& validation with solar irradiation
\end{tabular}

Table B.10

Coolant Temperature Model

\begin{tabular}{lc}
\hline \multicolumn{1}{c}{ File name } & File description \\
\hline coolant_updated.slx & Simulink model for characterizing \\
& effect of vehicle speed for \\
& Figures 4.6 and 4.7 \\
Test1004.mat & Test data for Figure 4.8 \\
coolant_initializescript.m & MATLAB initialization script \\
coolant_updated2_mtudc_feb18.slx & Simulink model for \\
& coolant temperature validation Figure 4.8 \\
\hline
\end{tabular}

Table B.11

Catalyst Temperature Model

\begin{tabular}{lc}
\hline \multicolumn{1}{c}{ File name } & File description \\
\hline 61608023.mat & Test Data for Figures 4.9(a) and 4.10(a) \\
61607021.mat & Test Data for Figures 4.9(b) and 4.10(b) \\
catalyst_heatup_nit.m & MATLAB initilization script \\
catalyst_heatup_model.slx & Simulink model for validation during heat-up \\
catalyst_cooldown_model.slx & Simulink model for validation during cool-down \\
\hline
\end{tabular}


Table B.12

Cabin Electric Heater Model

\begin{tabular}{lc}
\hline \multicolumn{1}{c}{ File name } & File description \\
\hline jan2019_hvac_cabin & MATLAB initialization script \\
heater_initializescript.m & \\
Test1004.mat & Test data for Figure 4.11(a) \\
Test1005.mat & Test data for Figure 4.11(b) \\
cabin_eheater_rules.slx & Simulink model for Figure 4.11 \\
\hline
\end{tabular}

Table B.13

A/C Compressor Model

\begin{tabular}{lc}
\hline \multicolumn{1}{c}{ File name } & File description \\
\hline 61608002.mat & Test data for Figure 4.12 \\
Compressor_NN_rev_2.m & Artificial Neural Network MATLAB function \\
ANL_61608002_cooldown & MATLAB script for validation \\
_validation_compressor_NN.m & \\
\hline
\end{tabular}

Table B.14

Integrated HVAC - Powertrain Operation Model

\begin{tabular}{lc}
\hline \multicolumn{1}{c}{ File name } & File description \\
\hline Test1008.mat & Test data \\
mtudc_optimizer & MATLAB script for \\
script_v1_updated.m & multiple simulations of model Figure 5.3 \\
mtudc_optimizermodel_v1.slx & Simulink model \\
mtudc_totalenergy.mat & Results data file \\
v2_workspace_test1008.mat & Initialization data for Figure 5.4 \\
HX_method_test1008_trial.m & MATLAB script for cabin heater core model \\
t_cabin_mtudc_test1008.m & MATLAB script for cabin temperature model \\
\hline
\end{tabular}


Table B.15

Coordinated Thermal Management Model

\begin{tabular}{lc}
\hline \multicolumn{1}{c}{ File name } & File description \\
\hline PT_thermal_init.m & MATLAB initialization script \\
PT_thermal.slx & Simulink model for illustrating \\
& concept of Figure 5.6 \\
DataToLoad_JCT_071417.mat & Initialization data \\
& for Engine dynamic model \\
Engine_dynamic_model.slx & Simulink model to determine \\
& fuel consumption for Table 5.3 \\
PT_thermal_integrated_v1_init.m & MATLAB initialization script \\
PT_thermal_integrated_v1.slx & Simulink model for Figure 5.7 \\
hvacpt_thermal_baseline_mtudc.mat & Results data file (Case A) \\
PT_thermal_integrated_v2.slx & Simulink model for Figure 5.8 \\
hvacpt_thermal_caseB_mtudc.mat & Results data file (Case B) \\
hvacpt_thermal_caseC_mtudc.mat & Results data file (Case C) \\
temp_plotting.m & MATLAB plotting script \\
& for Figures 5.7,5.8 \\
IniatilizeFile.m & MATLAB initialization script \\
mode_inputmtudc.mat & Initialization data for model \\
model.slx & Simulink model for SOC simulation \\
& during blended operation \\
\hline
\end{tabular}




\section{Appendix $\mathrm{C}$}

\section{Summary of Figure Files}

Table C.1

Chapter 1

\begin{tabular}{lc}
\hline \multicolumn{1}{c}{ File name } & Figure Reference \\
\hline trend.pdf & 1.1 \\
connected_trend.png & 1.2 \\
connected_penetration.jpg & 1.3 \\
old_overview_1.pdf & $1.4(\mathrm{a})$ \\
new_overview.jpg & $1.4(\mathrm{~b})$ \\
nextcar_overview.pdf & 1.5 \\
MTUDC_image.pdf & $1.6(\mathrm{a})$ \\
MTUDC_velocity.pdf & $1.6(\mathrm{~b})$ \\
MTUDC_energy_new.pdf & 1.7 \\
sample_engspd.pdf & $1.8(\mathrm{a})$ \\
sample_energy_new.pdf & $1.8(\mathrm{~b})$ \\
\hline
\end{tabular}


Table C.2

Chapter 2

\begin{tabular}{lc}
\hline \multicolumn{1}{c}{ File name } & Figure Reference \\
\hline krc_setup.pdf & 2.1 \\
blower_test.pdf & 2.2 \\
thermal_mass_test.pdf & 2.3 \\
vector_can_daq.pdf & $2.4(\mathrm{a})$ \\
dspace_daq.jpg & $2.4(\mathrm{~b})$ \\
\hline
\end{tabular}

Table C.3

Chapter 3

\begin{tabular}{lc}
\hline \multicolumn{1}{c}{ File name } & Figure Reference \\
\hline model_overview.pdf & 3.1 \\
hvacheating_new.pdf & 3.2 \\
hvac_cooling.pdf & 3.3 \\
cabin_model.pdf & 3.4 \\
coolant_model.pdf & 3.5 \\
HX.pdf & 3.6 \\
twc_model.pdf & 3.7 \\
ann_model.pdf & 3.8 \\
ann_performance.jpg & 3.9 \\
ann_crossval.jpg & 3.10 \\
\hline
\end{tabular}


Table C.4

Chapter 4

\begin{tabular}{lc}
\hline \multicolumn{1}{c}{ File name } & Figure Reference \\
\hline validation_thermal_mass.pdf & 4.1 \\
validation_blower.pdf & 4.2 \\
temp_distribution.pdf & 4.3 \\
validation_heat.pdf & $4.4(\mathrm{a})$ \\
validation_cool.pdf & $4.4(\mathrm{~b})$ \\
validation_solar.pdf & 4.5 \\
validation_clnt1.pdf & 4.6 \\
validation_clnt2.pdf & 4.7 \\
validation_clntfull.pdf & 4.8 \\
validation_cat_cool1.pdf & $4.9(\mathrm{a})$ \\
validation_cat_cool2.pdf & $4.9(\mathrm{~b})$ \\
validation_cat_heat1.pdf & $4.10(\mathrm{a})$ \\
validation_cat_heat2.pdf & $4.10(\mathrm{~b})$ \\
validation_heater1.pdf & $4.11(\mathrm{a})$ \\
validation_heater2.pdf & $4.11(\mathrm{~b})$ \\
validation_comp.pdf & 4.12 \\
\hline
\end{tabular}


Table C.5

Chapter 5

\begin{tabular}{lc}
\hline \multicolumn{1}{c}{ File name } & Figure Reference \\
\hline savingsconcept.pdf & 5.1 \\
volt_mtudc.pdf & 5.2 \\
opt_model.pdf & 5.3 \\
opt_cabintemp_new.pdf & 5.4 \\
baseline_heating_new.pdf & $5.5(\mathrm{a})$ \\
optimal_heating_new.pdf & $5.5(\mathrm{~b})$ \\
clnt_opt2_concept1.pdf & $5.6(\mathrm{a})$ \\
cat_opt2_concept1.pdf & $5.6(\mathrm{~b})$ \\
clnt_opt2_concept2.pdf & $5.6(\mathrm{c})$ \\
cat_opt2_concept2.pdf & $5.6(\mathrm{~d})$ \\
eng_baseline.pdf & $5.7(\mathrm{a})$ \\
clnt_baseline.pdf & $5.7(\mathrm{~b})$ \\
cat_baseline.pdf & $5.7(\mathrm{c})$ \\
cabin_baseline.pdf & $5.7(\mathrm{~d})$ \\
eng_caseB.pdf & $5.8(\mathrm{a})$ \\
clnt_caseB.pdf & $5.8(\mathrm{~b})$ \\
cat_caseB.pdf & $5.8(\mathrm{c})$ \\
cabin_caseB.pdf & $5.8(\mathrm{~d})$ \\
nsrdb_data.pdf & 5.9 \\
mc_temp_ip.pdf & 5.10 \\
energysaving_dist1.pdf & 5.11 \\
energysaving_dist2.pdf & 5.12 \\
\hline
\end{tabular}

